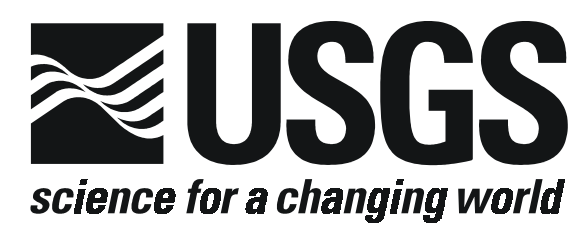

\title{
TIME-DOMAIN ELECTROMAGNETIC SOUNDINGS NEAR ANTIOCH, ILLINOIS, AND BERRIEN SPRINGS, MICHIGAN
}

\author{
by David L. Campbell ${ }^{1}$
}

Open-File Report 01-241

2001

This report is preliminary and has not been reviewed for conformity with U.S. Geological Survey editorial standards and stratigraphic nomenclature. Any use of trade, product, or firm names is for descriptive purposes only and does not imply endorsement by the U.S.

Government.

\section{U.S. DEPARTMENT OF THE INTERIOR U.S. GEOLOGICAL SURVEY}

\footnotetext{
${ }^{1}$ Denver, Colorado
} 
TIME DOMAIN ELECTROMAGNETIC SOUNDINGS

NEAR ANTIOCH, ILLINOIS, AND BERRIEN SPRINGS, MICHIGAN

by David L. Campbell

\section{CONTENTS}

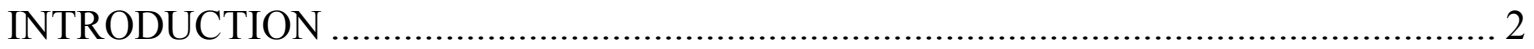

TEM SOUNDING AND INTERPRETATION PROCEDURE ......................................... 3

HYDROGEOLOGIC INTERPRETATION OF RESISTIVITY VALUES .......................... 6

OTHER TEM SOUNDINGS NEAR ANTIOCH, ILLINOIS ………………………….... 11

TEM SOUNDINGS NEAR BERRIEN SPRINGS, MICHIGAN …………………........ 14

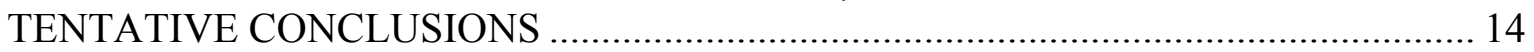

REFERENCES ...................................................................................... 18

APPENDIX A: OBSERVED DATA and TEM MODELS, ANTIOCH AREA …………. 19

APPENDIX B: OBSERVED DATA and TEM MODELS, BERRIEN SPRINGS AREA 37

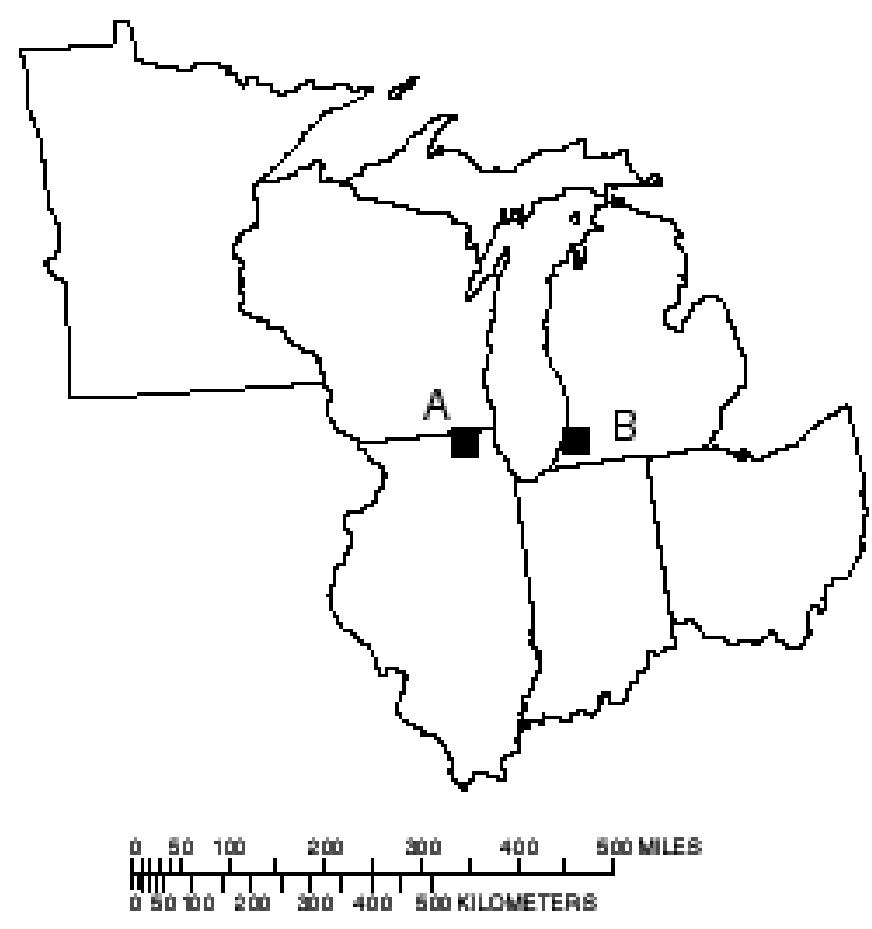

Figure 1. Outline map of the central Great Lakes region, showing locations of Antioch, IL (A) and Berrien Springs, MI (B) areas.

\section{INTRODUCTION}

In June, 2000, the U.S. Geological Survey (USGS) made time-domain electromagnetic (TEM) soundings near Antioch, Illinois, and Berrien Springs, Michigan. The soundings measured electrical resistivity to depths of about one hundred meters at these two places on approximately opposite sides of southern Lake Michigan (Fig. 1). The purpose of the work was to help develop a framework for further geoelectrical work to be done under the Central Great Lakes Geologic Mapping Coalition (CGLGMC). The CGLGMC members are USGS and state geological surveys of the states of Ohio, Indiana, Michigan and Illinois. The objective of CGLGMC is to make 3dimensional geological maps of surficial materials in the coalition area. The TEM work can help

constrain such maps, and also is of use in planning airborne electromagnetic surveys over the area's glacial terranes (Campbell, 2001). 
The TEM work in Illinois consisted of 11 soundings at scattered locations in the Antioch 7.5' quadrangle and one sounding in the Fox Lake 7.5' quadrangle, immediately to the west (fig. 6, below). These soundings are called "ANT1, .., ANT11". Many of the Antioch quad soundings were in Lake County Forest Preserve (CFP) parks.

The TEM work in Michigan consisted of 10 soundings ("SJ000, .., SJ-1200") across the St. Joseph River just downstream from the city of Berrien Springs, along the right of way where Route US-31 will extend to the north. The SJ soundings were made to investigate possible depths of incision of the ancestral St. Joseph River valley. One final sounding ("KLOCK") was made on the beach just north of where the St. Joseph River flows into Lake Michigan near the city of Benton Harbor. KLOCK was made to compare with the lithologic log of a drill hole made at that place from the USGS hovercraft.

\section{TEM SOUNDING AND INTERPRETATION PROCEDURE}

A detailed discussion of TEM theory and practice may be found in Nabighian and Macnae (1991) and in Fitterman and Stewart (1986). Briefly, TEM measurements involve sending an intermittent current into a transmitter loop so as to induce electrical currents in the ground. During times when the transmitter is off, a receiver loop is used to measure electromagnetic fields caused by the decay of those currents. Different rates of decay reflect geologic units with different electrical resistivities. This survey used PROTEM 47 equipment manufactured by Geonics Ltd., Mississauga, Ontario, Canada. For it, the transmitter (Tx) broadcasted into square loops consisting of insulated wire either $125 \mathrm{ft}(38.1 \mathrm{~m})$ or $250 \mathrm{ft}(76.2 \mathrm{~m})$ on a side, which lay flat on the ground. The receiver $(\mathrm{Rx})$ measured fields via a rigid, round, 1-mdiameter loop located at the center of the transmitter loop. The Rx loop was mounted horizontally on legs a few inches above the ground surface. TEM soundings of this type will typically investigate geoelectric structures in the range from $\sim 5$ to $100+\mathrm{m}$ depth. Note that they do not give good information about very shallow materials.

TEM results will be influenced by nearby metallic conductors such as wire fences. Our practice, based on experience, is to locate the nearest edge of a $125 \mathrm{ft} \mathrm{Tx}$ loop more than $75 \mathrm{ft}$ from the nearest fence, and that of a $250 \mathrm{ft}$ loop more than $150 \mathrm{ft}$ from a fence. Soundings SJ-500, $-600,-700,-750,-800$, and -900 were made inside a corn field using this rule.

A typical duty cycle for TEM work consists of four steps of equal time duration: 1) Tx on with positive polarity, 2) Tx off and Rx measuring fields, 3) Tx on with negative polarity, and 4) Tx off and Rx measuring. The PROTEM $47 \mathrm{Tx}$ unit allows step durations of $3.51 \mathrm{~ms}$ (U range), $13.3 \mathrm{~ms}$ (V range), and $33.3 \mathrm{~ms}$ (H range). The $\mathrm{Rx}$ unit samples signal amplitudes in 20 subintervals ("gates") during each measuring step, averaging the samples in each gate over a specified number of duty cycles so as to improve sampling statistics. The 20 gate widths are distributed exponentially over a measuring interval in each step of $0.8 \mathrm{~ms}$ (U range), $3.0 \mathrm{~ms}$ (V range), and $8.0 \mathrm{~ms}$ ( $\mathrm{H}$ range). We used the $\mathrm{U}$ range for all the soundings, and included measurements in the $\mathrm{V}$ and $\mathrm{H}$ ranges whenever signal quality was acceptable. Measurements began $0.0030 \mathrm{~ms}$ after Tx turn-off when using a $125 \mathrm{ft}$ square Tx loop, and 
$0.0050 \mathrm{~ms}$ after Tx turn-off for $250 \mathrm{ft}$ square loops. Measurements were repeated 3-6 times in each range.

For each sounding, repetitions were averaged and evaluated statistically using NTEMAVG v. 3.04, an unpublished USGS computer program by David V. Fitterman (written commun., 1999). Poor TEM data were dropped and the retained data were modeled using TEMIXGL, a commercial program by Interpex Ltd, Golden, Colorado. A model consists of a stack of successively deeper horizontal layers, each with a fixed thickness and resistivity, which we hope will correspond to thicknesses and resistivities of actual geologic units (or, possibly, lumped groups of thin geologic units). The bottommost layer represents the deepest unit the TEM method can detect, so is taken to have infinite thickness. The TEMIXGL program continually adjusts the thickness and resistivity values for all its model layers until it finds an acceptable fit to the observed TEM data.
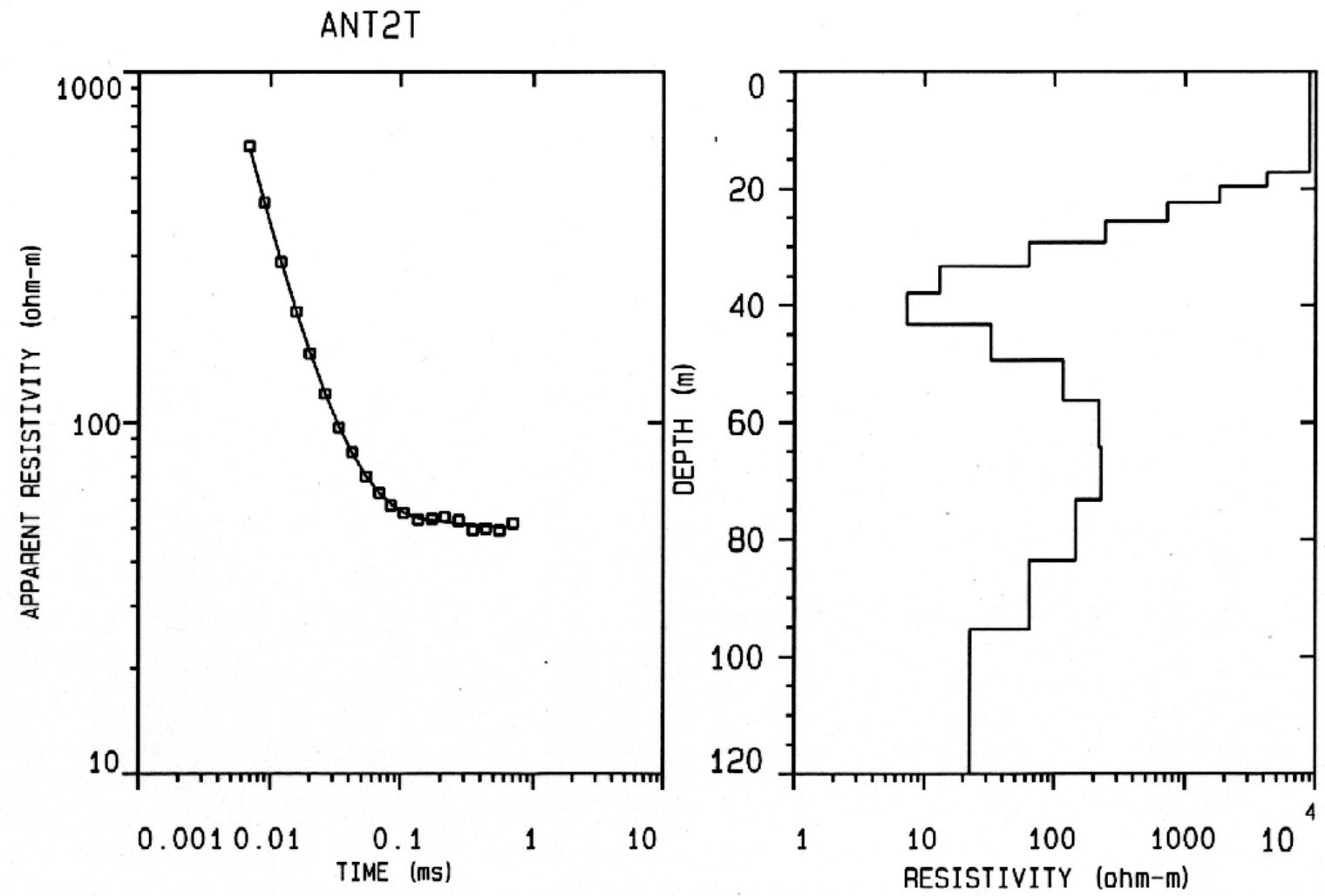

Figure 2. Observed resistivity-vs-time field data (left panel) and 15-layer smooth model (right panel) for sounding ANT2. The curve through the data points on the left panel show data calculated for the smooth model in the right panel.

Using TEMIXGL, a "smooth model" was first found for each sounding. A smooth model has many layers, approximately one per data point. Figure 2 shows the smooth model for sounding ANT2 in the right panel. The left panel shows the observed TEM data points at the ANT2 site, together with the continuous decay curve that results from that smooth model and which, in this case, fits the observed points quite well. We can see that the resistivity of the top layer is high, but as we proceed downward through the many layers their resistivities first 
drop, then rise, and finally drop again, so that the deepest detected layer has a low resistivity. An alternative way to model this sounding, therefore, would be to use 4 layers only. The resulting model would be a conservative one, in the sense that it uses the minimum number of layers needed to explain the observed data. (Three layers would be too few, for they could not duplicate the high-low - high - low resistivity sequence of the smooth model, whereas using 5 layers would give two adjacent layers with similar resistivity values.) Such minimum-layer-number models usually match geological structure better than do the smooth models, which distribute sharp resistivity interfaces over too large a range of depths (compare figs. 2 and 3). All ANT soundings had smooth models with a high-low-highlow resistivity structure, so were modeled using 4 layers. KLOCK and several of the SJ soundings, however, used 3-layer models.
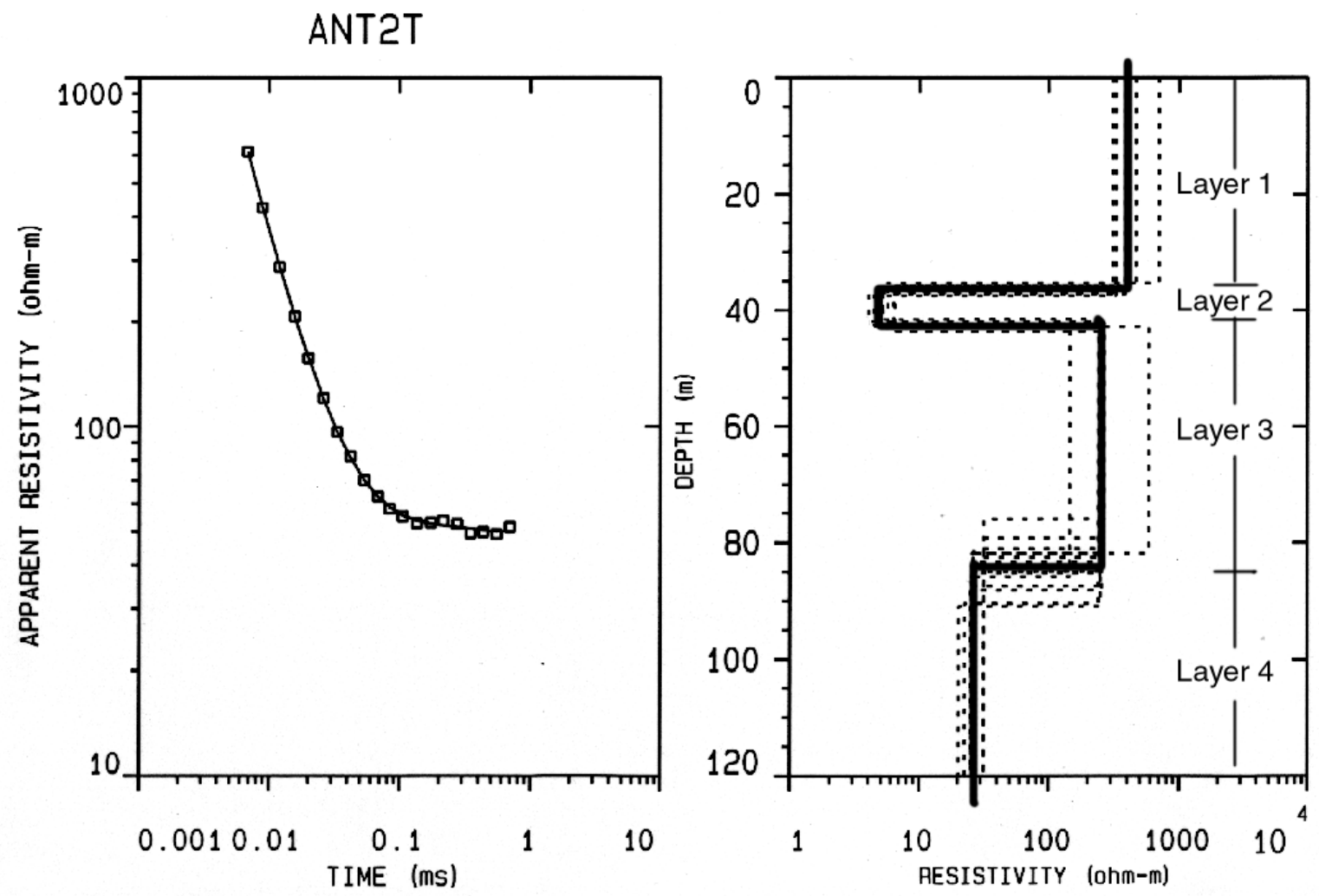

Figure 3. Observed resistivity-vs-time field data (left panel) and 4-layer model (solid lines, right panel) with equivalent models (dashed lines, right panel) for sounding ANT2. The curve through the data points on the left panel show data calculated for the 4-layer model in the right panel.

Figure 3 shows a 4-layer model for the ANT2 sounding (solid line). It fits the observed data with an error of $2.233 \%$. Clearly, there will be other 4-layer models that can fit the data about as well ("equivalent" models). Dashed lines show a number of equivalent models, representative members of a much larger family, which fit the observed data to $2.680 \%(=1.2$ times $2.233 \%$ ). An equivalent model plot can help one visualize the extent to which model resistivities and thicknesses can vary without substantially changing the fit to the observed data. 


\section{HYDROGEOLOGIC INTERPRETATION OF RESISTIVITY VALUES}

The electrical resistivity of a geologic unit depends on factors such as its composition and porosity, as well as the amount and purity of the water in its pores. The resistivity of geologic units composed of highly electrically resistive rock can be estimated using Archie's Law (Archie, 1942)

$$
\rho=\rho_{\mathrm{w}} \mathrm{F}
$$

where $\rho$ is resistivity of the formation, $\rho_{\mathrm{w}}$ that of the pore water or other fluid in the pores, and $\mathrm{F}$ is an adjustable parameter called the formation factor. For sandstones,

(2) $\mathrm{F} \sim 0.62 \Phi^{-2.15}$ (Humble formula, quoted by Ward, 1991)

and for low porosity carbonates

$$
\mathrm{F} \sim \Phi^{[1.87+0.019 / \Phi]} \text { (Shell formula, quoted by Ward, 1991). }
$$

In these equations $\Phi$ represents porosity of the rock, and the rock is assumed to be fully saturated with water. Unsaturated rocks will have higher resistivities; the drier the rock, the higher its resistivity.

Archie's Law says that to good approximation the resistivity of an appropriate unit will depend largely on that of its pore water. To determine the resistivity of a sandy formation, one merely multiplies that of its pore water by coefficient $\mathrm{F}$, which for sandstones typically falls in the range 5-20 (Humble formula, above). The resistivity of pore water depends in turn on the total dissolved solids (TDS) it contains. Thus, when dealing with sandy unconsolidated aquifers, relatively lower resistivity values can indicate the presense of less potable or even contaminated water, whereas relatively higher resistivity values can indicate purer water. As one proceeds to aquifers with lower and lower porosity, however, factor $\mathrm{F}$ rises. A high resistivity value, greater than $1000 \mathrm{ohm}-\mathrm{m}$, say, may therefore indicate a tight sandy aquifer that will produce little water and will recharge slowly.

The formation factor of Archie's Law must be modified for use with units containing clay (Waxman and Smits, 1968). That is because (mineralogical) clay is itself electrically conductive, so that electrical currents pass along the surfaces of clay platelets as well as through interstitial pore water. Such units will have lower resistivities than would be predicted by the standard Archie equation.

The above generalizations can help one infer which geologic unit(s) may be giving rise to a particular measured resistivity. Such an interpretation can be greatly improved using experience in a given study area. Faye and Smith (1994) collected samples of well water from about 120 wells in the coastal plain of the southeastern United States, and found the following power-law regression fits for their data: 


$$
\begin{aligned}
& \text { TDS }=5110 \rho_{\mathrm{w}}{ }^{-0.92} \\
& \rho_{\mathrm{w}}=0.56 \rho^{0.92}
\end{aligned}
$$

Measured values fell within a factor of about 5 from the values predicted by these equations, at a 95-percent prediction level. Some of the Faye-Smith samples came from bedrock aquifers, and many of them contained clays. The presence of clays may explain the relatively low apparent formation factors, F $\sim 2$, of these samples. Equations (4) and (5) predict that an aquifer having a formation resistivity of $100 \mathrm{ohm}-\mathrm{m}$ may be expected to contain water with a resistivity of about $38.7 \mathrm{ohm}-\mathrm{m}$, and that water in turn should have a TDS of about $177 \mathrm{mg} / \mathrm{L}$. At present, no results analogous to these seem to be available for aquifers of the central Great Lakes area. However, a TDS of $177 \mathrm{mg} / \mathrm{L}$ may be atypically low for ground water in the midwest. If that is so, we might expect to find many aquifers there with formation resistitivies under $100 \mathrm{ohm}-\mathrm{m}$. On the other hand, the TEM interpretations given below show several inferred aquifers that have measured formation resistivities substantially greater than $100 \mathrm{ohm}-\mathrm{m}$.

Sounding ANT1 was located a few hundred yards east of a drillhole on the Ron Riepe property, for which a good lithologic log was available. Figure 4 shows that lithologic log, with geologic units classified according to grain size, in the left panel. This panel, and the corresponding one in fig. 5, were provided by Andrew J. Stumpf of the Illinois State Geological Survey (written commun., June, 2000). A heavy vertical line has been drawn on the log to distinguish between fine diamict and finer grain sizes (to the left of the line) and fine sand and coarser grain sizes (to the right of the line). The right panel in fig. 4 shows the 4-layer TEM model of ANT1 (from Appendix A), stretched so as to make its depth axis match that of the lithologic log. Horizontal lines have been drawn between the two panels to mark layer boundaries. Layer 1 (756 ohm-m) corresponds to a geologic sequence composed dominantly of diamict, above the water table, and sand and gravel, below it. Apparently dry diamict and wet sand and gravel have similar, fairly high, resistivity values. Layer 2 (26.3 ohm-m) corresponds to a geologic sequence composed dominantly of coarse diamict. It is likely that the coarse diamict unit contains enough clay to bring the formation resistivity down to this observed value. If so, this means that electromagnetic methods cannot distinguish between fine and coarse dimicton sequences. This sequence, though watersaturated, probably contains too much fine-grained material (at least in the upper two-thirds of the sequence) for ready transmission of ground water. Layer $3(324 \mathrm{ohm}-\mathrm{m})$ corresponds to a geologic sequence whose upper part is composed dominantly of sands and gravels, and which probably represent a good aquifer. The lower part of Layer 3 corresponds to bedrock limestone. Griffiths and King (1965) show that resistivities for typical porous limestones fall in the 100-5,000 ohm-m range. It seems likely, therefore, that the limestone bedrock found in this well probably has a resistivity that is not very different from that of the wet sand and gravel overlying it. This means that geoelectrical measurements probably will be unable to distinguish bedrock limestone in the Antioch area. The top of Layer 4 (20.7 ohm-m) falls in the range $88-110 \mathrm{~m}$ depth at the $7.10 \%$ error level. Layer 4 therefore lies below the top of the limestone bedrock, which is at $68 \mathrm{~m}$ depth. Layer 4 probably represents shale of the Ordovician Maquoketa Shale Group, the unit which lies stratigraphically below the "limestone" (actually, a cherty dolomite of the Silurian Alexandrian Series; Ardith Hansel, 
Illinois State Geological Survey, written commun., 3/5/01). Griffiths and King (1965) show the histogram for soft shale to fall in the range $0.5-20 \mathrm{ohm}-\mathrm{m}$, whereas that for hard shale spans the range 7-800 ohm-m. We infer that the Maquoketa shale is a low-resistivity hard(?) shale, and that the limestone found at the bottom of Riepe's well is $\sim 30 \mathrm{~m}$ thick. This compares with its thickness of $\sim 35 \mathrm{~m}$ in a logged well at Round Lake Beach, about $5 \mathrm{mi}$ to the south (Hensel, written commun., 3/5/01).

Another lithologically-logged water well was available at the location of ANT2, on the Sun Lake CFP (fig. 5). Some of the resistivity-lithology correlations found on fig. 4 also hold true at this place, but others do not. In particular, the likely surficial aquifer at ANT2 is composed largely of silt and diamict, but nevertheless has a higher resistivity (lower part of Layer 1, $235 \mathrm{ohm}-\mathrm{m})$. Layer 2, whose lower resistivity ( $9 \mathrm{ohm}-\mathrm{m})$ is appropriate for clay or diamict, spans depths where sand and gravel are dominant. Broadly speaking, the resistivity characteristics of Layer 2 and the lower part of Layer 1 are reversed from what we expected. Part of this difference could be resolved, though, if some of the "sands" between 35-45m depth were actually sandy clays. The lithologic correlations for Layers 3 and 4 at ANT2 resemble those found at ANT1. At both places Layer 3 has a resistivity of several hundred ohm-m, reflecting a sand and gravel aquifer in the upper part, and a porous limestone bedrock in the lower part, whereas Layer 4 probably reflects shale underlying the limestone unit. 


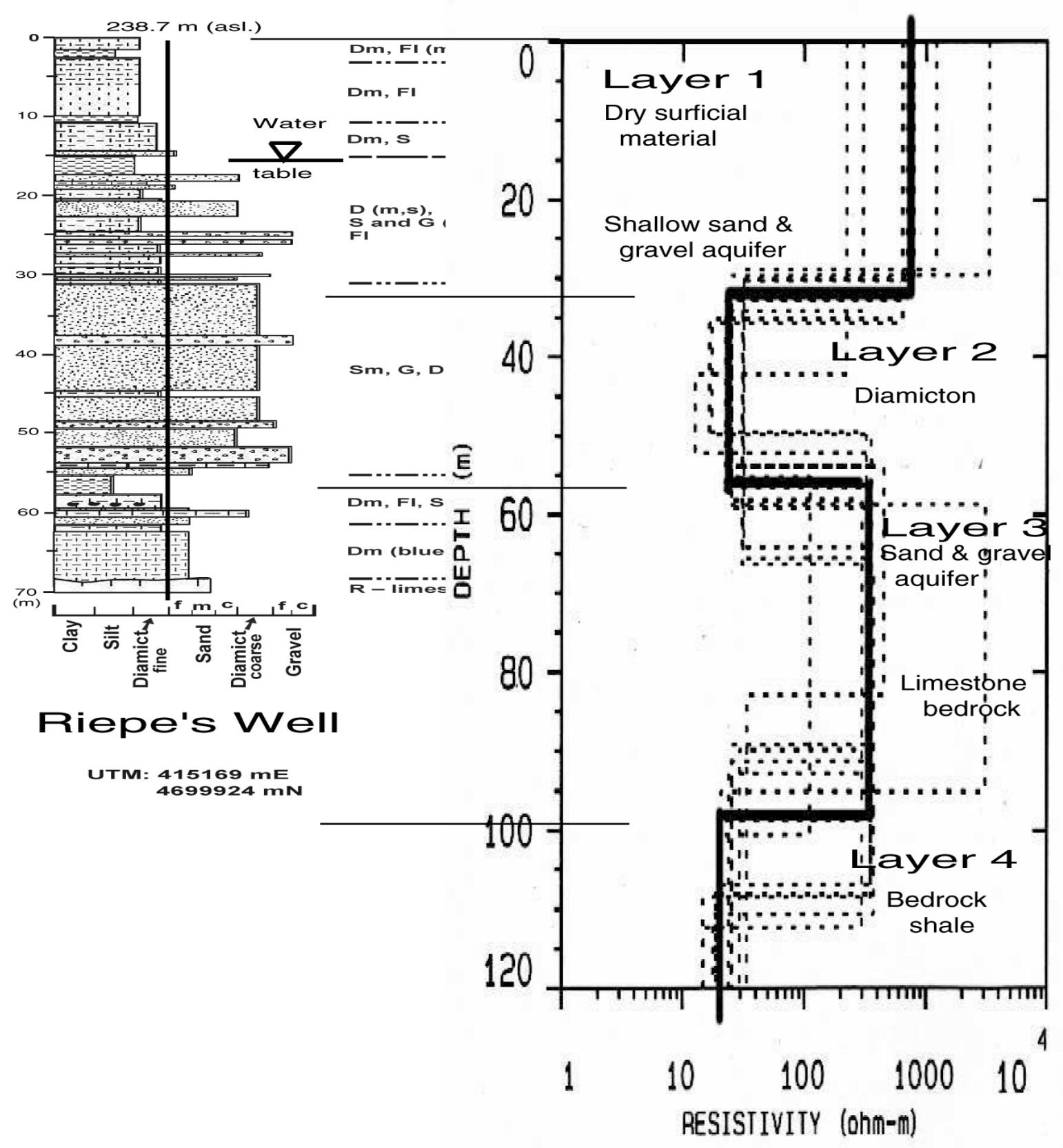

Figure 4. Lithologic log of a water well near ANT1 (left panel) and 4-layer model of the TEM sounding (right panel) near the logged well. Heavy vertical line on well log panel divides grain sizes such that below the water table sequences left of the heavy line roughly correlate with lower resistivity values and those to the right of it roughly correlate with higher ones. Coarse diamict, however, correlates with low resistivities. 


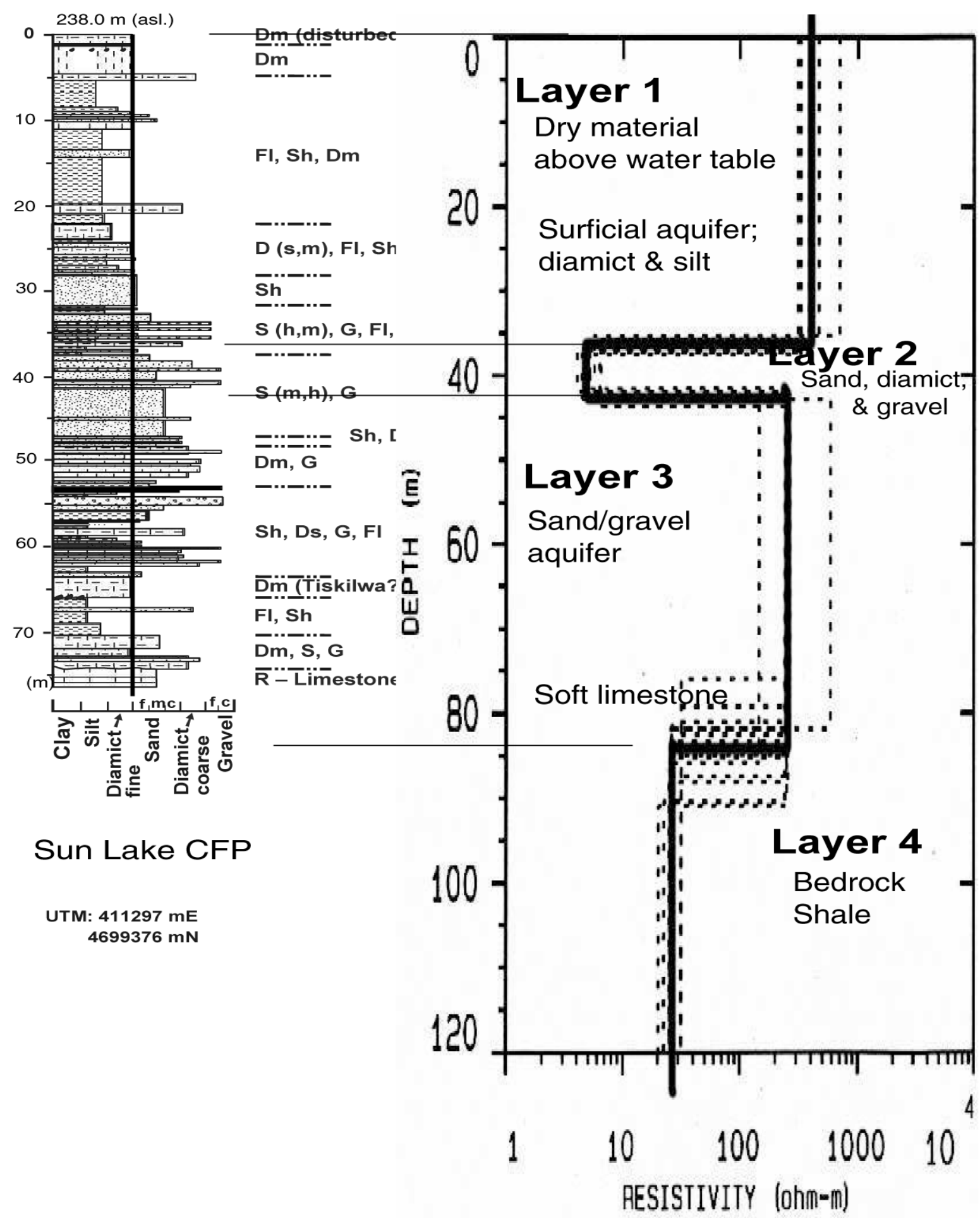

Figure 5. Lithologic log of a water well at Sun Lake CFP and 4-layer model of TEM sounding ANT2, located at the logged well (right panel). Heavy vertical line on well log panel is as on fig. 4 , but here the correlation between grain sizes and resistivity is much poorer. 
Table 1 pulls together the different strands of evidence discussed in this section to list possible geologic units that may correspond to four ranges of resistivity found in layer models of the TEM soundings.

Table 1. Resistivity ranges and possible geological units that may correlate with them in the central Great Lakes region.

\begin{tabular}{|l|l|}
\hline $\begin{array}{l}\text { Resistivity } \\
(\mathrm{ohm}-\mathrm{m})\end{array}$ & Possible geology \\
\hline$<30$ & $\begin{array}{l}\text { Units with high clay content. If shallow, water saturated diamicton; } \\
\text { If deep, bedrock shale. }\end{array}$ \\
\hline $30-100$ & Saturated diamicton/sandy mixtures; higher values mean more sand \\
\hline $100-1000$ & $\begin{array}{l}\text { If shallow, dry surficial material; } \\
\text { If deeper, saturated sand and gravel units (good aquifers) }\end{array}$ \\
\hline$>1000$ & $\begin{array}{l}\text { If shallow, dry surficial material; } \\
\text { If deep, low porosity limestone bedrock, limestone (cf., Shell formula). }\end{array}$ \\
\hline
\end{tabular}

\section{OTHER TEM SOUNDINGS NEAR ANTIOCH, ILLINOIS}

Figure 6 shows locations of the 11 TEM soundings made near Antioch IL. Plots of observed data and 4-layer models for these soundings are given in Appendix A, and a listing of the thicknesses and resistivities of the 4-layer models is given in Table 2. As a guide to our thinking, but subject to revision as we learn more, we characterize the 4 layers of the geoelectric models as follows:

Layer 1 - dry material above water table, and saturated silt, diamict, and sand below it. Layer 2 - saturated diamict or sandy clay.

Layer 3 - saturated sand-gravel aquifer and bedrock limestone.

Layer 4 - bedrock shale.

The 4-layer models given in Appendix A show interesting differences from place to place in the study area. Figure 7 shows 4 TEM soundings along a 3.5 mile-long, east-west, traverse in the northeast part of the study area. Substantial changes are seen within even this short distance. In particular, diamicton units may thin to the east, and the bedrock shale may become shallower in that direction.

Such substantial changes over short distances may well be typical of glacial terranes like those of the Antioch IL study area. Only about 1.5 miles south of ANT10 and ANT11, for example, in the McDonald Woods CFP, we find very different geoelectric sections at ANT7 and ANT6. There the Layer 3 resistivities are the highest in the data set, 2010 and 1214 ohm-m, respectively. Either the sand-gravel-limestone sequence there is tighter than elsewhere (that is, it has substantially lower porosity and so may not bear water so readily), or else some different lithologic sequence may be present. Nevertheless, at ANT5, only another $0.5 \mathrm{mi}$ south of ANT6, we again find a geoelectric section that is fairly typical for this area, and where the upper part of Layer 3 probably represents a good aquifer. 


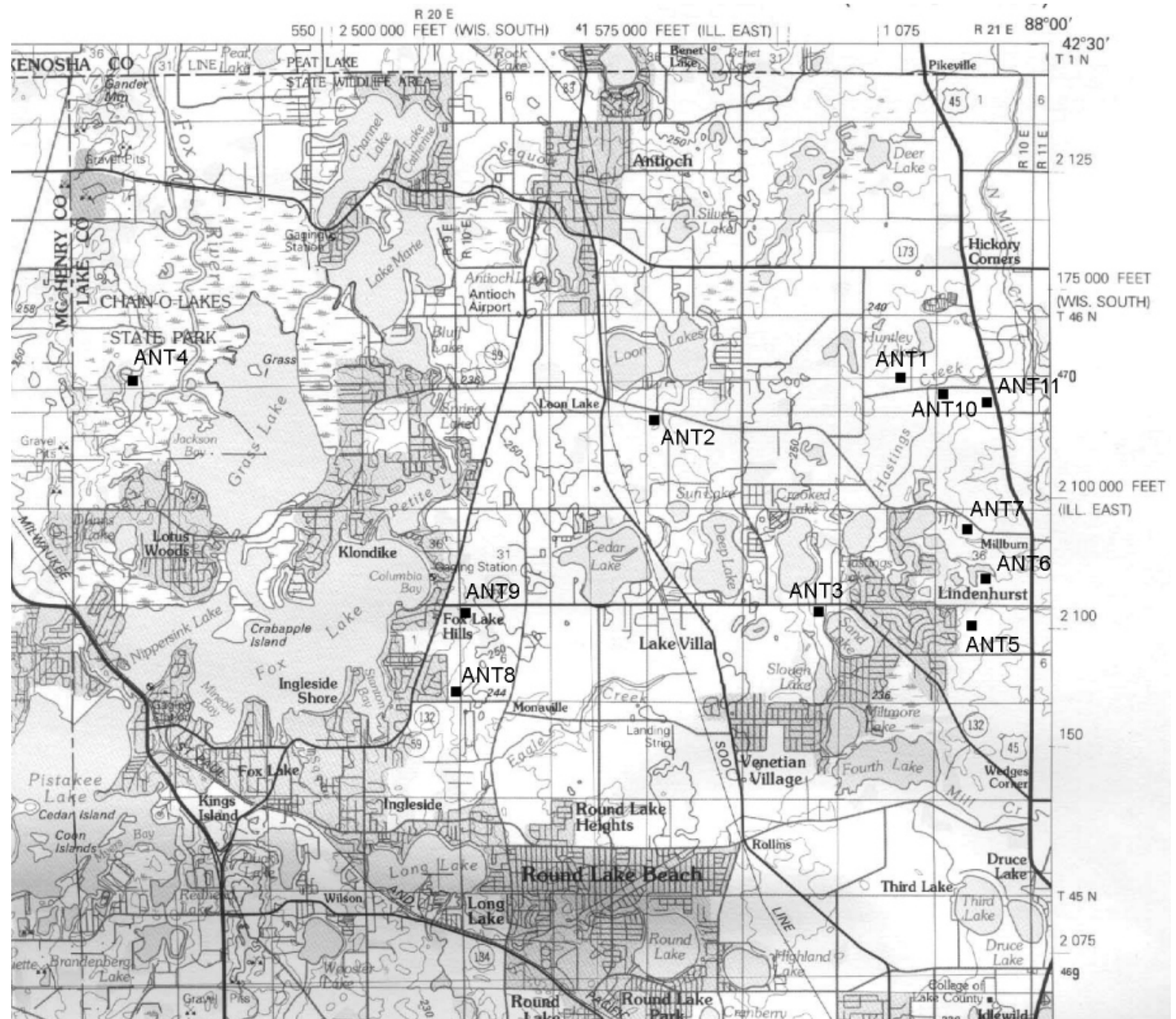

Figure 6. Locations of TEM soundings (ANT1, ..., ANT11) near Antioch, Illinois. Base map is a part of the U.S. Geological Survey metric topographic map of the Elgin, Illinois-Wisconsin 30x60 minute quadrangle. 


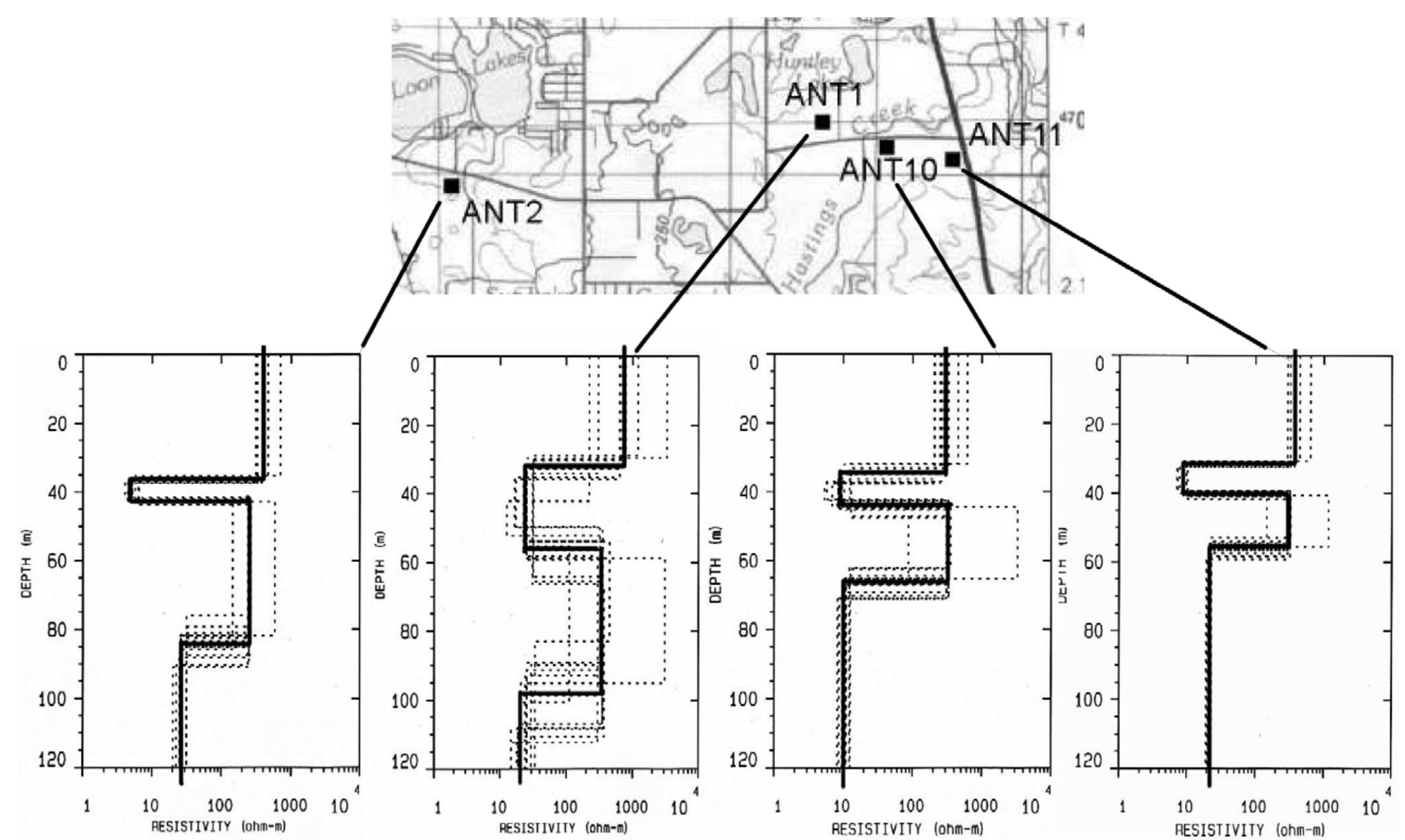

Figure 7. Changes in geoelectric structure along a short east-west traverse near Antioch, IL. Map at top (from fig. 6) shows locations of 4 TEM soundings, whose 4-layer models are displayed below, all to the same scale. 


\section{TEM SOUNDINGS NEAR BERRIEN SPRINGS, MICHIGAN}

TEM sounding KLOCK (Appendix B; Table 2) was made at Jean Klock Park, on the beach of Lake Michigan immediately north of St. Joseph, MI. Layer 1, which is $\sim 33 \mathrm{~m}$ thick, probably represents beach sand saturated with low-TDS Lake Michigan water. This result is consistent with those from a borehole drilled at that location from the USGS hovercraft, which found $5.8 \mathrm{~m}$ of esker and fill material above a glacial lake sand, fining downwards to a total depth of $\sim 20$ m (Byron Stone, USGS, oral commun., 3/2/01). Layer 2 may represent diamicton, and Layer 3 may represent a shale in the pre-glacial bedrock. Milstein (1987) indicates that the bedrock unit in this area is the upper Devonian Ellsworth Shale, or possibly Antrim shale, also of Devonian age, which lies immediately under the Ellsworth shale.

Soundings SJ000, ..., SJ-1200 crossed the valley of the St. Joseph River just downstream from the town of Berrien Springs, MI. Figure 8 is a section view of the results. Under the bluff that bounds the north side of the river, Layer 1 resistivities are quite high. South of the river, Layer 1 resistivities are compatible with surficial sandy units. Layer 2 may represent clay or silt. South of the river, under its broad flood plain, Layer 3 appears to represent a thick wedge of sandy deposits, which might have been deposited by river meanders. This unit disappears as one climbs up out of the river valley to the south. Layer 4 is a very conductive everywhere, and probably represents bedrock shale.

Figure 8 seems to say that the ancestral St. Joseph River incised very deeply into the shale country rock. At SJ-500 the top of the unit we interpret to represent bedrock shale is $\sim 120 \mathrm{~m}$ deep; that is, at an elevation of $\sim 63 \mathrm{~m}$ above present-day sea level. We note for comparison that the present-day elevation of Lake Michigan, into which the St. Joseph River drains, is at $177 \mathrm{~m}$. Could Lake Michigan once have been low enough to provide a base level at less than $63 \mathrm{~m}$ for the St. Joseph River? Surprisingly, the answer to this question is that that very likely was so. A reconstruction of the recent geological history of the Great Lakes region by Larsen (1987) shows that during the Chippewa low water level, $\sim 9700$ B.P., the southern part of Lake Michigan was separated from the rest of ancestral Lake Michigan, and its water level was at $\sim 55 \mathrm{~m}$. The ancestral St. Joseph River flowed into that low lake, and at that time could well have incised to $\sim 63 \mathrm{~m}$ depth near present-day Berrien Springs.

\section{TENTATIVE CONCLUSIONS}

This study has led to several tentative conclusions, most of which must be verified and refined by further work.

In the Antioch, IL, area:

- All TEM soundings detected 4 layers, which we think may represent (1) dry material above water table and surficial aquifer below it, (2) water-saturated diamict or diamict-sand sequences, probably a fair aquifer, (3) sand-gravel-limestone sequences, probably a good aquifer, and (4) bedrock shale.

- Geoelectrical methods probably cannot distinguish between dry and wet surficial sediments. In other words, they cannot map the water table. 
- Geoelectrical methods probably cannot distinguish between fine diamict and coarse diamict. They can readily distinguish thick sand/gravel aquifers from diamict ones.

- Geoelectrical methods probably cannot distinguish between bedrock limestone and overlying sand-gravel units in the Antioch, IL, area. However, they probably can distinguish the top of the bedrock shale unit below the limestone.

- The bedrock limestone found in the bottom of wells in the Antioch, IL, area is probably only a few 10 's of meters thick in most places. There seems to be up to $\sim 40$ $\mathrm{m}$ of relief on the bedrock shale which underlies that limestone.

In the Berrien Springs, MI, area:

- A series of TEM soundings across the St. Joseph River valley show interpreted units that can reasonably be attributed to downcutting and sedimentation in a meandering river valley. The top of the interpreted bedrock shale unit, however, is $\sim 120 \mathrm{~m}$ deep at its deepest point on the profile. This large value seems to imply that the ancestral St. Joseph River once cut down to $\sim 63 \mathrm{~m}$ above present-day sea level.

\section{ACKNOWLEDGEMENTS}

We thank Lake County, Illinois, for access to Lake County Forest Preserve lands, with special thanks to Joshua Skolnick for showing us around the preserves. We also thank Prof. Ron Riepe of the College of Lake County, Grayslake, Illinois, for many useful discussions of geology and hydrology of the Antioch area, and Mrs. Riepe for iced tea and cookies on several hot June afternoons. Thanks, too, to Marilyn Brant, W.L. Robinson, and Kathy Stuart for letting us work on their properties near Antioch, and Tom Chiddick of Andrews University, Berrien Springs, Michigan, for access to Andrews University farm fields. 


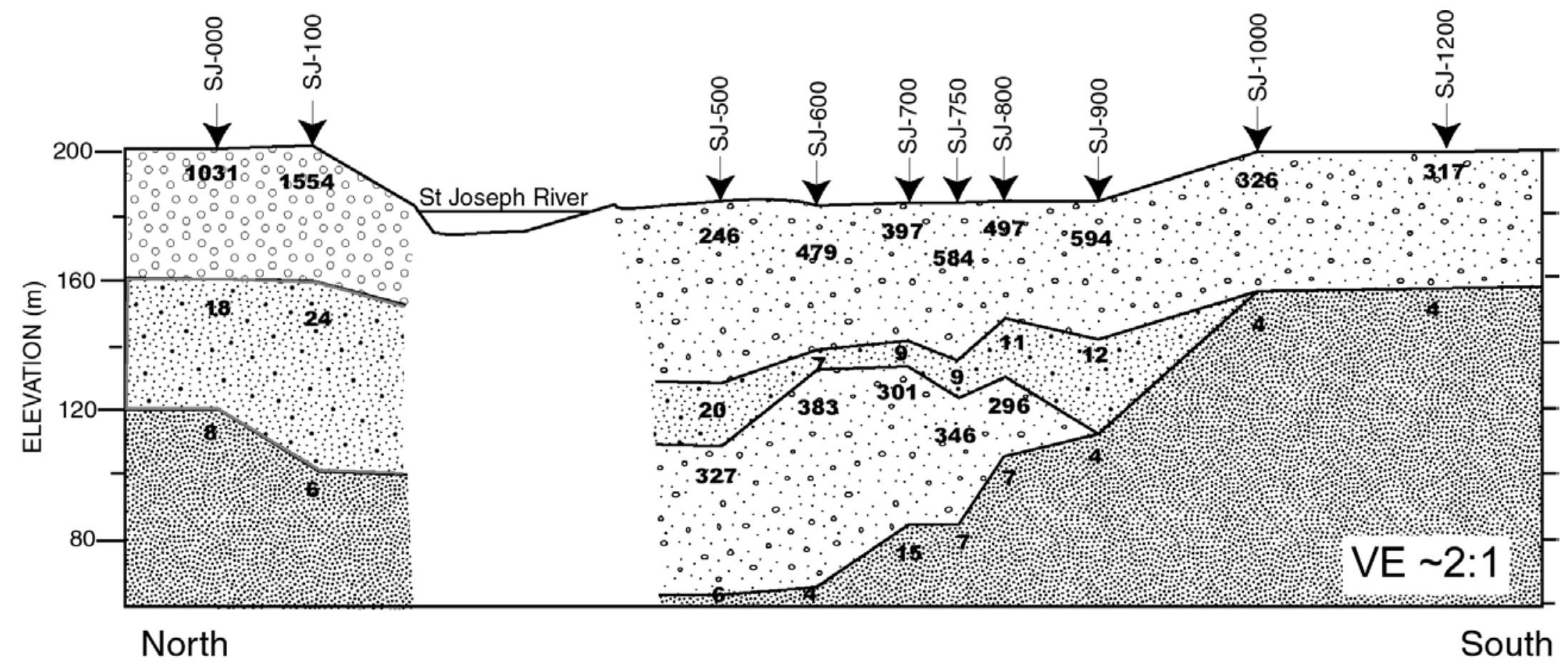

Figure 8. Section view showing TEM layer models across the St. Joseph River just downstream from Berrien Springs MI, along the projected extension of Route US-31. Vertical exaggeration is approximately 2:1. Superposed numbers give layer resistivity in ohm-m. This section implies that the ancestral St. Joseph River may have incised very deeply into the country rock. 
Table 2. Best models for the TEM soundings in this report. All elevations are approximate.

\begin{tabular}{|c|c|c|c|c|}
\hline \multicolumn{2}{|c|}{$\begin{array}{c}\text { Sounding } \\
\text { Fit Error } \\
{[\%]}\end{array}$} & \multicolumn{3}{|c|}{$\begin{array}{l}\text { Layer } 1 \\
\text { Surf. Resist. Thick } \\
\text { Elev }(m)[0 h m-m][m]\end{array}$} \\
\hline NT01 & 8.114 & 237.1 & 717.2 & 32.4 \\
\hline ANT02 & 2.125 & 240.8 & 394.3 & 36.5 \\
\hline ANT03 & 5.558 & 241.7 & 497.7 & 39.6 \\
\hline ANT04 & 7.812 & 227.1 & 575.8 & 41.8 \\
\hline ANT05 & 6.008 & 236.8 & 471.0 & 37.9 \\
\hline ANT06 & 6.326 & 228.6 & 320.4 & 32.0 \\
\hline ANT07 & 5.579 & 235.3 & 346.4 & 33.0 \\
\hline ANT08 & 1.542 & 243.2 & 331.3 & 29.2 \\
\hline ANT09 & 0.808 & 238.4 & 328.5 & 29.7 \\
\hline ANT10 & 5.465 & 235.3 & 293.8 & 34.8 \\
\hline ANT11 & 1.616 & 234.1 & 373.5 & 31.6 \\
\hline KLOCK & 2.341 & 177.5 & 1133.5 & 33.1 \\
\hline & 4.918 & 201.2 & 1030.7 & 40. \\
\hline SJ-100 & 6.248 & 201.2 & 1553.5 & 41.5 \\
\hline SJ-500 & 2.245 & 183.8 & 246.1 & 54.7 \\
\hline SJ-600 & 6.356 & 182.3 & 478.5 & 43.3 \\
\hline SJ-700 & 4.894 & 183.5 & 397.2 & 42.4 \\
\hline SJ-750 & 3.477 & 183.5 & 583.5 & 50.2 \\
\hline SJ-800 & 5.081 & 183.8 & 496.6 & 35.7 \\
\hline SJ-900 & 5.752 & 183.5 & 593.7 & 42.2 \\
\hline SJ-1000 & 11.940 & 198.7 & 326.2 & 43.1 \\
\hline SJ-1200 & 8.796 & 198.1 & 317.4 & 41.3 \\
\hline
\end{tabular}

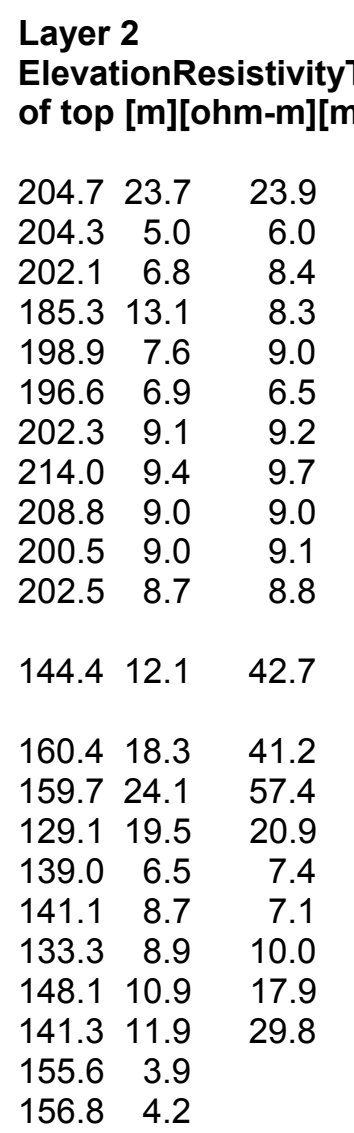

Layer 3

Resist.Thickness of top [m][ohm-m][m]

$\begin{array}{rrr}180.8 & 349.9 & 42.1 \\ 198.3 & 248.8 & 41.7 \\ 193.7 & 61.9 & 24.3 \\ 177.1 & 164.0 & 25.9 \\ 189.9 & 110.6 & 46.0 \\ 190.1 & 516.8 & 51.0 \\ 193.1 & 342.4 & 48.4 \\ 204.3 & 75.0 & 29.4 \\ 199.7 & 136.8 & 52.0 \\ 191.3 & 328.6 & 22.4 \\ 193.7 & 320.5 & 15.6\end{array}$

$101.7 \quad 6.0$

$119.2 \quad 8.1$

$102.3 \quad 5.7$

$\begin{array}{lll}108.2 & 326.6 & 44.9\end{array}$

$\begin{array}{lll}131.6 & 383.0 & 66.0\end{array}$

$\begin{array}{lll}134.0 & 300.8 & 49.4\end{array}$

$\begin{array}{lll}123.2 & 346.2 & 38.4\end{array}$

$\begin{array}{lll}130.3 & 295.9 & 24.4\end{array}$

$111.6 \quad 4.4$
Layer 4

Elev. Resistivity of top [m][ohm-m]

$\begin{array}{ll}138.7 & 20.7\end{array}$ $156.6 \quad 25.6$

$169.4 \quad 5.3$

$151.1 \quad 45.0$

$143.9 \quad 8.5$

$139.1 \quad 21.1$

$144.7 \quad 23.8$

$174.9 \quad 13.3$

$147.7 \quad 20.6$

$168.9 \quad 10.3$

$\begin{array}{ll}178.1 & 21.1\end{array}$

$63.4 \quad 5.7$

$\begin{array}{ll}65.6 & 4.2\end{array}$

$84.5 \quad 14.5$

$84.8 \quad 7.2$

$105.9 \quad 7.1$ 


\section{REFERENCES}

Archie, G.E., 1942, The electrical resistivity log as an aid to determining some reservoir characteristics: Transactions of the American Institute of Mining, Metallurgical and Petroleum Engineering, vol. 146, p. 54-62.

Campbell, D.L., 2001, Airborne geophysical survey and ground-based geoelectrical soundings near Berrien Springs, Michigan (abstract): GSA Abstracts with Programs, v. 33, no. 4 , p. A-45.

Faye, R.E., and Smith, W.G., 1994, Relations of borehole resistivity to the horizontal hydraulic conductivity and dissolved-solids concentration in water of clastic coastal plain aquifers in the southeastern United States: U.S. Geological Survey Water-Supply Paper 2414, $33 \mathrm{p}$.

Fitterman, D.V., and Stewart, M.T., 1986, Transient electromagnetic sounding for groundwater: Geophysics, v. 51, no. 4, p. 995-1005.

Griffiths, D.H., and King, R.F., 1965, Applied geophysics for engineers and geologists: Oxford, Pergamon Press, p. 10.

Hem, J.D., 1985, Study and interpretation of the chemical characteristics of natural water: U.S. Geological Survey Water-Supply Paper 2254, 263 p.

Larsen, C.E., 1987, Geological history of glacial Lake Algonquin and the upper Great Lakes: U.S. Geological Survey Bulletin 1801, 36 p.

Milstein, R.L., 1987, Bedrock geology of southern Michigan: State of Michigan Department of Natural Resources, 1 sheet, 1:500,000 scale.

Nabighian, M.N., and Macnae, J.C., 1991, Time domain electromagnetic prospecting methods, in Nabighian. M.N., ed., Electromagnetic Methods in Applied Geophysics, Volume 2-Applications: Tulsa OK, Society of Exploration Geophysicists, p. 427-520.

Ward, S.H., 1991, Resistivity and induced polarization methods, in Ward, S.H., ed., Geotechnical and Environmental Geophysics, Volume II-Enviromental and Groundwater: Tulsa OK, Society of Exploration Geophysicists, p. 147-189.

Waxman, M.H., and Smits, L.J.M., 1968, Electrical conductivities in oil-bearing shaly sands: Transactions of the American Institute of Mining, Metallurgy, and Petroleum Engineering, v. 243, Part II, p.107-122. 


\section{APPENDIX A: OBSERVED DATA and TEM MODELS, ANTIOCH AREA}

TEM Sounding locations were recorded on 1:24,000 scale topographic maps that had 10-ft contour intervals. The UTM coordinates and elevations given below were measured from these field maps. The location given is nominally that of the small Rx loop, which in turn was located in the center of a square $\mathrm{Tx}$ loop either 38.1 or $76.2 \mathrm{~m}$ on a side. Likely uncertainty in UTM coordinates is thought to be about $20 \mathrm{~m}$, whereas the likely uncertainty in elevations is about half a contour interval, or 5 ft.

Each data set in this appendix contains a header briefly describing the TEM site, followed by a section giving tabled data for each data range (u, $\mathrm{v}$, or $\mathrm{h}$ ) that was used at that site, and concluding with a graph of the results. The data table includes for each time gate the individual apparent resistivities ( $r h o$ a, in ohm-m) that make up a series of repeated measurements, followed by the average apparent resistivity value for the series and standard error of its estimate (\%std). The left panel of the graph section shows the time decay of apparent resistivity with measured averages appearing as squares ( $u$ range) or diamonds ( $v$ and $h$ ranges). The right panel shows models of apparent resistivity versus depth; the heavy line represents the best model that was found, whereas lighter dashed lines represent a suite of equivalent models that fit the observed data almost as well. The continuous line in the left panel is calculated from the best model and shows how well it fits the observed data. All graphs are at the same scale to facilitate comparisons between them.

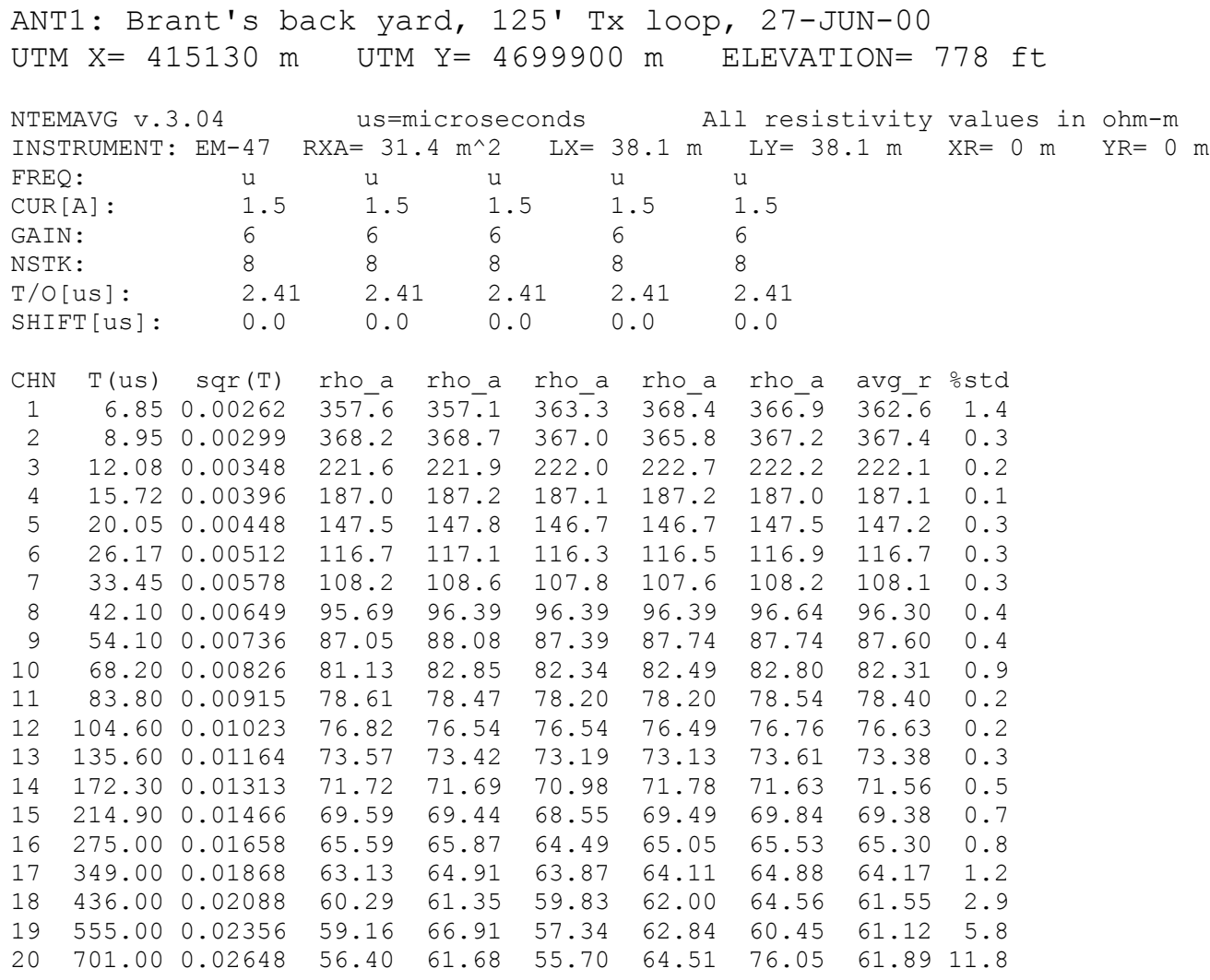




$\begin{array}{llll}\text { FREQ : } & \mathrm{v} & \mathrm{v} & \mathrm{V} \\ \text { CUR [A] : } & 1.5 & 1.5 & 1.5 \\ \text { GAIN : } & 6 & 6 & 6 \\ \text { NSTK : } & 8 & 8 & 8 \\ \text { T/O[us] : } & 2.41 & 2.41 & 2.41 \\ \text { SHIFT [us] : } & 0.0 & 0.0 & 0.0\end{array}$

$\begin{array}{crrrrrrr}\text { CHN } & \text { T(ms) } & \text { sqr (T) } & \text { rho_a } & \text { rho_a } & \text { rho_a } & \text { avg_r } & \text { ostd } \\ 1 & 0.0483 & 0.00695 & 85.62 & 85.50 & 85.02 & 85.38 & 0.4 \\ 2 & 0.0569 & 0.00754 & 84.45 & 84.45 & 83.89 & 84.26 & 0.4 \\ 3 & 0.0693 & 0.00832 & 81.45 & 81.37 & 80.93 & 81.25 & 0.3 \\ 4 & 0.0840 & 0.00917 & 80.08 & 80.28 & 79.33 & 79.89 & 0.6 \\ 5 & 0.1010 & 0.01005 & 79.36 & 80.00 & 79.15 & 79.50 & 0.6 \\ 6 & 0.1250 & 0.01118 & 78.41 & 78.90 & 78.63 & 78.65 & 0.3 \\ 7 & 0.1545 & 0.01243 & 77.79 & 79.06 & 78.09 & 78.31 & 0.8 \\ 8 & 0.1890 & 0.01375 & 76.75 & 77.46 & 76.06 & 76.75 & 0.9 \\ 9 & 0.2370 & 0.01539 & 72.60 & 72.60 & 71.72 & 72.30 & 0.7 \\ 10 & 0.2940 & 0.01715 & 72.63 & 71.43 & 72.33 & 72.13 & 0.9 \\ 11 & 0.3570 & 0.01889 & 65.02 & 63.99 & 65.48 & 64.82 & 1.2 \\ 12 & 0.4410 & 0.02100 & 63.10 & 63.10 & 57.78 & 61.20 & 5.2 \\ 13 & 0.5630 & 0.02373 & 65.45 & 54.13 & 53.83 & 57.21 & 10.5 \\ 14 & 0.7100 & 0.02665 & 50.58 & 50.58 & 50.58 & 50.58 & 0.0 \\ 15 & 0.8810 & 0.02968 & 47.53 & 44.49 & 46.88 & 46.26 & 3.5 \\ 16 & 1.122 & 0.03350 & 67.49 & 38.84 & 41.41 & 45.77 & 25.8 \\ 17 & 1.414 & 0.03760 & 123.8 & 30.40 & 36.62 & 45.57 & 72.2 \\ 18 & 1.763 & 0.04199 & 61.55 & 28.76 & 31.78 & 35.58 & 33.0 \\ 19 & 2.240 & 0.04733 & 132.5 & 16.75 & 17.28 & 22.64 & 61.9 \\ 20 & 2.825 & 0.05315 & 23.50 & 10.26 & 109.1 & 26.07 & >>\end{array}$
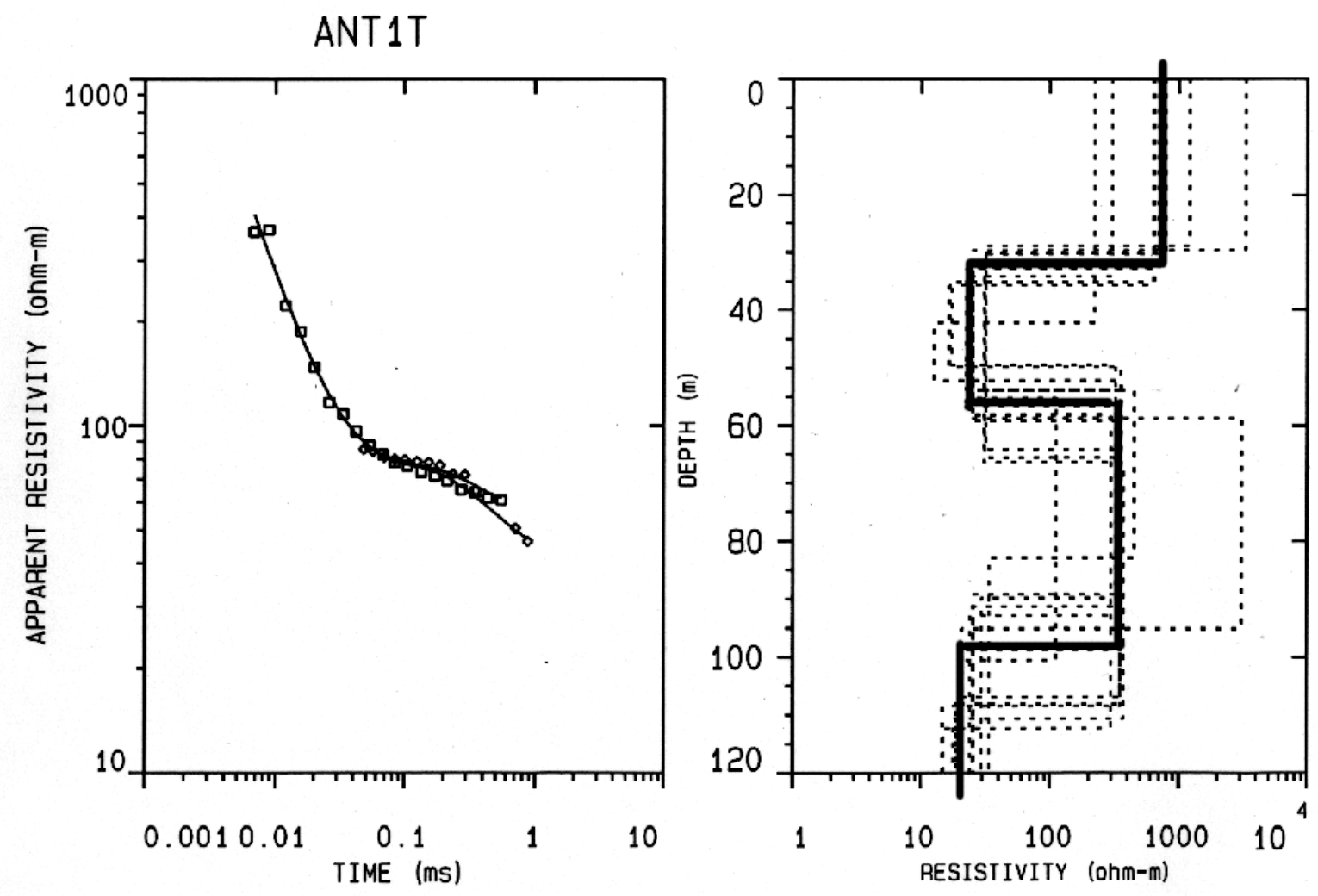

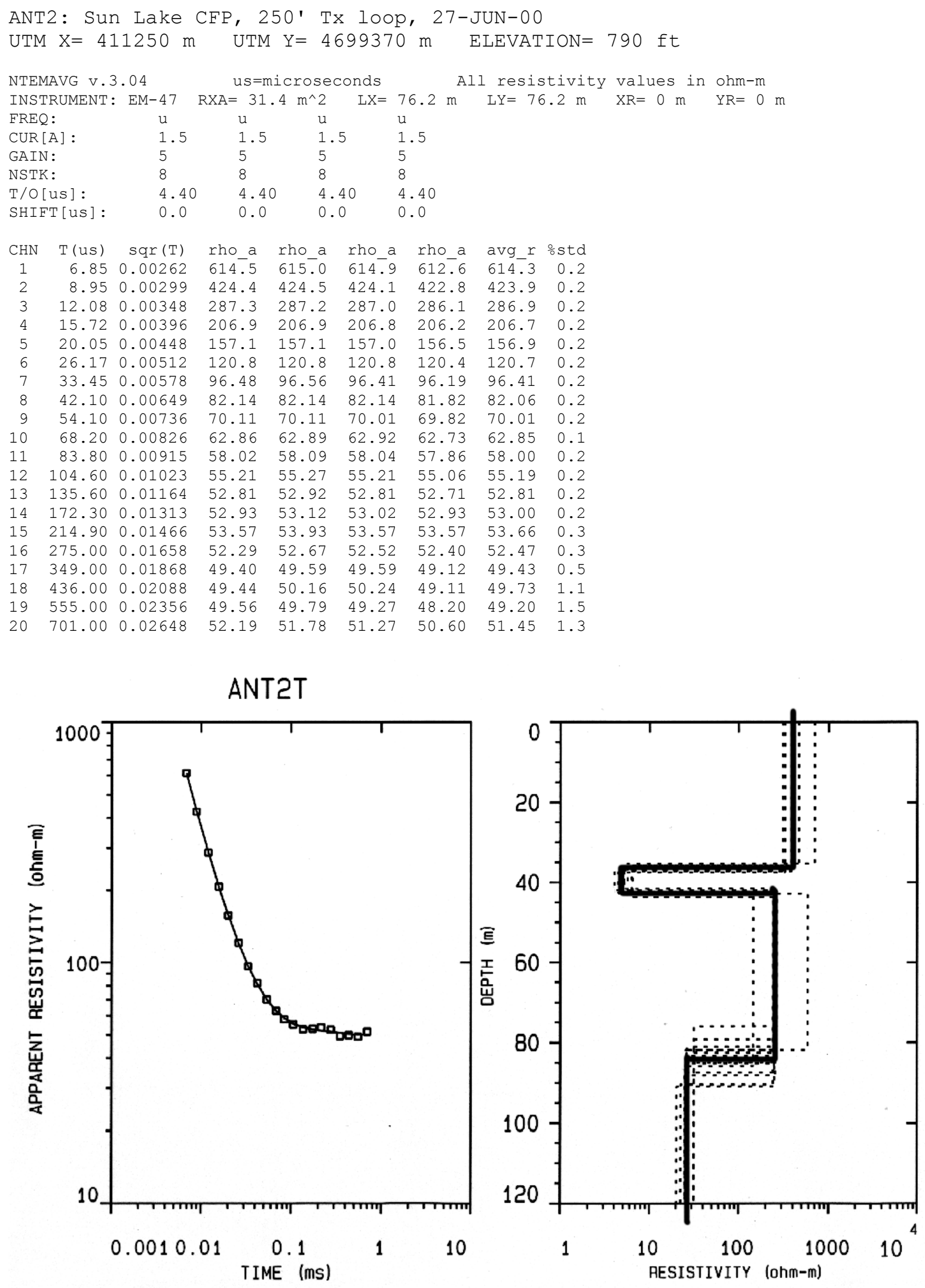


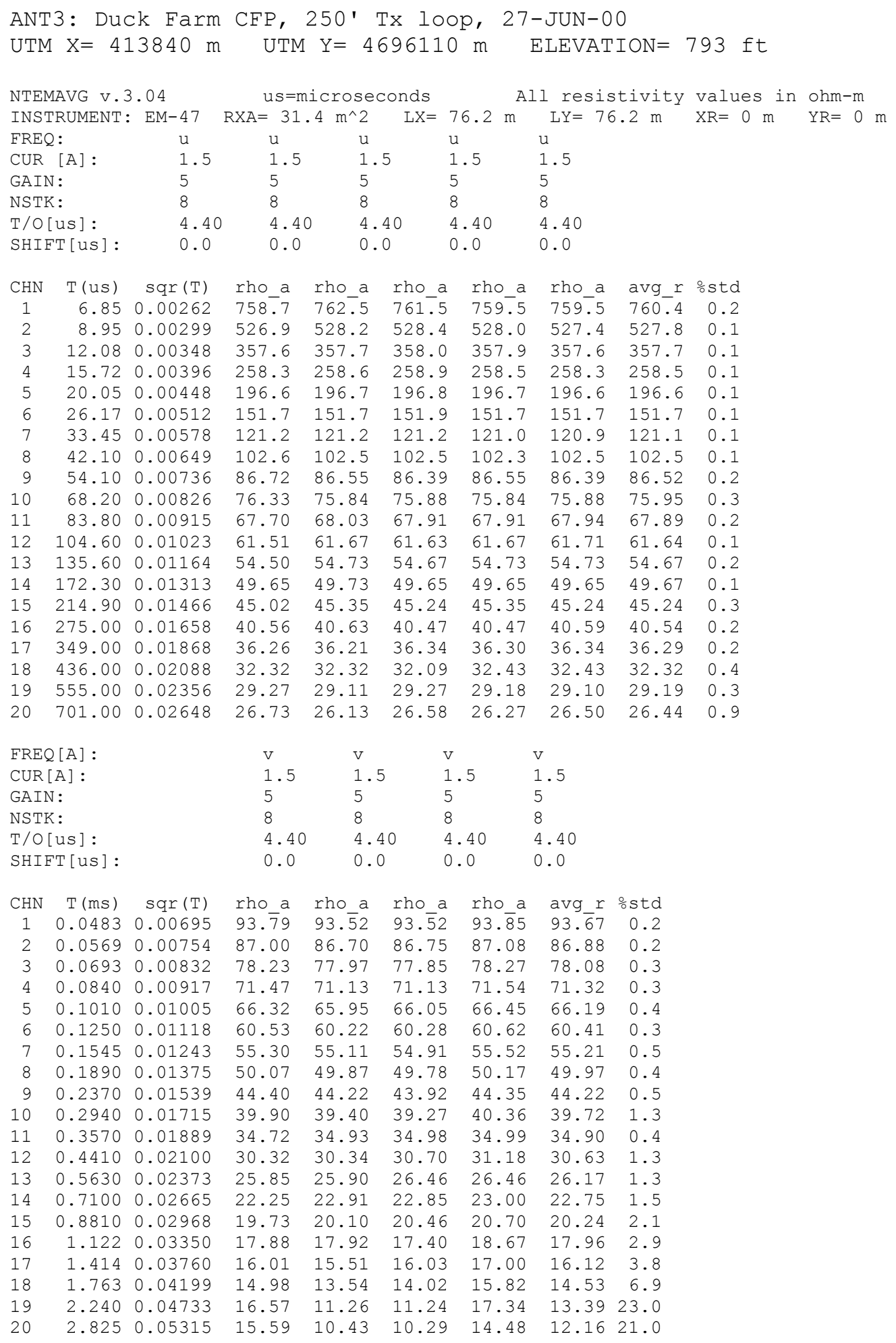



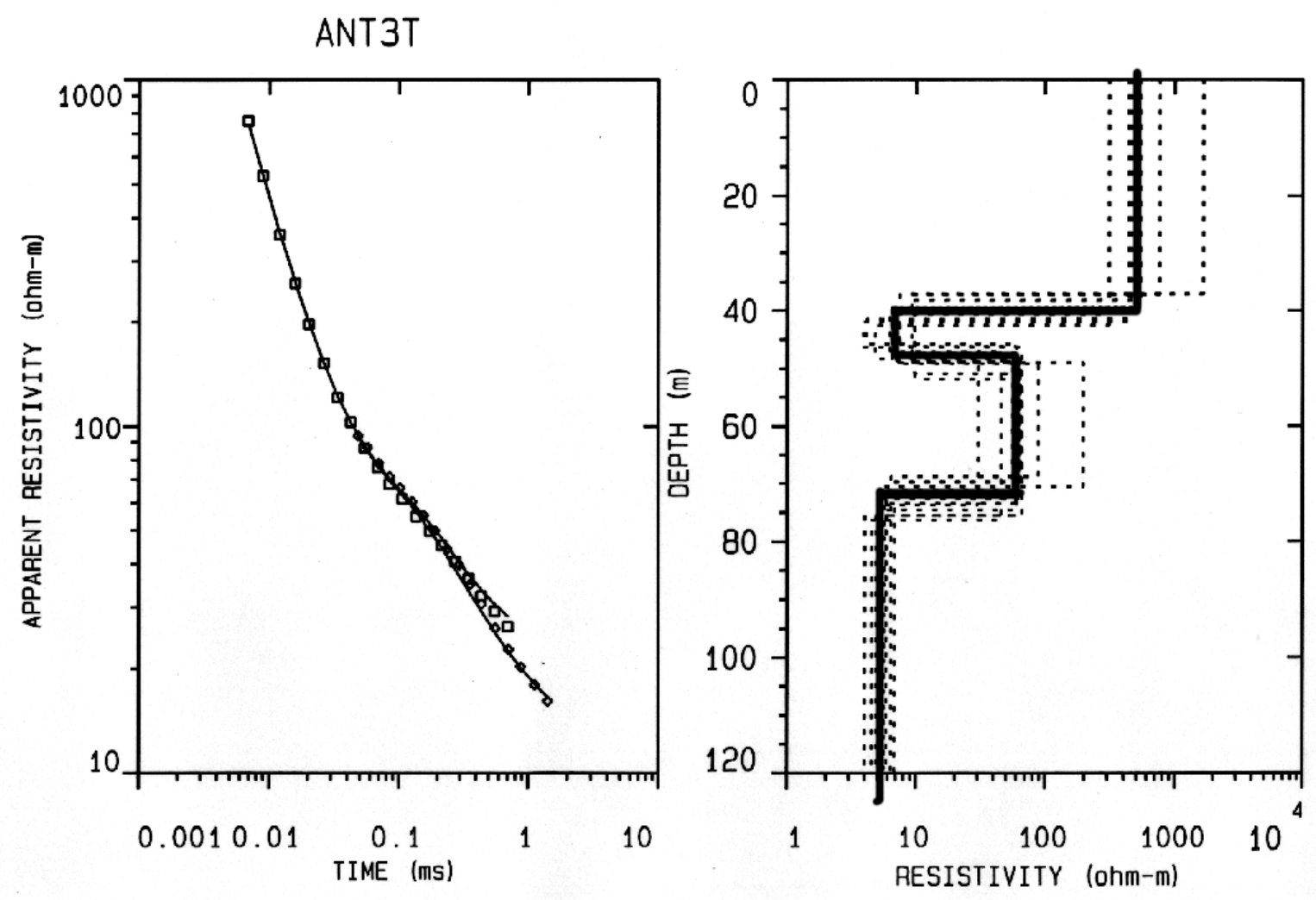


\begin{tabular}{|c|c|c|c|c|c|c|c|c|c|c|}
\hline UTM & $X=40$ & $02530 \mathrm{~m}$ & UTM & $Y=4$ & 00230 & $\mathrm{~m}$ & & LEVAT & $\mathrm{ION}=745$ & ft \\
\hline NTEN & IAVG $v \cdot 3$ & 3.04 & $u s=m$ & icrose & onds & & Lesis & stivity & values in & $\mathrm{ohm}-\mathrm{m}$ \\
\hline INST & 'RUMENT : & EM-47 & $\mathrm{RXA}=31$ & . $4 \mathrm{~m}^{\wedge} 2$ & $L X=3$ & $8.1 \mathrm{~m}$ & $L Y=38$ & $8.1 \mathrm{~m}$ & $\mathrm{XR}=0 \mathrm{~m}$ & $\mathrm{YR}=0 \mathrm{~m}$ \\
\hline FREQ & & $\mathrm{u}$ & $\mathrm{u}$ & $u$ & & & & & & \\
\hline CUR & A] : & 1.5 & 1.5 & 1. & & .5 & & & & \\
\hline GAII & & 6 & 6 & 6 & 6 & & & & & \\
\hline NSTK & & 8 & 8 & 8 & $\varepsilon$ & & & & & \\
\hline $\mathrm{T} / \mathrm{O}$ & us ] : & 2.41 & 2.47. & & & .41 & & & & \\
\hline SHIE & "T [us] : & 0.0 & 0.0 & 0 & & .0 & & & & \\
\hline $\mathrm{CHN}$ & $\mathrm{T}$ (us) & $\operatorname{sqr}(T)$ & rho_a & rho a & rho a & rho_a & $\operatorname{avg} r$ & ostd & & \\
\hline 1 & 6.85 & 0.00262 & 539.7 & 539.5 & 539.3 & 537.4 & 539.0 & 0.2 & & \\
\hline 2 & 8.95 & 0.00299 & 387.1 & 387.6 & 388.0 & 389.6 & 388.1 & 0.3 & & \\
\hline 3 & 12.08 & 0.00348 & 288.6 & 288.3 & 288.0 & 287.3 & 288.0 & 0.2 & & \\
\hline 4 & 15.72 & 0.00396 & 225.4 & 225.4 & 224.8 & 225.4 & 225.2 & 0.1 & & \\
\hline 5 & 20.05 & 0.00448 & 178.7 & 178.9 & 178.7 & 178.9 & 178.8 & 0.1 & & \\
\hline 6 & 26.17 & 0.00512 & 148.6 & 148.6 & 148.3 & 148.4 & 148.5 & 0.1 & & \\
\hline 7 & 33.45 & 0.00578 & 132.1 & 132.3 & 132.2 & 132.4 & 132.2 & 0.1 & & \\
\hline 8 & 42.10 & 0.00649 & 120.8 & 120.8 & 120.7 & 120.8 & 120.8 & 0.1 & & \\
\hline 9 & 54.10 & 0.00736 & 110.1 & 109.8 & 109.7 & 110.0 & 109.9 & 0.1 & & \\
\hline 10 & 68.20 & 0.00826 & 102.7 & 102.7 & 102.8 & 102.9 & 102.8 & 0.1 & & \\
\hline 11 & 83.80 & 0.00915 & 96.41 & 96.61 & 96.41 & 96.41 & 96.46 & 0.1 & & \\
\hline 12 & 104.60 & 0.01023 & 90.44 & 90.78 & 90.86 & 90.88 & 90.74 & 0.2 & & \\
\hline 13 & 135.60 & 0.01164 & 82.64 & 82.76 & 82.83 & 83.35 & 82.89 & 0.4 & & \\
\hline 14 & 172.30 & 0.01313 & 76.68 & 76.86 & 76.46 & 77.35 & 76.83 & 0.5 & & \\
\hline 15 & 214.90 & 0.01466 & 72.78 & 71.63 & 71.63 & 72.62 & 72.16 & 0.9 & & \\
\hline 16 & 275.00 & 0.01658 & 69.85 & 70.47 & 69.36 & 70.01 & 69.92 & 0.7 & & \\
\hline 17 & 349.00 & 0.01868 & 69.56 & 67.88 & 69.14 & 69.65 & 69.05 & 1.2 & & \\
\hline 18 & 436.00 & 0.02088 & 70.11 & 72.14 & 71.19 & 74.06 & 71.84 & 2.3 & & \\
\hline 19 & 555.00 & 0.02356 & 71.56 & 81.60 & 80.22 & 91.29 & 80.42 & 10.0 & & \\
\hline 20 & 701.00 & 0.02648 & 99.65 & 117.9 & 98.48 & 103.4 & 104.2 & 7.8 & & \\
\hline FREQ & & $\mathrm{v}$ & $\mathrm{v}$ & $\mathrm{v}$ & $\mathrm{v}$ & & & & & \\
\hline CUR I & A] : & 1.5 & 1.5 & 1. & & .5 & & & & \\
\hline GAII & & 6 & 6 & 6 & 6 & & & & & \\
\hline NSTK & & 8 & 8 & 8 & $\varepsilon$ & & & & & \\
\hline $\mathrm{T} / \mathrm{Ol}$ & us ] : & 2.41 & 2.47 & & & .41 & & & & \\
\hline SHIF & "T [us ] : & 0.0 & 0.0 & 0 & & .0 & & & & \\
\hline CHN & $\mathrm{T}(\mathrm{ms})$ & $\operatorname{sqr}(\mathrm{T})$ & rho_a & rho_a & rho_a & rho_a & avg_r & ostd & & \\
\hline 1 & 0.0483 & 0.00695 & 108.9 & 108.9 & 108.7 & 109.2 & 108.9 & 0.2 & & \\
\hline 2 & 0.0569 & 0.00754 & 107.5 & 107.4 & 107.1 & 107.4 & 107.3 & 0.2 & & \\
\hline 3 & 0.0693 & 0.00832 & 102.7 & 103.0 & 103.3 & 102.8 & 102.9 & 0.3 & & \\
\hline 4 & 0.0840 & 0.00917 & 99.10 & 98.98 & 99.57 & 99.10 & 99.19 & 0.3 & & \\
\hline 5 & 0.1010 & 0.01005 & 97.00 & 96.65 & 96.31 & 96.82 & 96.69 & 0.3 & & \\
\hline 6 & 0.1250 & 0.01118 & 91.63 & 92.02 & 91.89 & 93.21 & 92.18 & 0.8 & & \\
\hline 7 & 0.1545 & 0.01243 & 87.39 & 85.68 & 87.88 & 88.08 & 87.24 & 1.3 & & \\
\hline 8 & 0.1890 & 0.01375 & 82.91 & 81.66 & 80.99 & 83.62 & 82.28 & 1.4 & & \\
\hline 9 & 0.2370 & 0.01539 & 77.02 & 78.07 & 80.52 & 73.69 & 77.23 & 3.7 & & \\
\hline 10 & 0.2940 & 0.01715 & 77.63 & 76.56 & 78.36 & 82.30 & 78.64 & 3.1 & & \\
\hline 11 & 0.3570 & 0.01889 & 78.11 & 83.56 & 80.33 & 80.59 & 80.59 & 2.8 & & \\
\hline 12 & 0.4410 & 0.02100 & 87.72 & 86.13 & 80.43 & 84.61 & 84.61 & 3.8 & & \\
\hline 13 & 0.5630 & 0.02373 & 95.04 & 93.84 & 121.4 & 87.37 & 97.56 & 13.1 & & \\
\hline 14 & 0.7100 & 0.02665 & 136.1 & 126.3 & 108.1 & 154.9 & 128.6 & 15.1 & & \\
\hline 15 & 0.8810 & 0.02968 & 249.1 & 190.1 & 135.3 & 627.8 & 1582. & >> & & \\
\hline 16 & 1.122 & 0.03350 & 148.5 & 95.21 & 98.80 & 96.97 & 105.4 & 17.9 & & \\
\hline 17 & 1.414 & 0.03760 & 68.51 & 50.33 & 44.48 & 84.09 & 57.26 & 27.4 & & \\
\hline 18 & 1.763 & 0.04199 & 36.68 & 94.97 & 170.2 & 32.12 & 49.39 & 57.6 & & \\
\hline 19 & 2.240 & 0.04733 & 27.21 & 24.61 & 43.88 & 28.09 & 29.17 & 21.4 & & \\
\hline 20 & 2.825 & 0.05315 & 25.21 & 24.60 & 29.81 & 29.81 & 27.08 & 10.4 & & \\
\hline
\end{tabular}



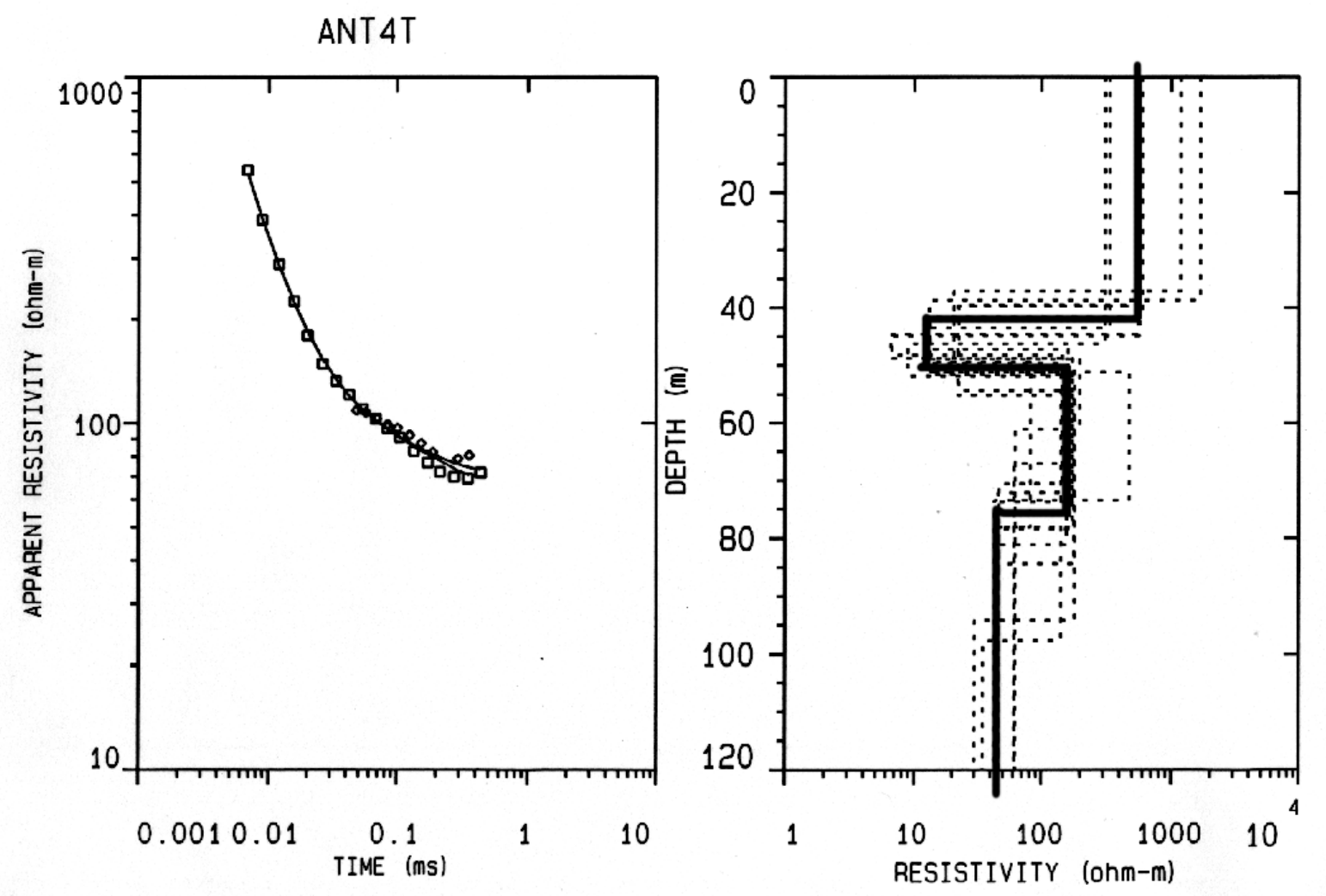


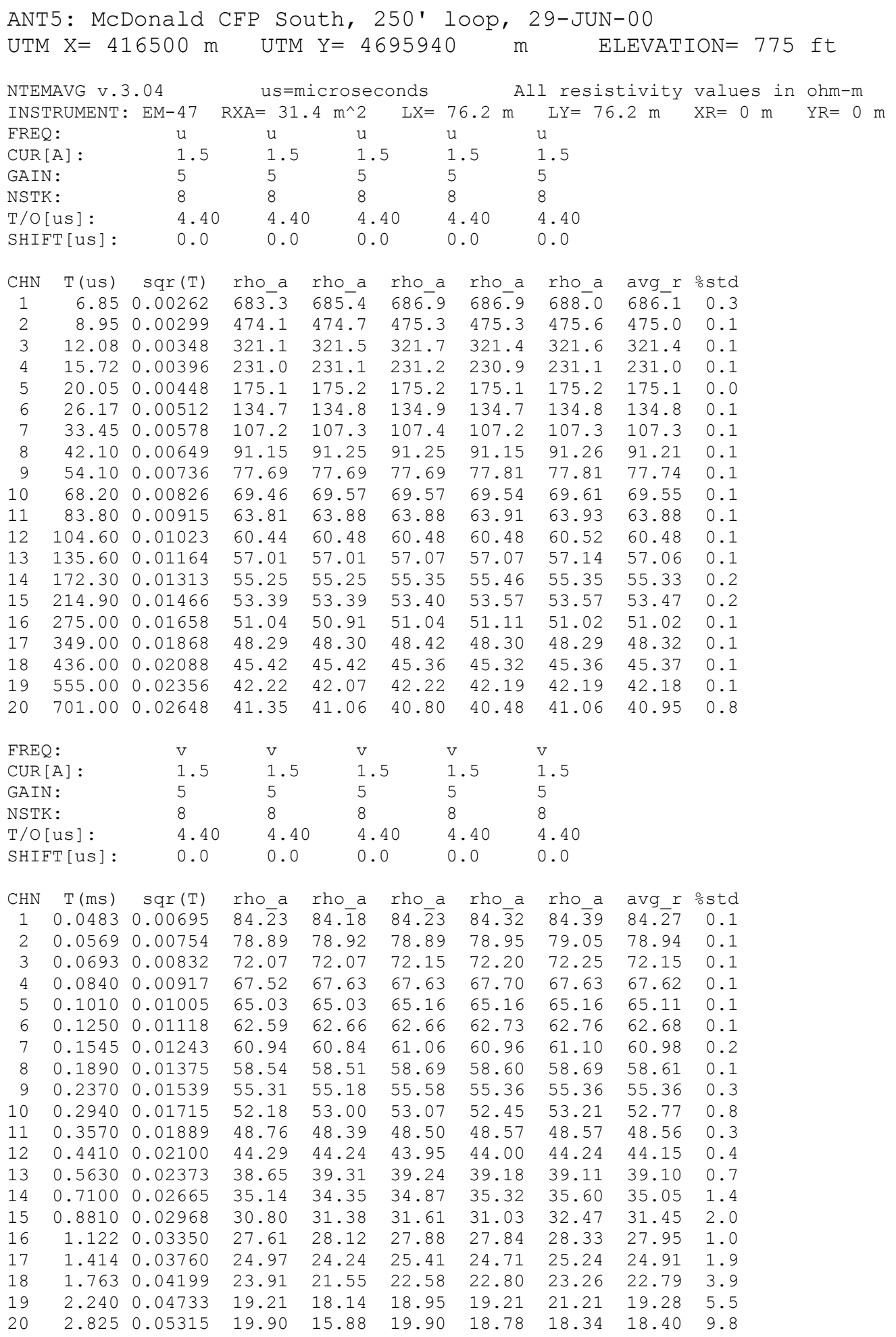



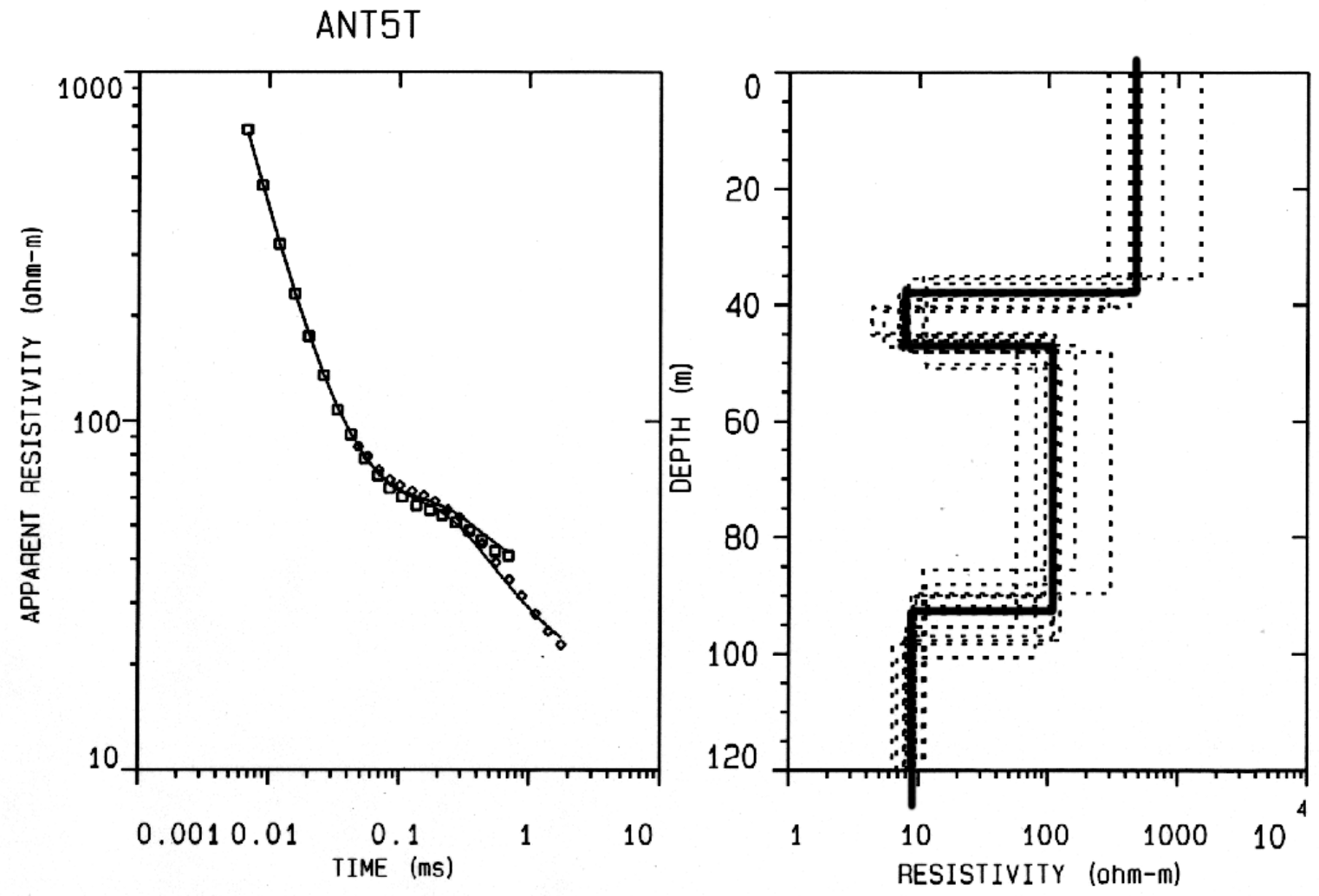


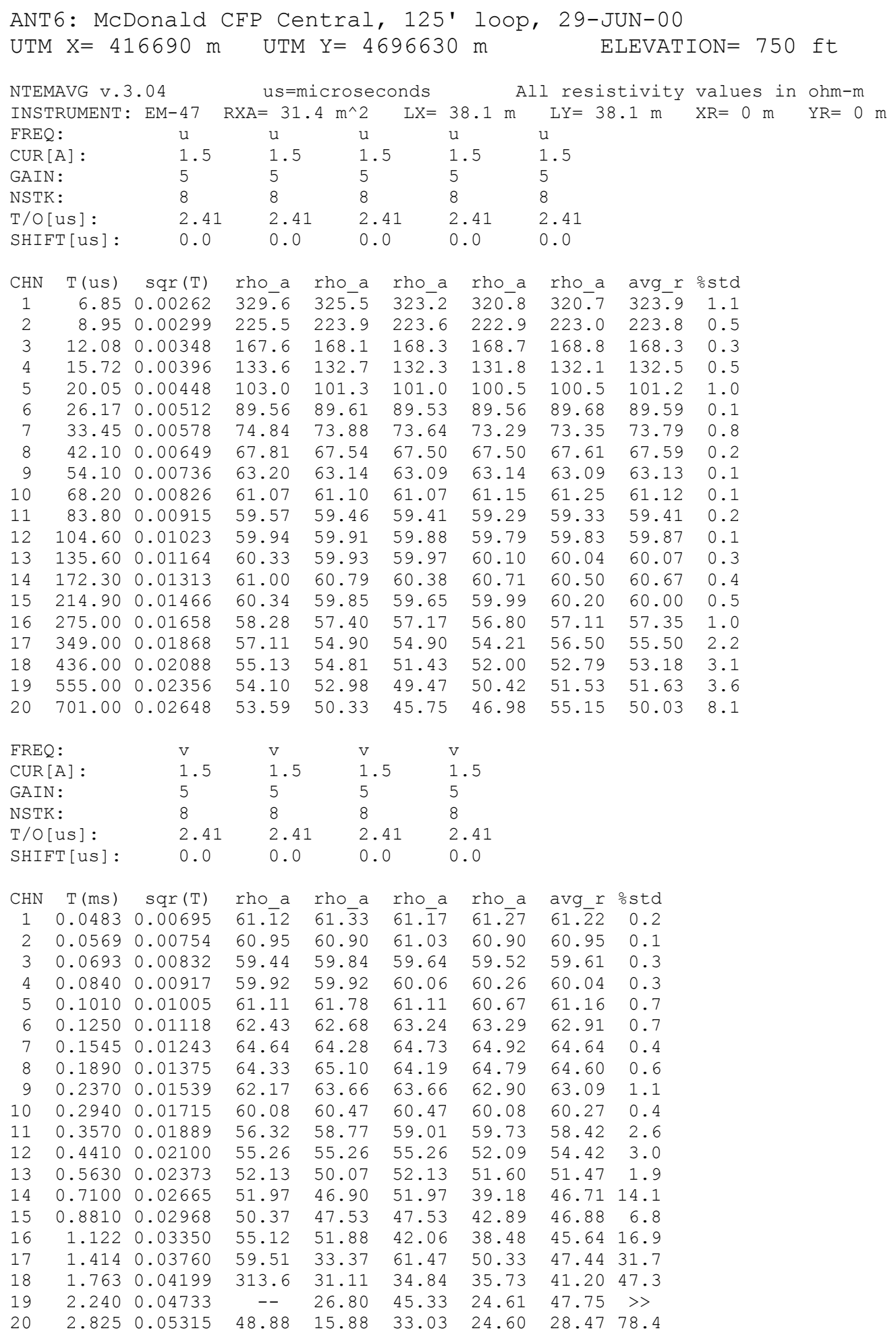



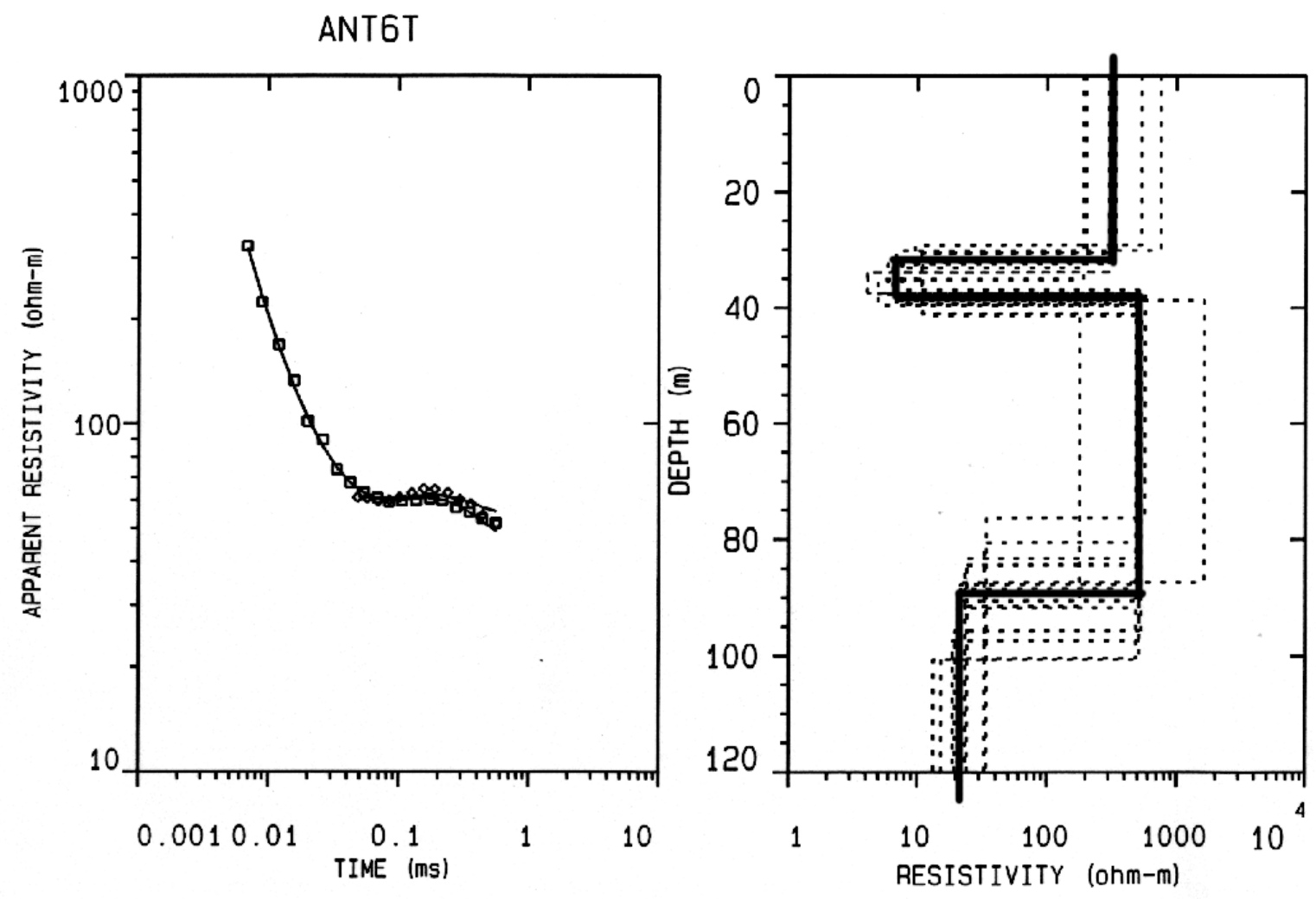


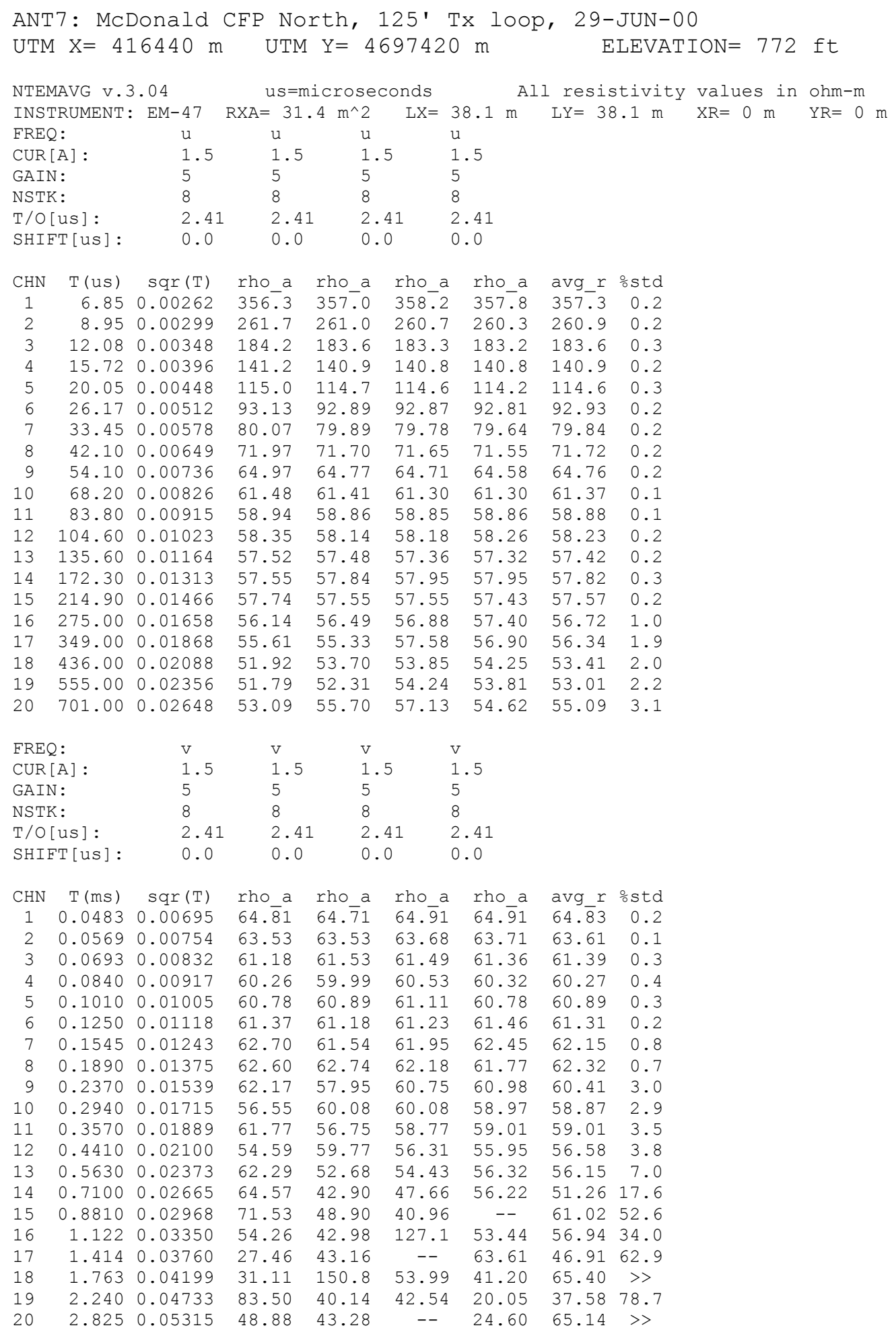



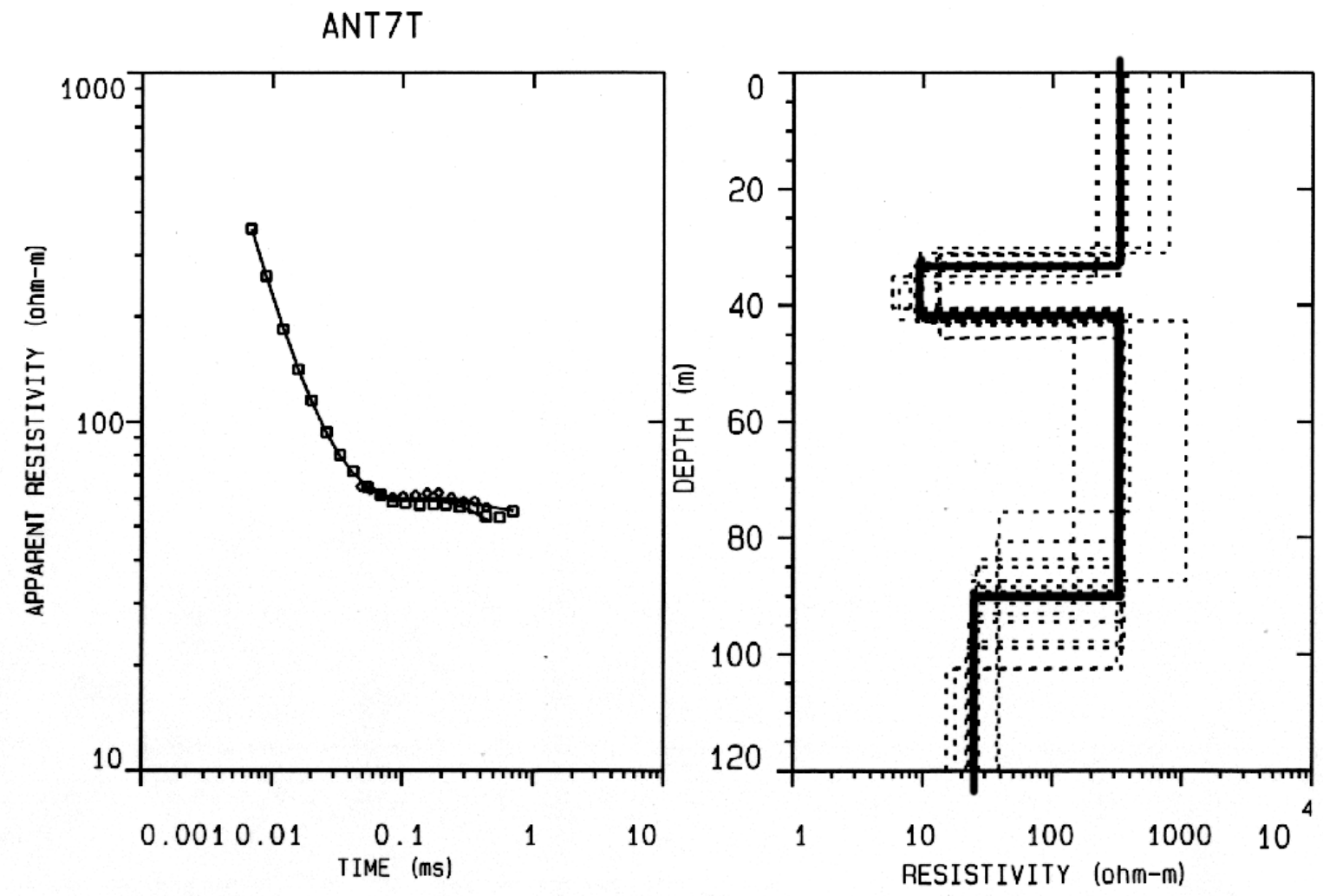


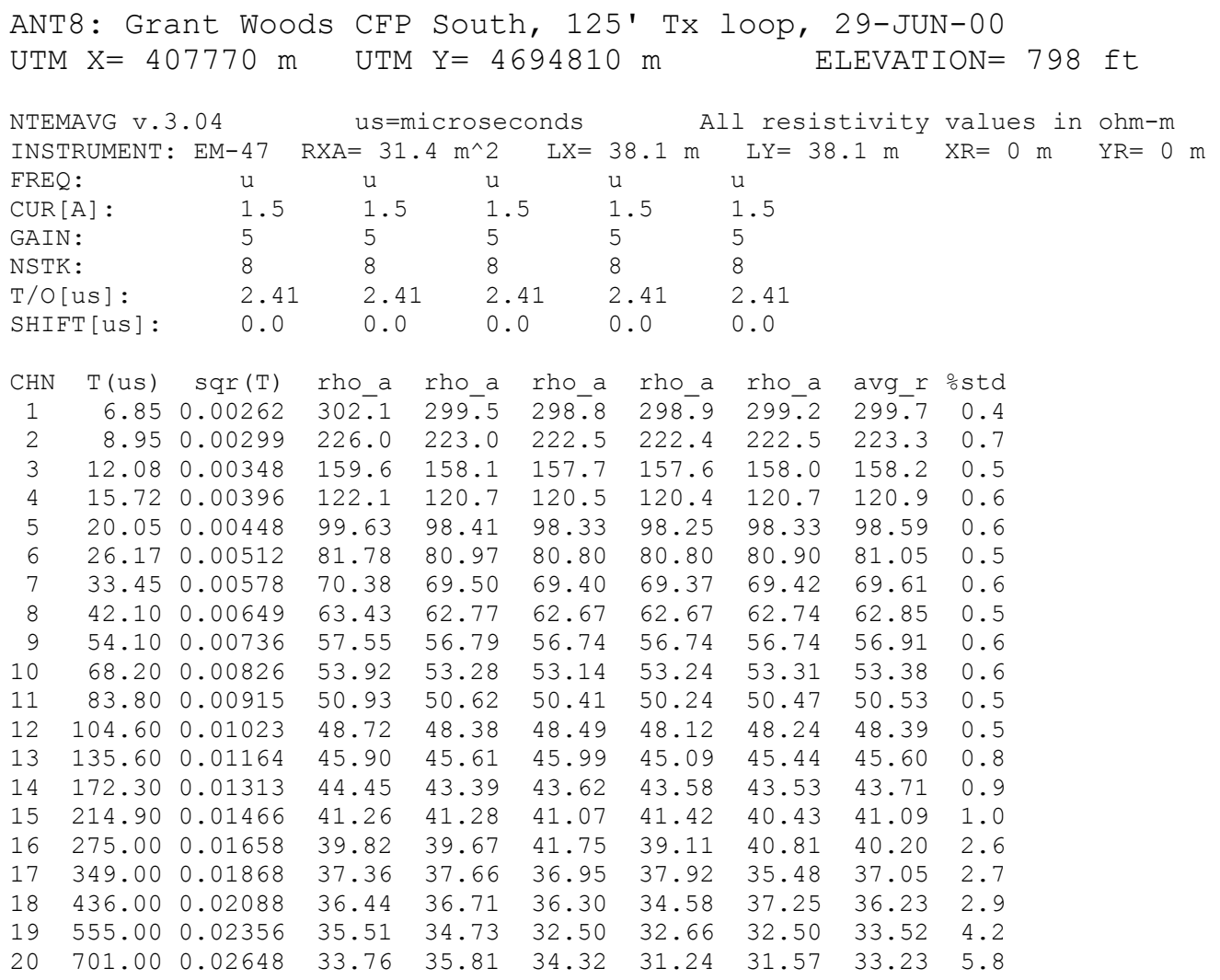
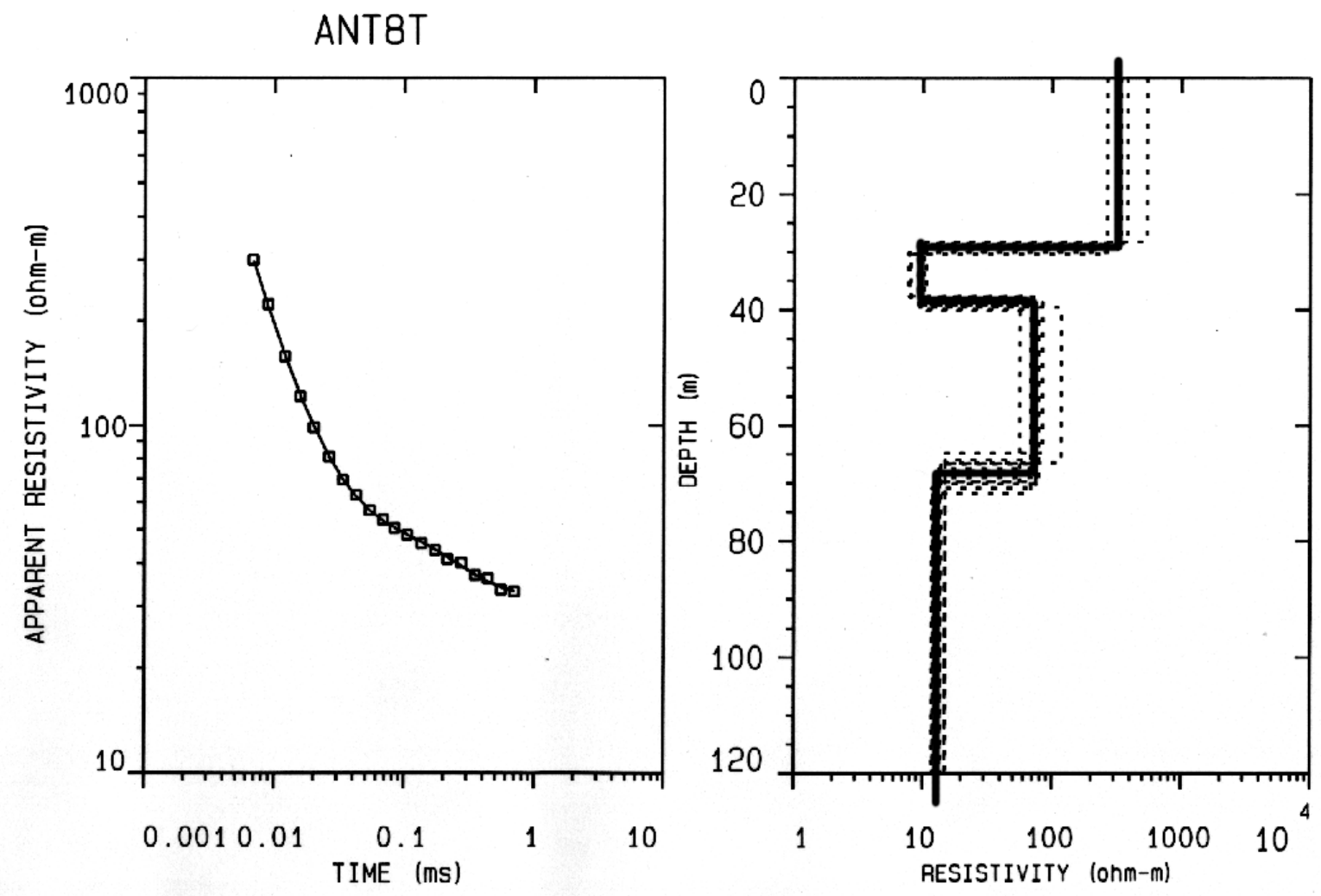

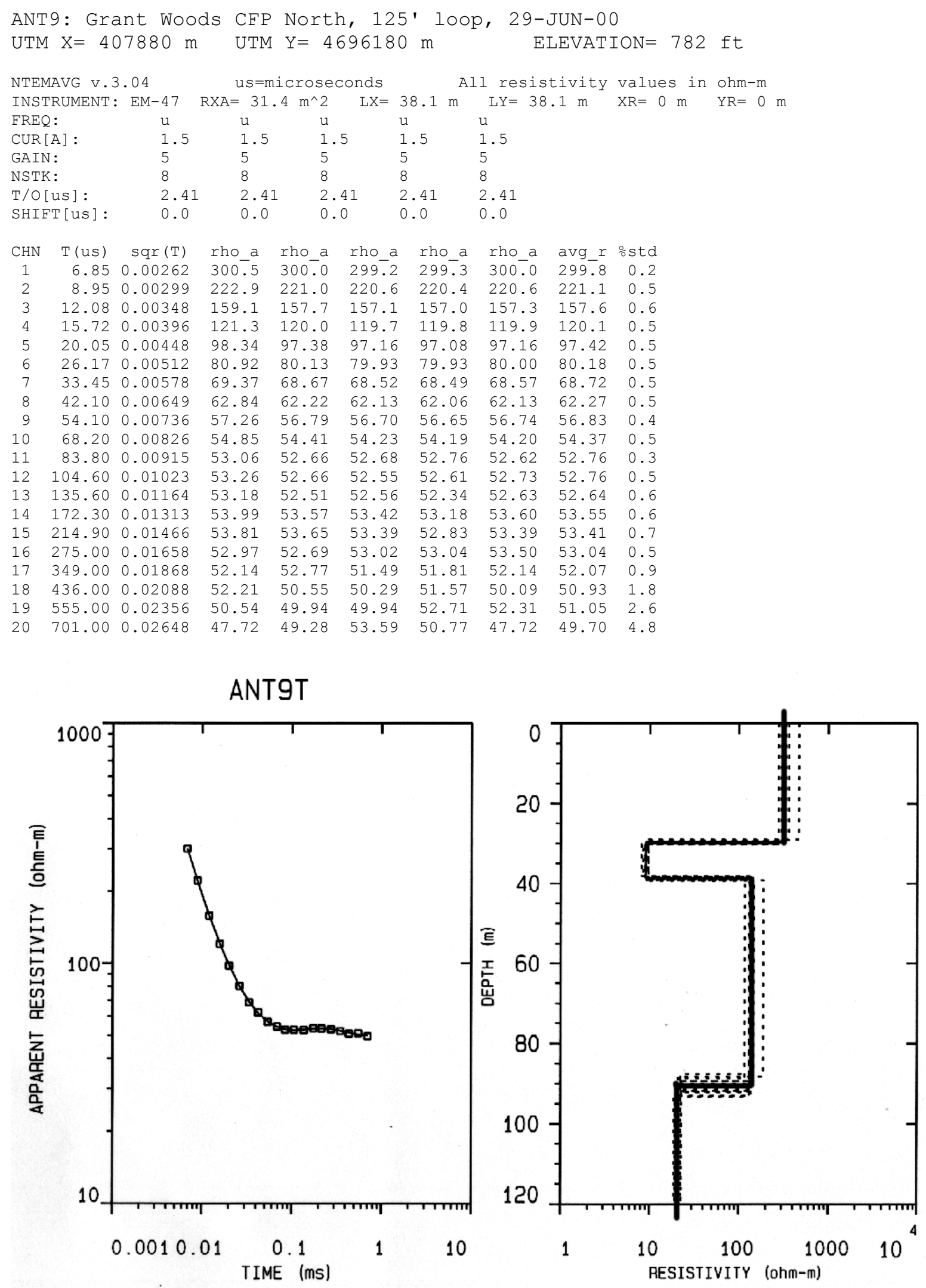
ANT10: Kathy Stuart's horse pasture, 125' Tx 10op, 30-JUN-00

UTM X $=415940 \mathrm{~m} \quad \mathrm{UTM} Y=4699750 \mathrm{~m} \quad$ ELEVATION= $772 \mathrm{ft}$

\begin{tabular}{|c|c|c|c|c|c|c|c|c|c|}
\hline \multicolumn{3}{|c|}{ NTEMAVG v.3.04 } & \multicolumn{3}{|c|}{ us=microseconds } & \multicolumn{3}{|c|}{ All resistivity } & valu \\
\hline \multicolumn{3}{|c|}{ INSTRUMENT: EM-47 } & $\mathrm{RXA}=31$ & $4 \mathrm{~m}^{\wedge} 2$ & $\mathrm{LX}=$ & $38.1 \mathrm{~m}$ & $L Y=3 \varepsilon$ & $1 \mathrm{~m}$ & $\mathrm{XR}=$ \\
\hline \multirow{2}{*}{\multicolumn{2}{|c|}{$\begin{array}{l}\text { FREQ: } \\
\text { CUR [A] : }\end{array}$}} & $\mathrm{u}$ & u & u & & a & $\mathrm{u}$ & & \\
\hline & & 1.5 & 1.5 & & & 1.5 & 1.5 & & \\
\hline \multicolumn{2}{|c|}{$\begin{array}{l}\text { CUR [A] : } \\
\text { GAIN : }\end{array}$} & 5 & 5 & 5 & & 5 & 5 & & \\
\hline \multicolumn{2}{|c|}{ NSTK: } & 8 & 8 & 8 & & & 8 & & \\
\hline \multicolumn{2}{|c|}{ T/O[us ] : } & 2.41 & 2.4 & & & 2.41 & 2.41 & & \\
\hline \multicolumn{2}{|c|}{ SHIFT[us] : } & 0.0 & 0.0 & & & 0.0 & 0.0 & & \\
\hline $\mathrm{CHN}$ & $\mathrm{T}$ (us) & $\operatorname{sqr}(\mathrm{T})$ & rho_a & rho_a & rho_a & rho_a & rho_a & avg_r & \\
\hline 1 & 6.85 & 0.00262 & 373.4 & 374.6 & 375.7 & 377.0 & 377 & 375.7 & \\
\hline 2 & 8.95 & 0.00299 & & & & & & & \\
\hline 3 & 12.08 & 0.00348 & & & & & & & \\
\hline 4 & 15. & 0.0 & & & & & & & \\
\hline 5 & 20.05 & 0.0 & 130.0 & 130.2 & 0.3 & 130.5 & & & \\
\hline 6 & 26.17 & 0.00 & 103.1 & 103.1 & 103.2 & 103.1 & 103 & 3.1 & \\
\hline 7 & 33.45 & 0.0 & .60 & & .65 & & & & \\
\hline 8 & 42.10 & 0.00649 & .71 & & & & & & \\
\hline 9 & & 0.0 & & & & & & & \\
\hline 10 & 68.2 & 0.0 & .44 & & & 5.63 & & & \\
\hline 11 & 83.80 & 0.00915 & 61.35 & & 61.61 & 61.57 & 61. & 1.56 & \\
\hline 12 & 104.60 & 0.01023 & 57.90 & 57. & 58.01 & 58.03 & 58 & & \\
\hline 13 & 135.60 & 0.01164 & 51.74 & 51.86 & 51.77 & 51.74 & 51. & 1.81 & \\
\hline 14 & & & & & & 47.80 & & 7.81 & \\
\hline 15 & 214.9 & 0.0 & & & & & & & \\
\hline 1 & 275.0 & 0.016 & & & 39.21 & & & & \\
\hline 17 & 349.00 & 0.01868 & 35.43 & 35.64 & 35.56 & 35.33 & 35. & 35.47 & \\
\hline 18 & 436.00 & 0.02088 & 33.33 & 33.37 & 32.87 & 33.42 & 32.69 & 33.13 & \\
\hline 19 & 555.00 & 0.02356 & 31.46 & 32.15 & 31.31 & 30.85 & 31.50 & 31.45 & \\
\hline 20 & 701.00 & 0.02648 & 32.26 & 30.73 & 30.86 & 30.42 & 31.64 & 31.16 & \\
\hline
\end{tabular}

\begin{tabular}{|c|c|c|c|c|c|c|c|c|c|}
\hline \multicolumn{2}{|c|}{ FREQ: } & $\mathrm{V}$ & \multicolumn{2}{|l|}{$\mathrm{V}$} & $v$ & & \multicolumn{3}{|l|}{$v$} \\
\hline \multicolumn{2}{|c|}{ CUR $[A]:$} & 1.5 & \multicolumn{2}{|c|}{1.5} & 1.5 & 1.5 & \multicolumn{3}{|l|}{1.5} \\
\hline \multicolumn{2}{|c|}{ GAIN: } & 6 & \multicolumn{2}{|l|}{6} & 6 & 6 & \\
\hline \multicolumn{2}{|c|}{ NSTK: } & 8 & 8 & 8 & $\varepsilon$ & & 8 & & \\
\hline \multirow{2}{*}{\multicolumn{2}{|c|}{$\begin{array}{l}\text { T/O[us] : } \\
\text { SHIFT [us] : }\end{array}$}} & 2.41 & & 2.41 & 2.41 & \multicolumn{3}{|l|}{2.41} \\
\hline & & 0.0 & \multicolumn{2}{|c|}{0.0} & 0.0 & 0.0 & \multicolumn{3}{|l|}{0.0} \\
\hline $\mathrm{CHN}$ & $\mathrm{T}(\mathrm{ms})$ & $\operatorname{sqr}(T)$ & rho_a & rho_a & rho_a & rho_a & rho_a & avg_r & ostd \\
\hline 1 & 0.0483 & 0.00695 & & .77 & $70 . \overline{91}$ & & & $70 . \overline{82}$ & 0.2 \\
\hline 2 & 0.0569 & 0.00754 & .47 & 33 & & & 68. & & 0.1 \\
\hline 3 & 0.0693 & 0.00832 & 65.04 & 65.12 & 65.19 & 65. & 65. & & 0.2 \\
\hline 4 & 0.0840 & 0.00917 & 63.55 & 63.94 & 63.55 & 63.98 & 63.98 & 63.80 & 0.4 \\
\hline 5 & 0.1010 & 0.01005 & 60.62 & 61.22 & 60.35 & 60. & 60.78 & & 0.5 \\
\hline 6 & 0.1250 & & & & & & & & 0.9 \\
\hline 7 & 0.1 & 0.0 & & & & & 51. & & 0.6 \\
\hline 8 & 0.1890 & 0.01375 & .09 & 47.95 & 48.53 & 47.81 & 48.68 & 48.21 & 0.8 \\
\hline 9 & 0.2370 & 0.01539 & .12 & 44.38 & 42.83 & 44.22 & 44.22 & 43.74 & 1.7 \\
\hline 10 & 0.2940 & 0.01715 & 9.84 & 39.84 & 39.97 & 38.97 & 38.65 & & 1.5 \\
\hline 11 & 0.3570 & 0.01889 & & 35.89 & & & 35.02 & & 2.2 \\
\hline 12 & 0.4410 & 0.0 & & .88 & & & 31. & & 1.2 \\
\hline 13 & 0.5630 & 0.02373 & 29.75 & 28.42 & 29.22 & 28.13 & 29.10 & 28.91 & 2.2 \\
\hline 14 & 0.7100 & 0.02665 & 25.79 & 26.75 & 26.84 & 27.91 & 28.01 & 27.03 & 3.4 \\
\hline 15 & 0.8810 & 0.02968 & 23.51 & 24.59 & 26.55 & 24.22 & 25.66 & 24.85 & 4.8 \\
\hline 16 & 1.122 & 0.03350 & 23.54 & 23.38 & 22.98 & 24.82 & 21.74 & 23.24 & 4.8 \\
\hline 17 & 1.414 & 0.03760 & 22.23 & 17.88 & 19.10 & 21.83 & 23.52 & & 11.7 \\
\hline 18 & 1.763 & 0.04199 & 17.48 & 20.46 & 16.10 & 17.79 & 30.18 & 19.22 & 20.6 \\
\hline 19 & 2.240 & 0.04733 & 14.64 & 18.30 & 14.29 & 13.80 & 18.30 & 15.56 & 13.3 \\
\hline & & & & 11.13 & 12.53 & 20.81 & 22.05 & 15.28 & 30. \\
\hline
\end{tabular}



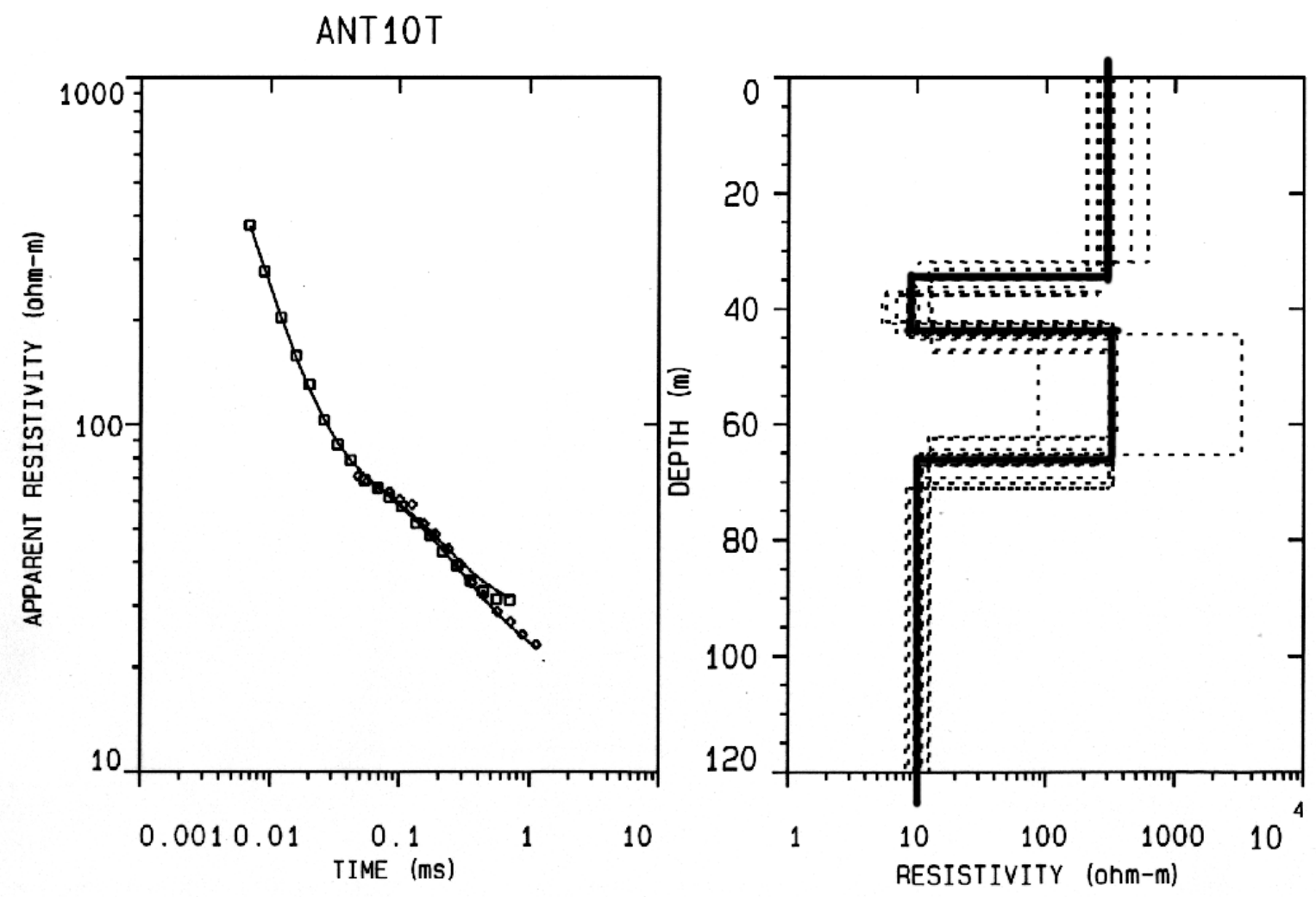


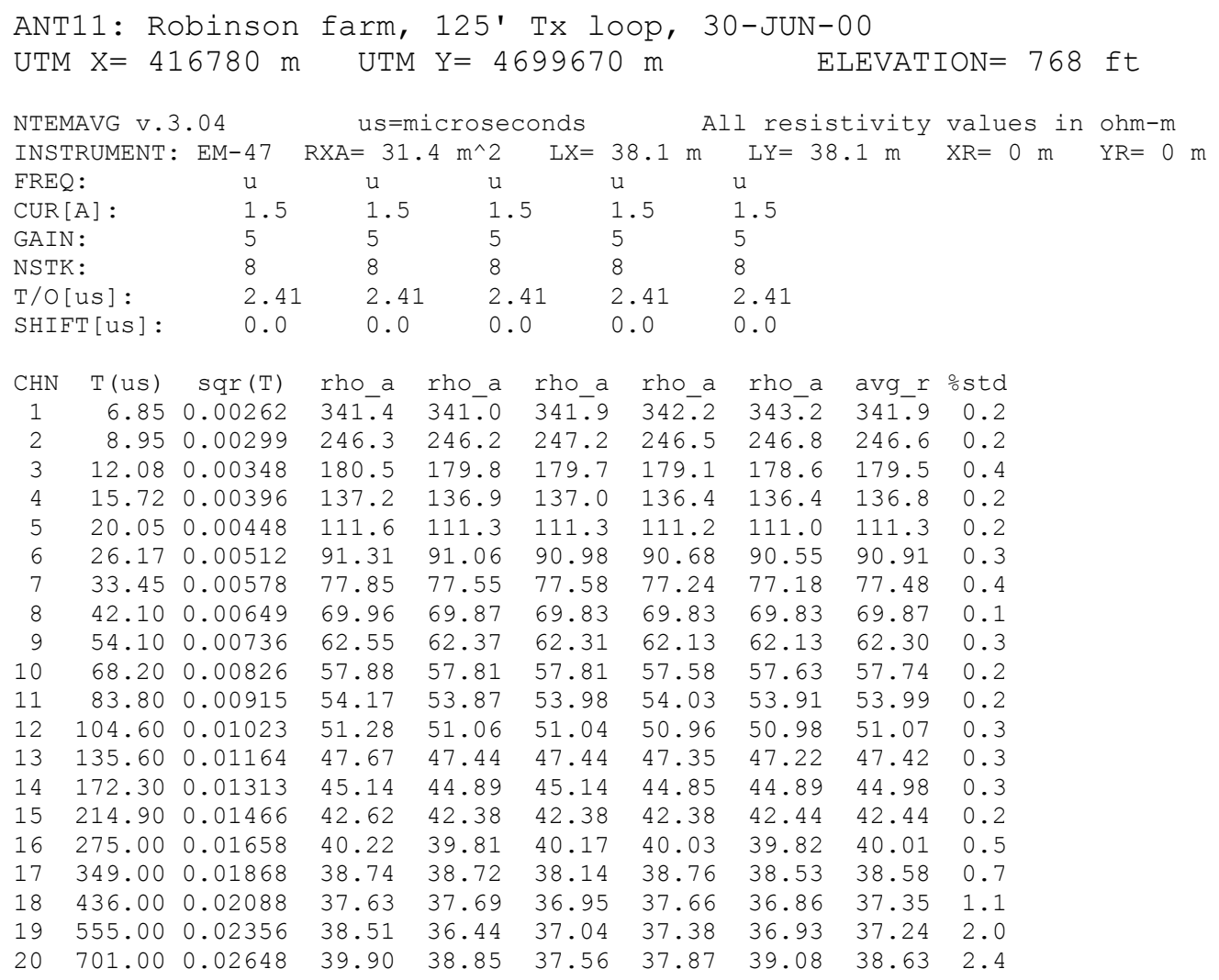
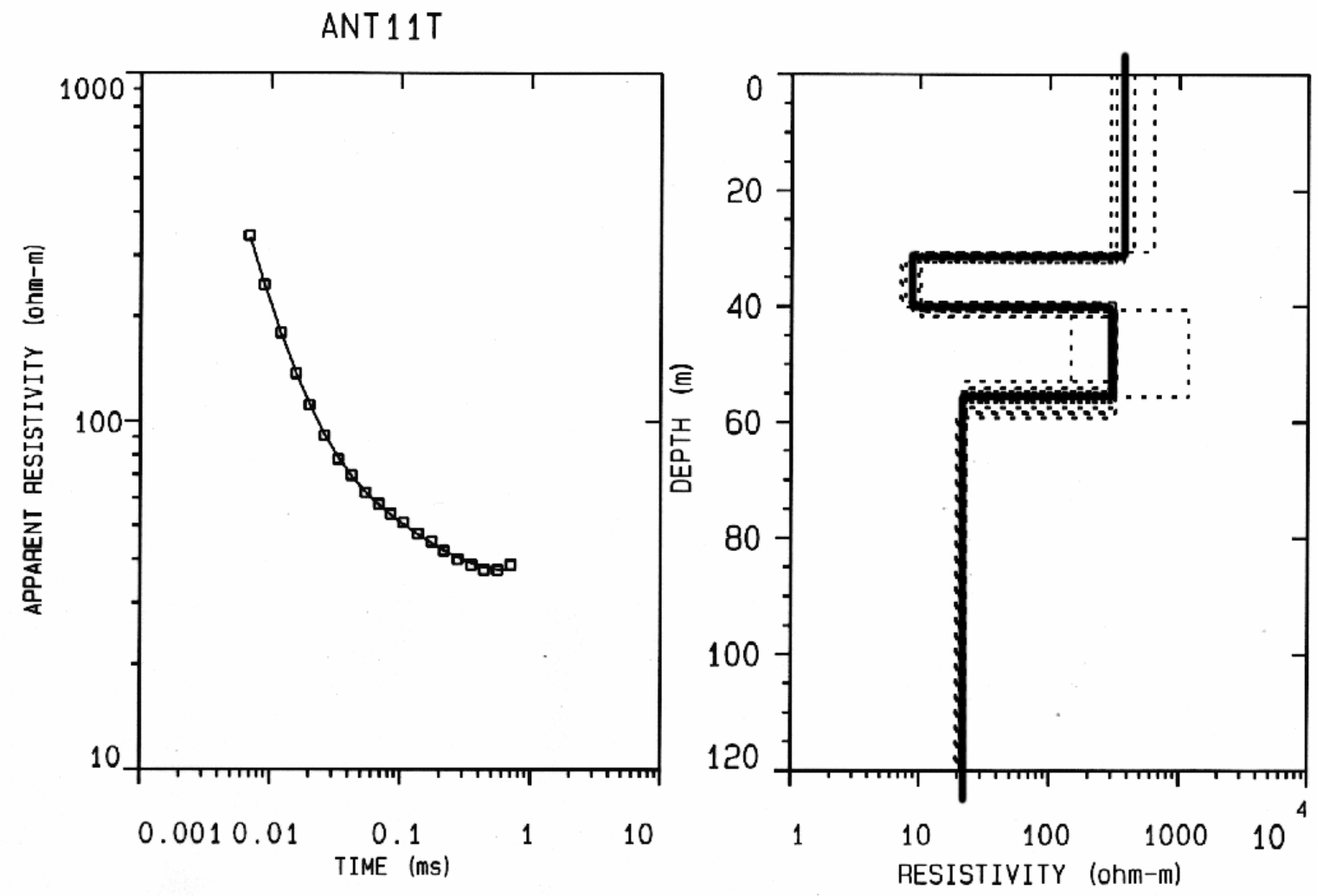


\section{APPENDIX B: OBSERVED DATA and TEM MODELS, BERRIEN SPRINGS AREA}

TEM Sounding locations were recorded on 1:24,000 scale topographic maps that had 10-ft contour intervals. The UTM coordinates and elevations given below were measured from these field maps. The location given is nominally that of the small Rx loop, which in turn was located in the center of a square $\mathrm{Tx}$ loop either 38.1 or $76.2 \mathrm{~m}$ on a side. Likely uncertaintly in elevations is about half a contour interval, or $5 \mathrm{ft}$, for KLOCK, SJ-500, 600, 700, 750, 800, and 900, but thought to be as much as about $15 \mathrm{ft}$ for SJ-000, 100, 1000, and 1200. Likely uncertainty in UTM coordinates is thought to be about $20 \mathrm{~m}$ for Klock, but is about $50 \mathrm{~m}$ for the SJ stations. The greater uncertainty for the SJ locations arises because they were sited relative to the graded right of way for the extension of Route US-31, which was not shown on our older topographic maps. The locations of the SJ stations relative to one another were measured by pacing, and are correct within about $5 \mathrm{~m}$.

Each data set in this appendix contains a header briefly describing the TEM site, followed by a section giving tabled data for each data range (u, $\mathrm{v}$, or $\mathrm{h}$ ) that was used at that site, and concluding with a graph of the results. The data table includes for each time gate the individual apparent resistivities (rho_a, in ohm-m) that make up a series of repeated measurements, followed by the average apparent resistivity value for the series and standard error of its estimate (\%std). The left panel of the graph section shows the time decay of apparent resistivity with measured averages appearing as squares ( $u$ range) or diamonds ( $v$ and $h$ ranges). The right panel shows models of apparent resistivity versus depth; the heavy line represents the best model that was found, whereas lighter dashed lines represent a suite of equivalent models that fit the observed data almost as well. The continuous line in the left panel is calculated from the best model and shows how well it fits the observed data. All graphs are at the same scale to facilitate comparisons between them.

KLOCK: Klock Park hovercraft drillhole site, 250' TX loop, 23-JUN-00 UTM $X=543520 \mathrm{~m} \quad$ UTM $Y=4663830 \mathrm{~m} \quad \mathrm{Z}=582 \mathrm{ft}$

\begin{tabular}{|c|c|c|c|c|c|c|c|}
\hline \multicolumn{3}{|c|}{ NTEMAVG V.3.04 } & \multicolumn{3}{|c|}{ us $=$ microseconds } & \multicolumn{2}{|c|}{ All re } \\
\hline \multicolumn{3}{|c|}{ INSTRUMENT: EM-47 } & $\mathrm{RXA}=31$ & $.4 m^{\wedge} 2$ & $L X=$ & $6.2 \mathrm{~m}$ & $L Y=$ \\
\hline \multicolumn{2}{|c|}{ FREQ: } & $\mathrm{u}$ & $\mathrm{u}$ & u & & & \\
\hline \multicolumn{2}{|c|}{$\operatorname{CUR}[A]:$} & 1.5 & 1.5 & & & & \\
\hline \multicolumn{2}{|c|}{ GAIN : } & 4 & 4 & 4 & & & \\
\hline \multicolumn{2}{|c|}{ NSTK: } & 8 & 8 & 8 & & & \\
\hline \multicolumn{2}{|c|}{ T/O[us]: } & 4.40 & 4.4 & & & & \\
\hline \multicolumn{2}{|c|}{ SHIFT [us]: } & 0.0 & 0.0 & & & & \\
\hline CHN & $T$ (us) & $\operatorname{sqr}(T)$ & rho a & rho a & rho a & $\operatorname{avg} r$ & ostd \\
\hline 1 & 6.85 & 0.00262 & 646.1 & 646.9 & 648 & 647.0 & 0.2 \\
\hline 2 & 8.95 & 0.00299 & 459.3 & 460.3 & 460.5 & 460.0 & 0.1 \\
\hline 3 & 12.08 & 0.00348 & 321.0 & 320.4 & 320.8 & 320.7 & 0.1 \\
\hline 4 & 15.7 & 0.00396 & 238.1 & & & 237.9 & 0. \\
\hline 5 & 20. & 0.00448 & 85.6 & & & 185.6 & 0. \\
\hline 6 & 26.17 & 0.00512 & 145.9 & 145.7 & 145.9 & 145.8 & 0.1 \\
\hline 7 & 33.45 & 0.00578 & 116.5 & 116.5 & 116.3 & 116.4 & 0.1 \\
\hline 8 & 42.10 & 0.00649 & 98.44 & 98.26 & 98.40 & 98.37 & 0.1 \\
\hline 9 & 54.10 & 0.00736 & 80.86 & 81.14 & & 81.05 & 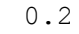 \\
\hline 10 & 68.20 & 0.00826 & 68.97 & & & 68.71 & 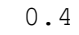 \\
\hline 11 & 83.80 & 0.00915 & 59.98 & & 59. & 59.96 & 0.1 \\
\hline 12 & 104.60 & 0.01023 & 52.70 & 52.74 & 52.84 & 52.76 & 0.1 \\
\hline 13 & 135.60 & 0.01164 & 45.58 & 45.47 & 45. & 45.56 & 0.2 \\
\hline 14 & 172.30 & .01313 & 40.59 & 40.68 & 40.68 & 40.65 & 0.1 \\
\hline & 214.90 & 1466 & 36.90 & 36.70 & 37.02 & 36.87 & 0.5 \\
\hline
\end{tabular}




$\begin{array}{llllllll}16 & 275.00 & 0.01658 & 33.40 & 33.16 & 33.27 & 33.28 & 0.4 \\ 17 & 349.00 & 0.01868 & 30.66 & 30.64 & 30.45 & 30.58 & 0.4 \\ 18 & 436.00 & 0.02088 & 27.80 & 27.98 & 28.34 & 28.04 & 1.0 \\ 19 & 555.00 & 0.02356 & 26.17 & 25.23 & 25.94 & 25.77 & 1.9 \\ 20 & 701.00 & 0.02648 & 24.41 & 24.55 & 24.69 & 24.55 & 0.6\end{array}$
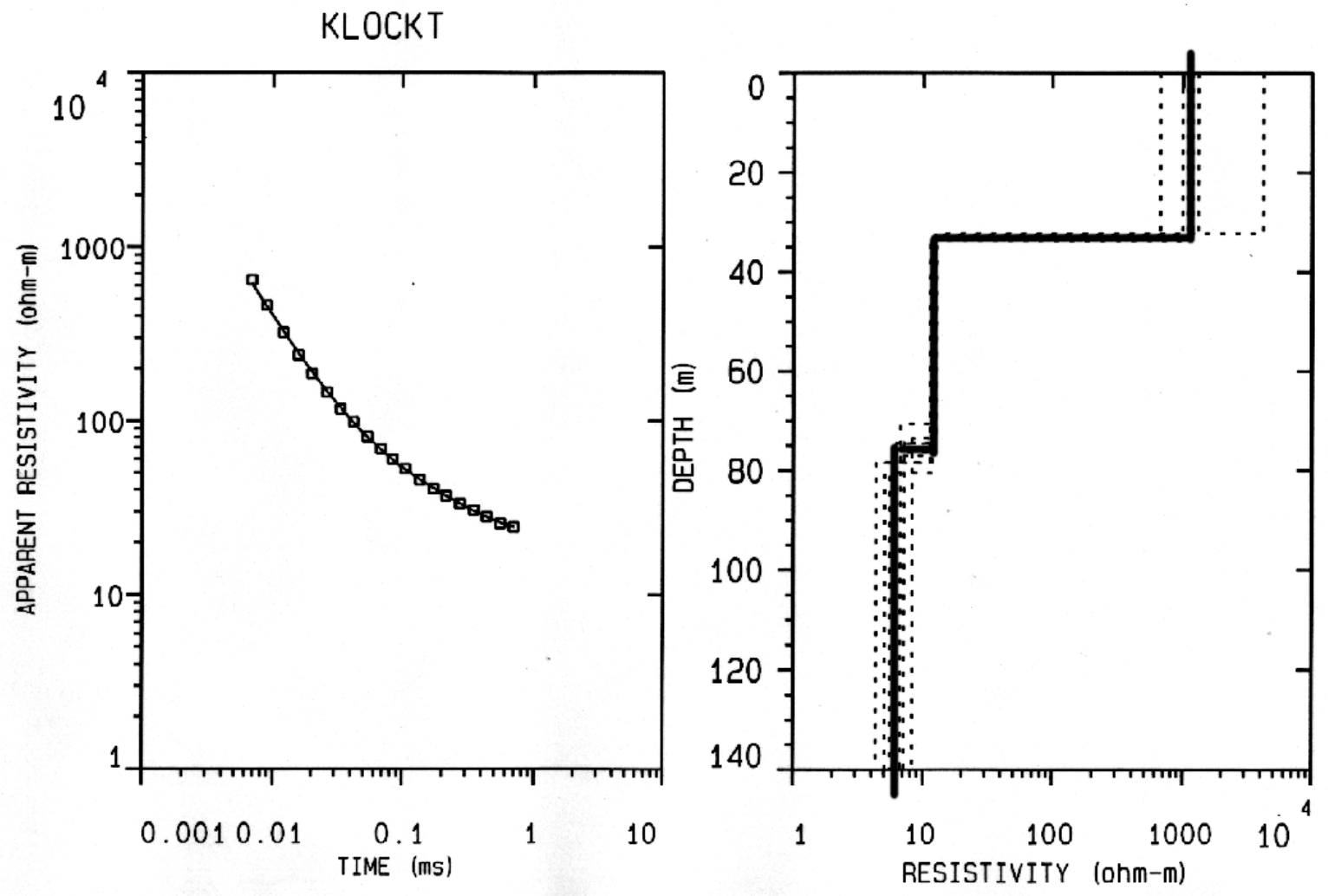


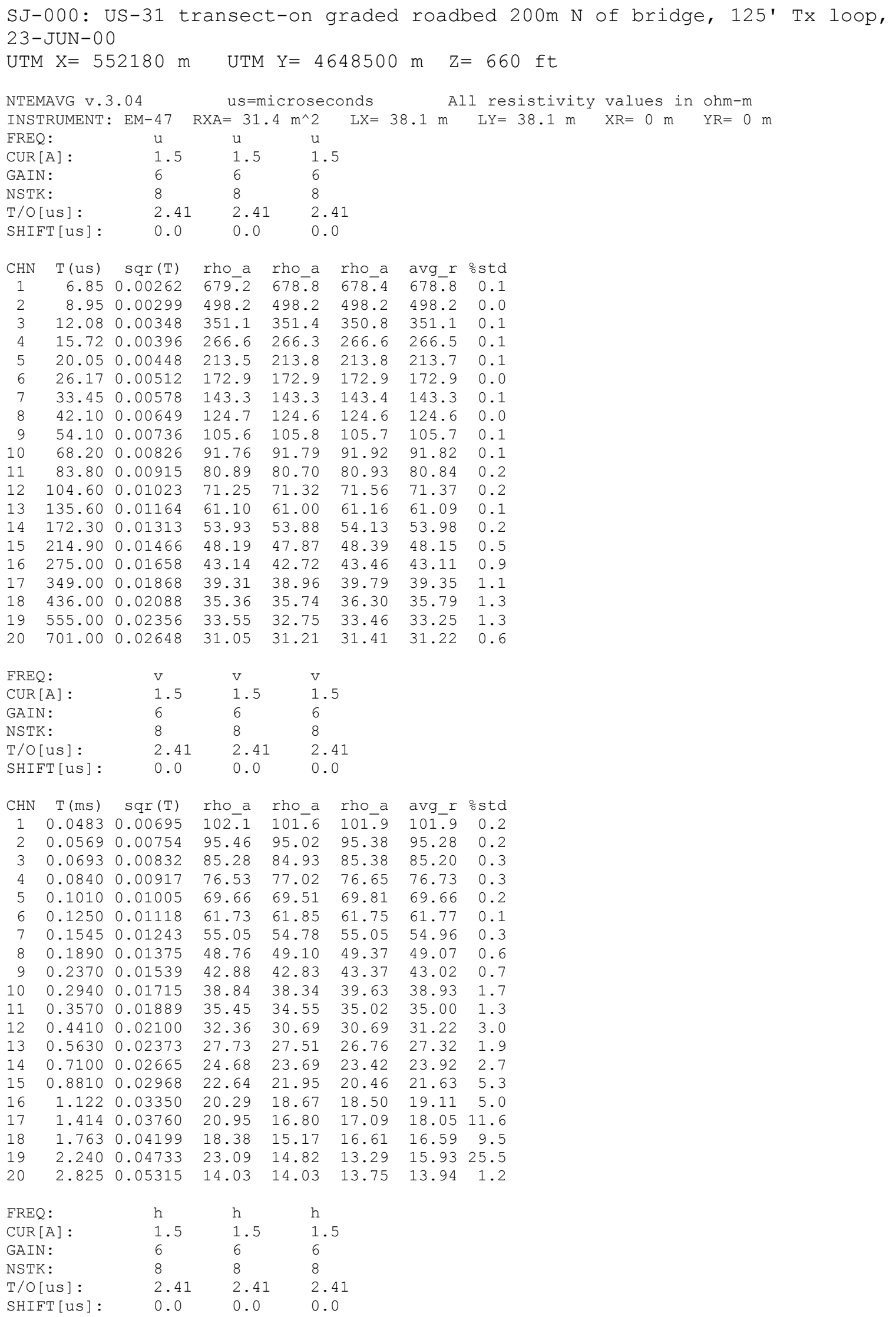




$\begin{array}{rrrrrrrr}\text { CHN } & \text { T(ms) } & \text { sqr(T) } & \text { rho_a } & \text { rho_a } & \text { rho_a } & \text { avgrr } & \text { ostd } \\ 1 & 0.1000 & 0.01000 & 76.84 & 77.81 & 76.65 & 77.09 & 0.8 \\ 2 & 0.1210 & 0.01100 & 68.72 & 71.01 & 69.42 & 69.70 & 1.7 \\ 3 & 0.1510 & 0.01229 & 60.77 & 61.07 & 60.77 & 60.87 & 0.3 \\ 4 & 0.1880 & 0.01371 & 53.52 & 54.08 & 52.78 & 53.45 & 1.2 \\ 5 & 0.2310 & 0.01520 & 47.61 & 48.82 & 47.15 & 47.85 & 1.8 \\ 6 & 0.2910 & 0.01706 & 42.05 & 44.68 & 41.90 & 42.83 & 3.6 \\ 7 & 0.3650 & 0.01910 & 37.50 & 37.00 & 36.34 & 36.94 & 1.6 \\ 8 & 0.4520 & 0.02126 & 32.51 & 33.64 & 34.04 & 33.38 & 2.4 \\ 9 & 0.5700 & 0.02387 & 28.78 & 30.31 & 27.87 & 28.94 & 4.2 \\ 10 & 0.7120 & 0.02668 & 25.96 & 24.38 & 27.83 & 25.96 & 6.6 \\ 11 & 0.8710 & 0.02951 & 24.68 & 22.77 & 24.43 & 23.92 & 4.5 \\ 12 & 1.080 & 0.03286 & 21.94 & 21.94 & 21.32 & 21.73 & 1.6 \\ 13 & 1.390 & 0.03728 & 17.12 & 18.95 & 19.82 & 18.54 & 7.6 \\ 14 & 1.750 & 0.04183 & 19.44 & 20.27 & 20.27 & 19.98 & 2.4 \\ 15 & 2.180 & 0.04669 & 25.08 & 11.86 & 34.67 & 18.62 & 56.4 \\ 16 & 2.780 & 0.05273 & 20.62 & 12.87 & 20.99 & 17.02 & 30.0 \\ 17 & 3.520 & 0.05933 & 23.78 & 14.16 & 13.44 & 56.31 & >> \\ 18 & 4.390 & 0.06626 & 19.68 & 8.239 & 12.40 & 14.61 & >> \\ 19 & 5.560 & 0.07457 & 25.10 & 10.31 & 9.348 & 38.17 & >> \\ 20 & 7.040 & 0.08390 & 6.956 & 4.719 & 8.143 & 9.115 & >>\end{array}$
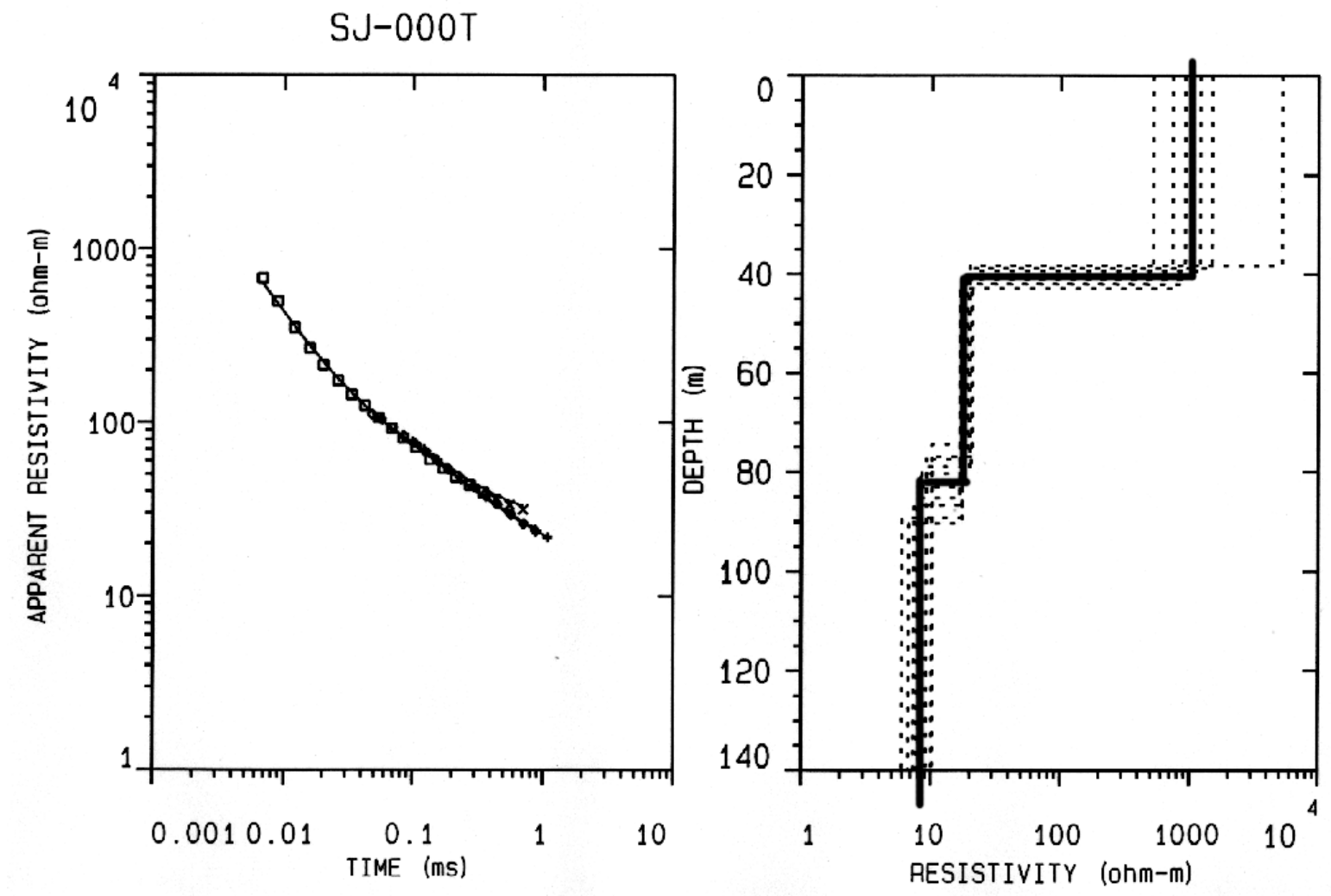


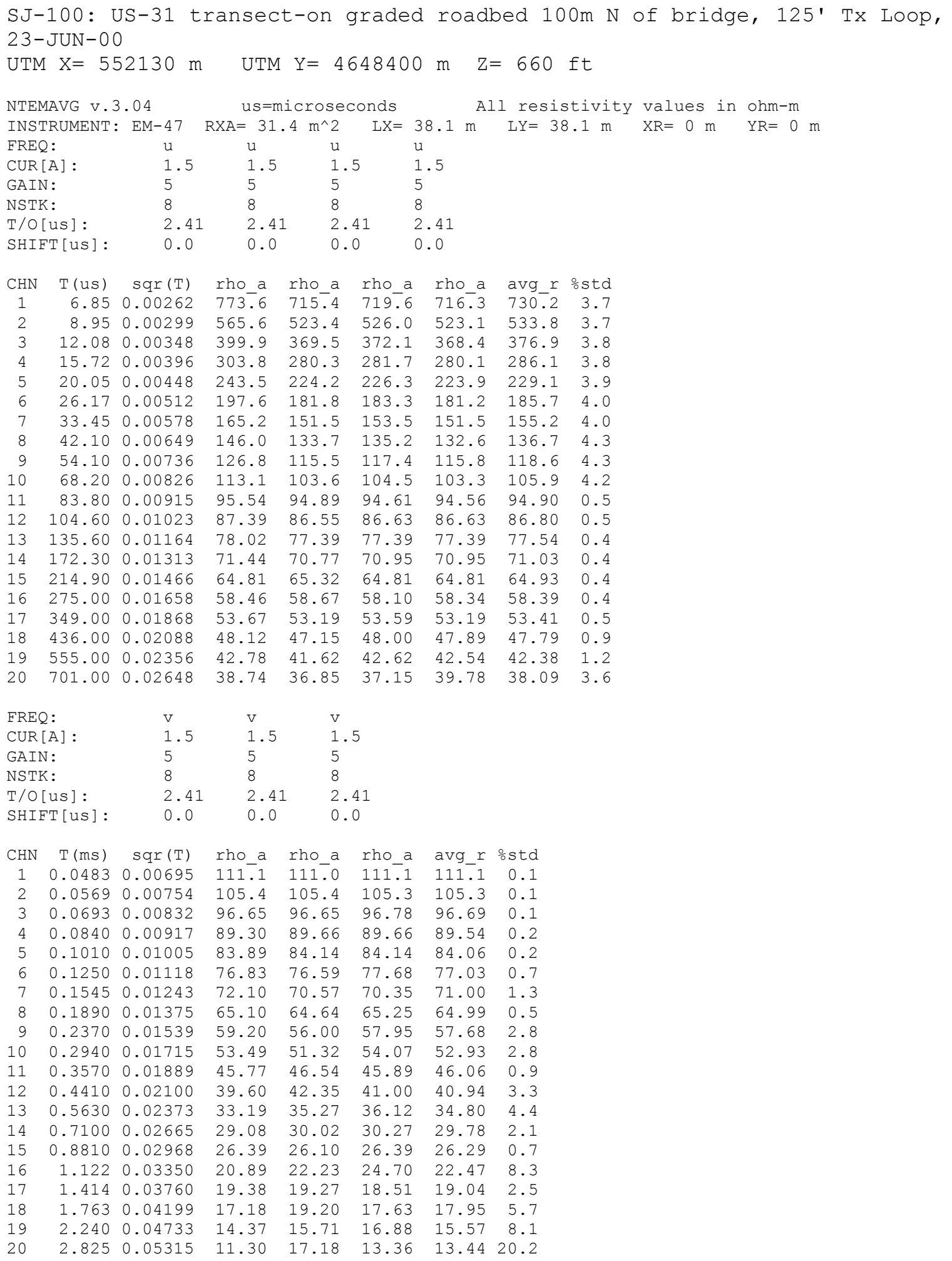



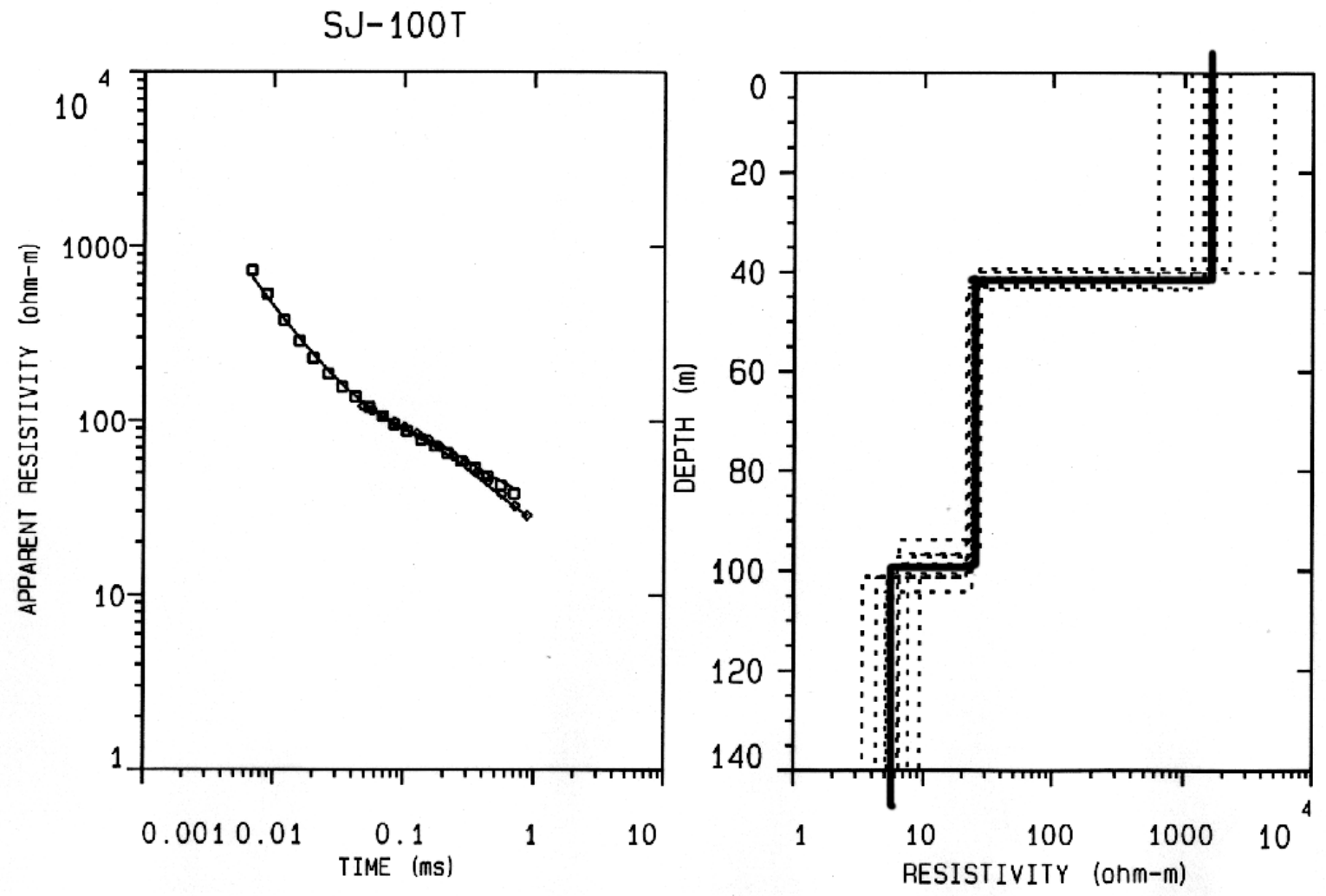

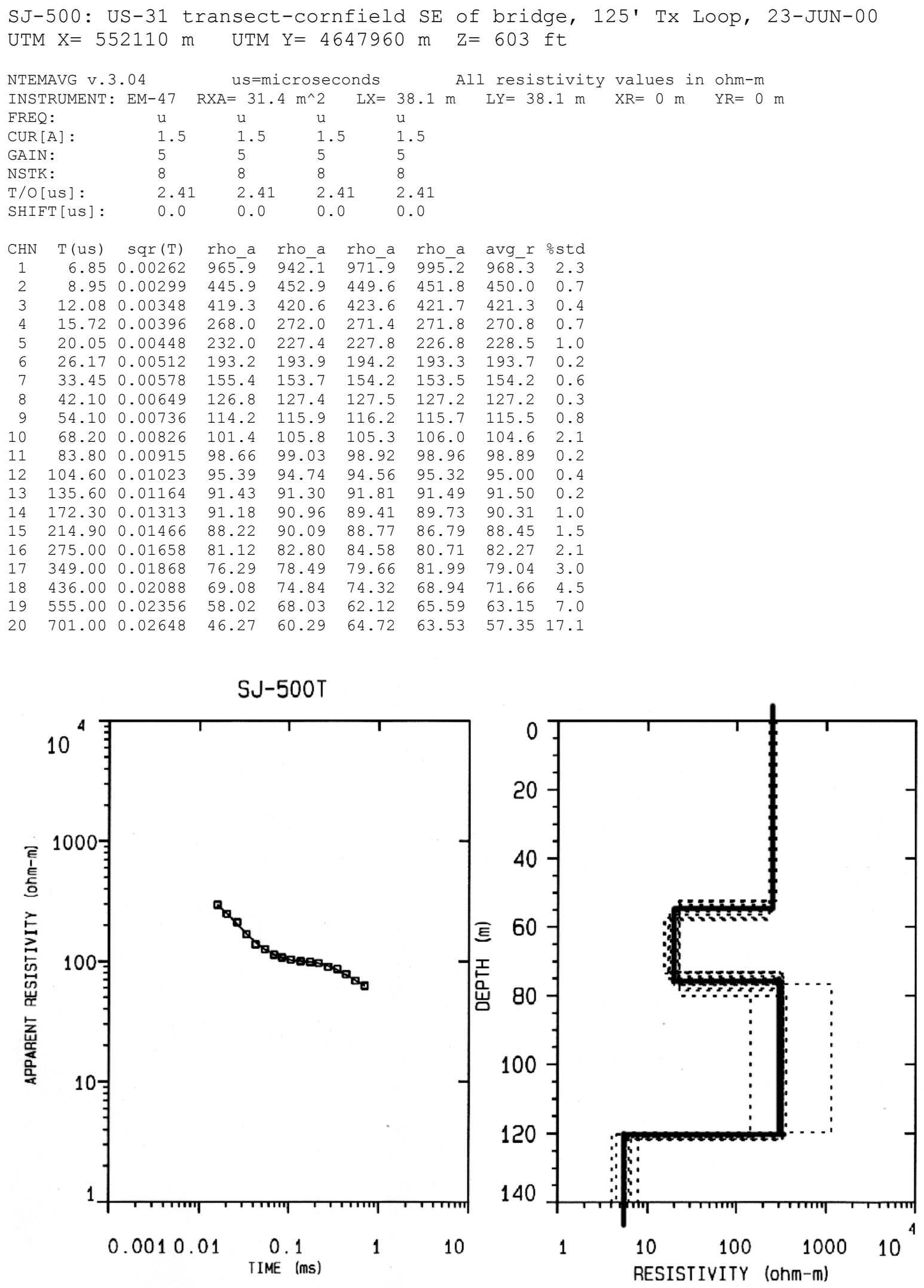


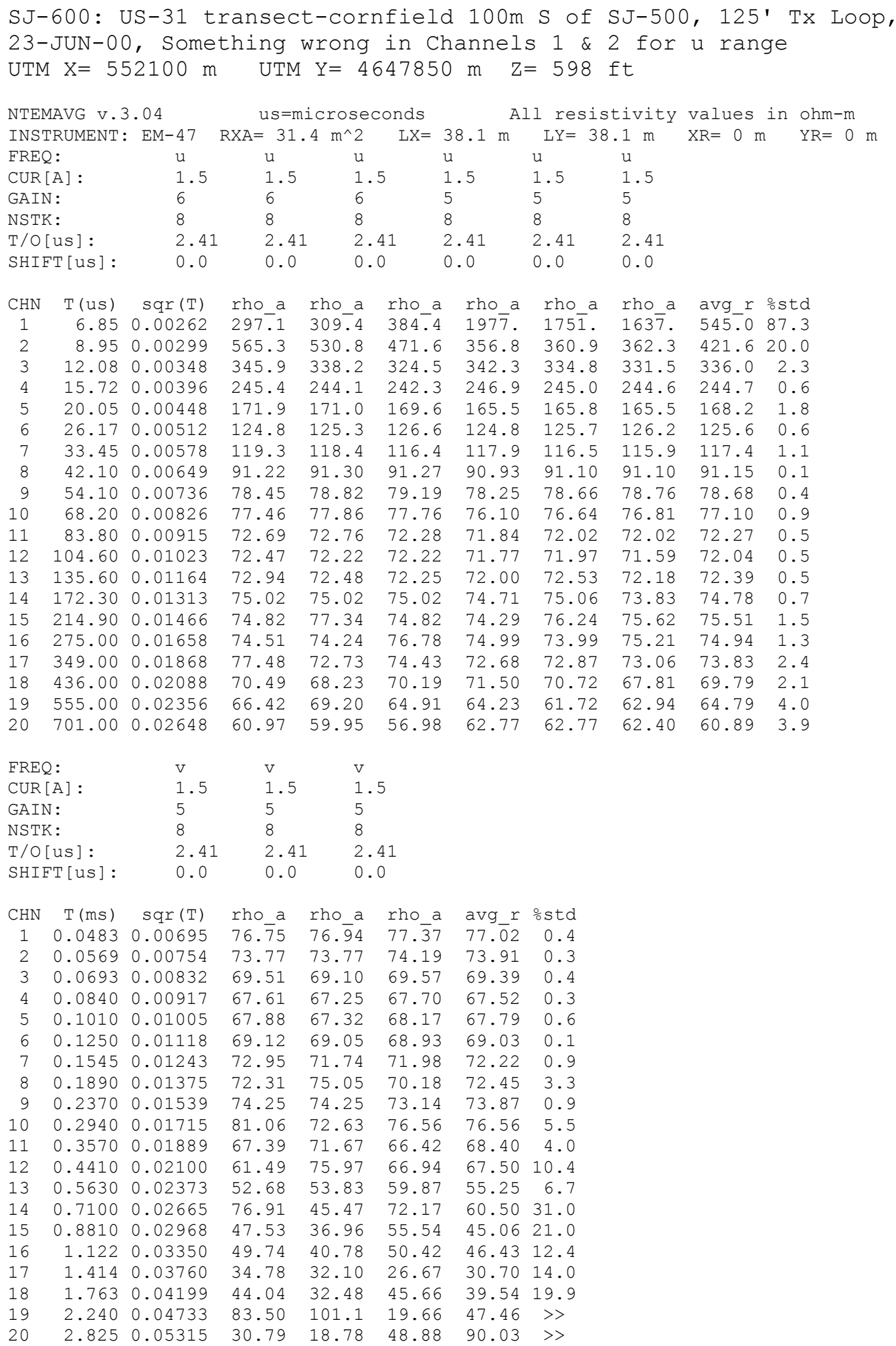



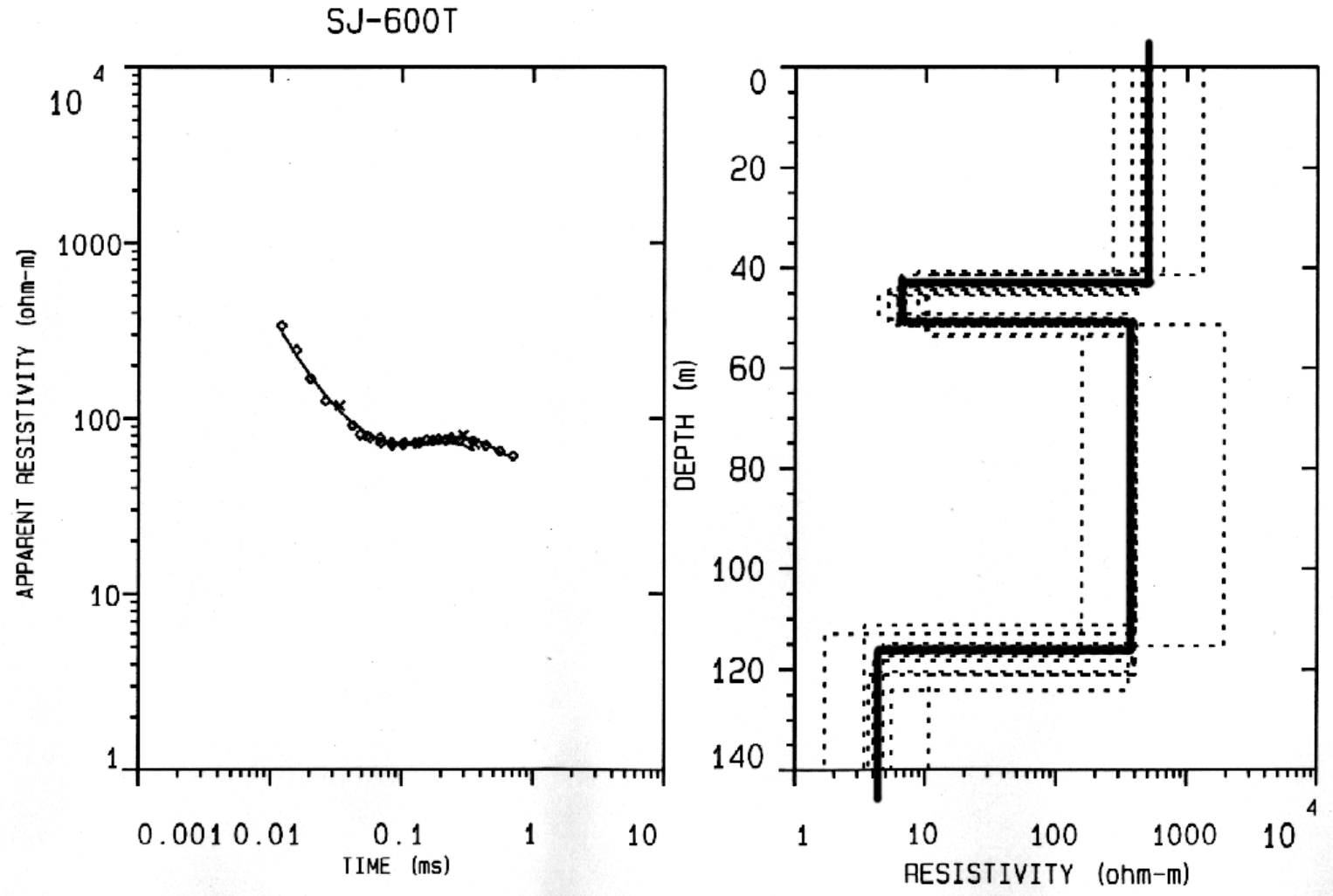


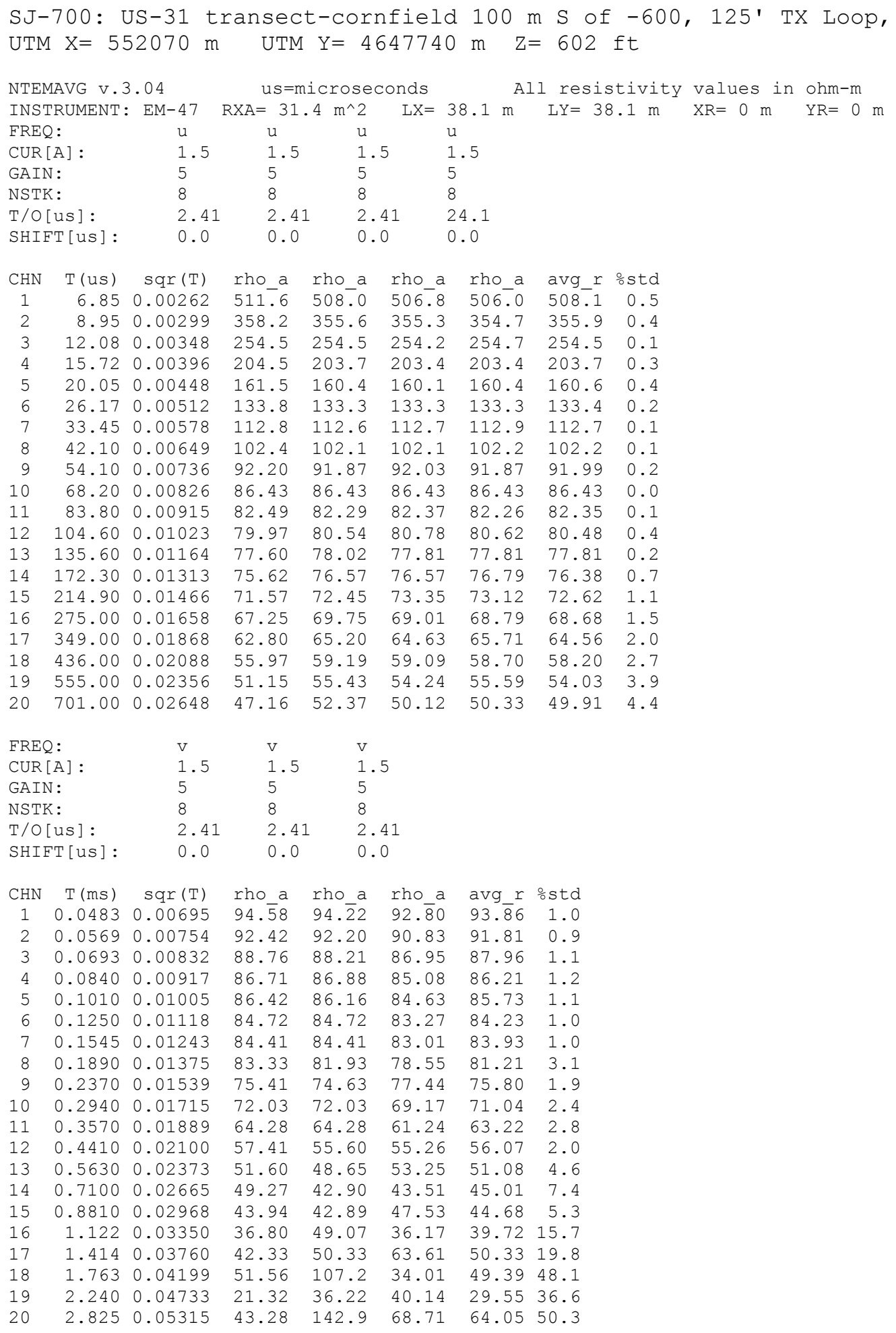



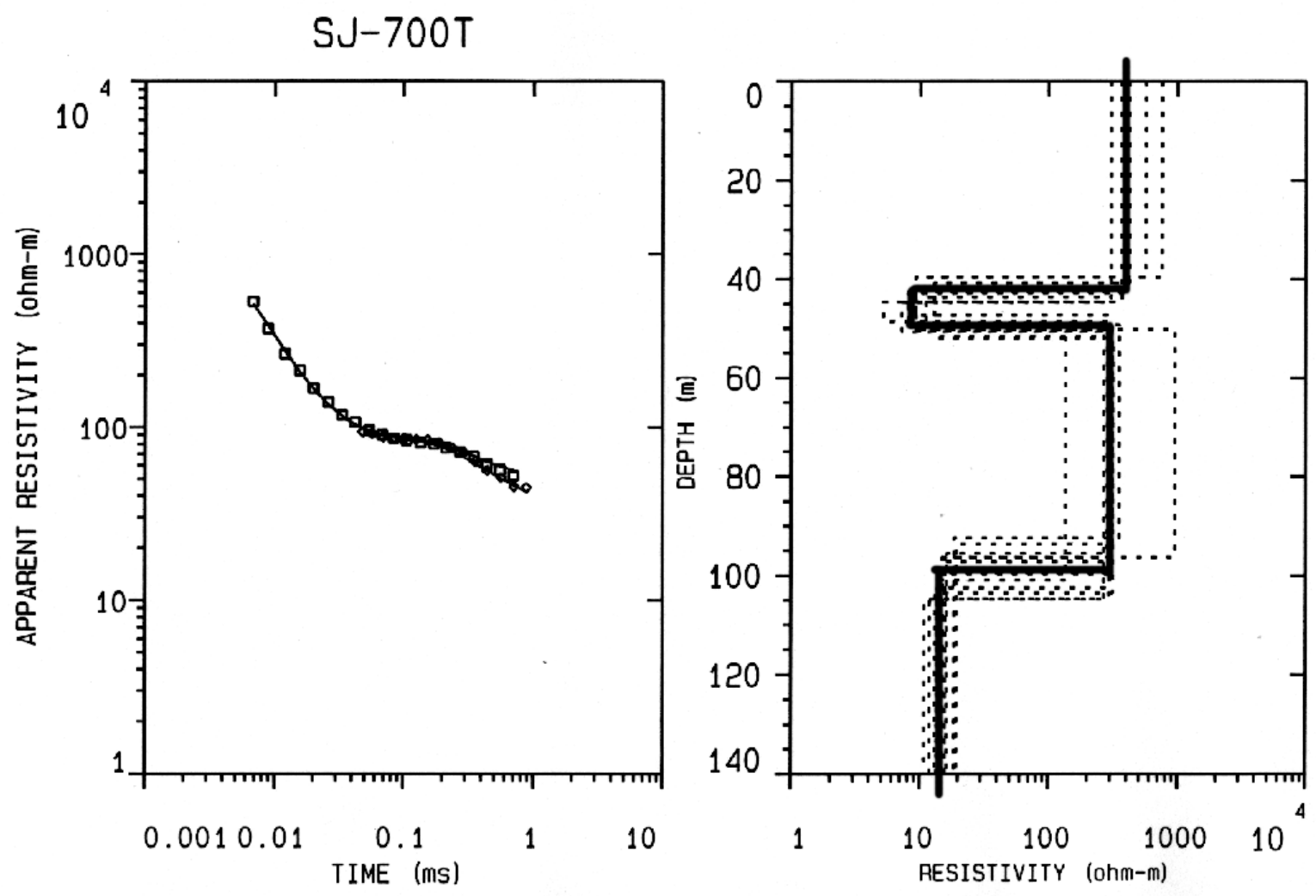


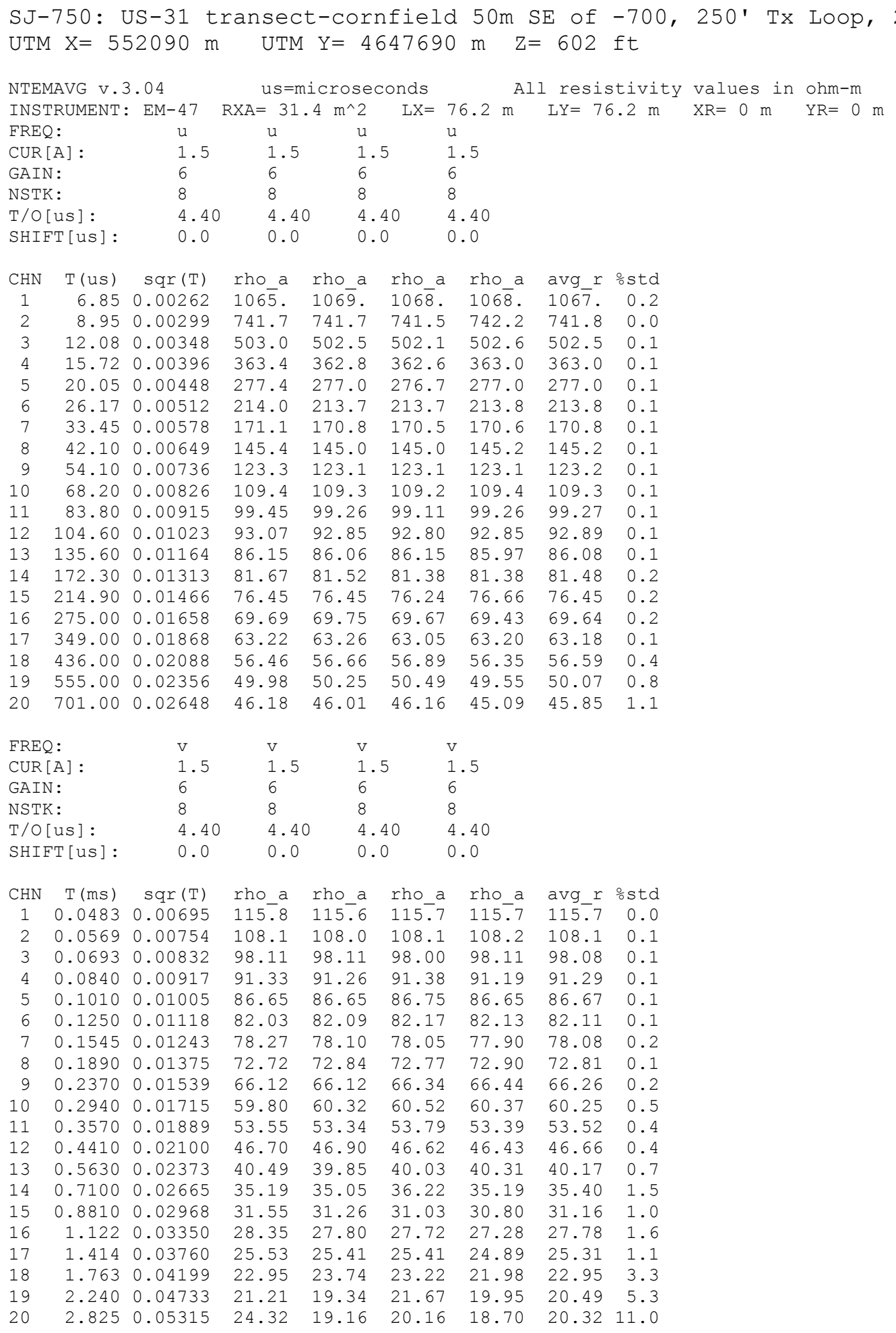



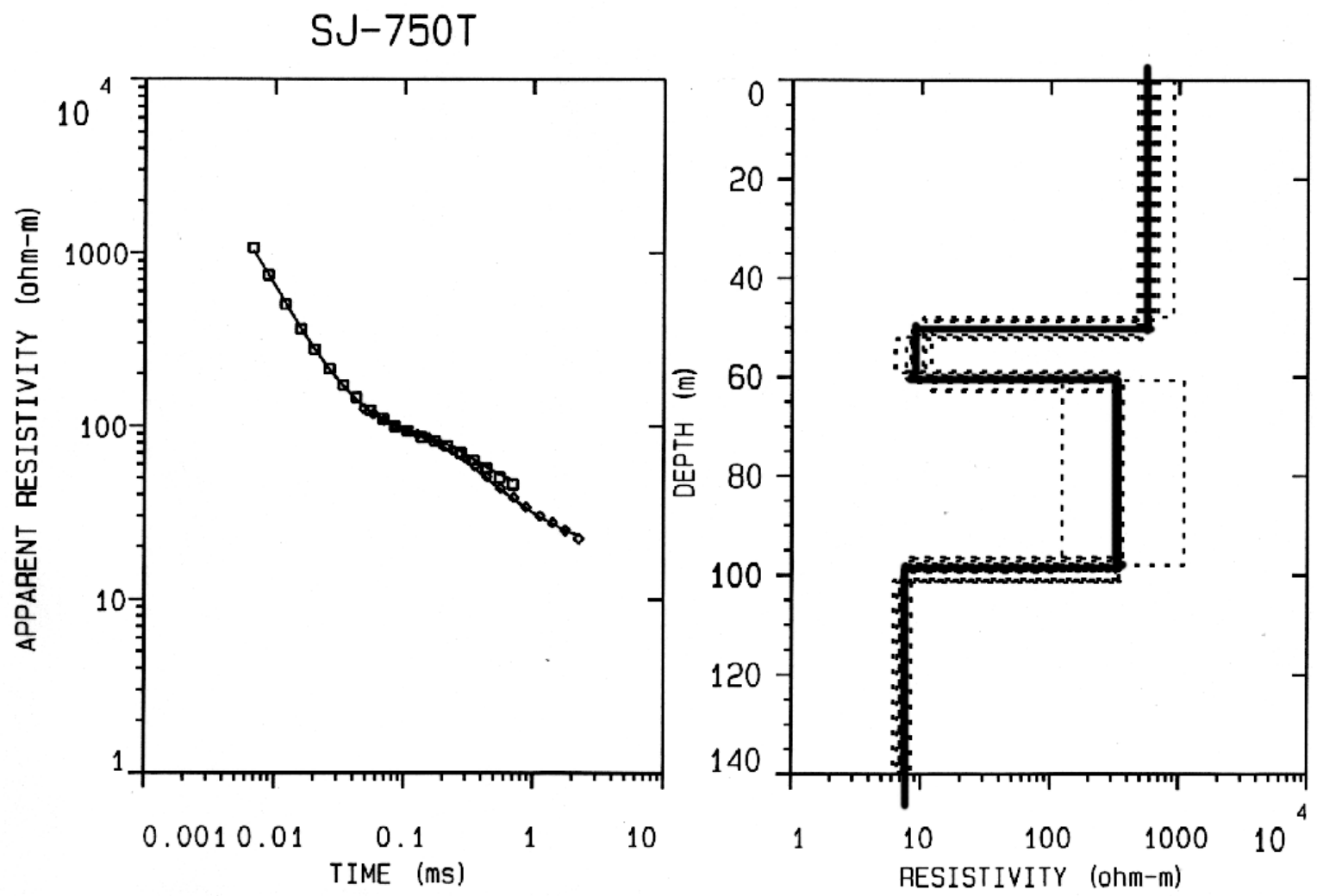


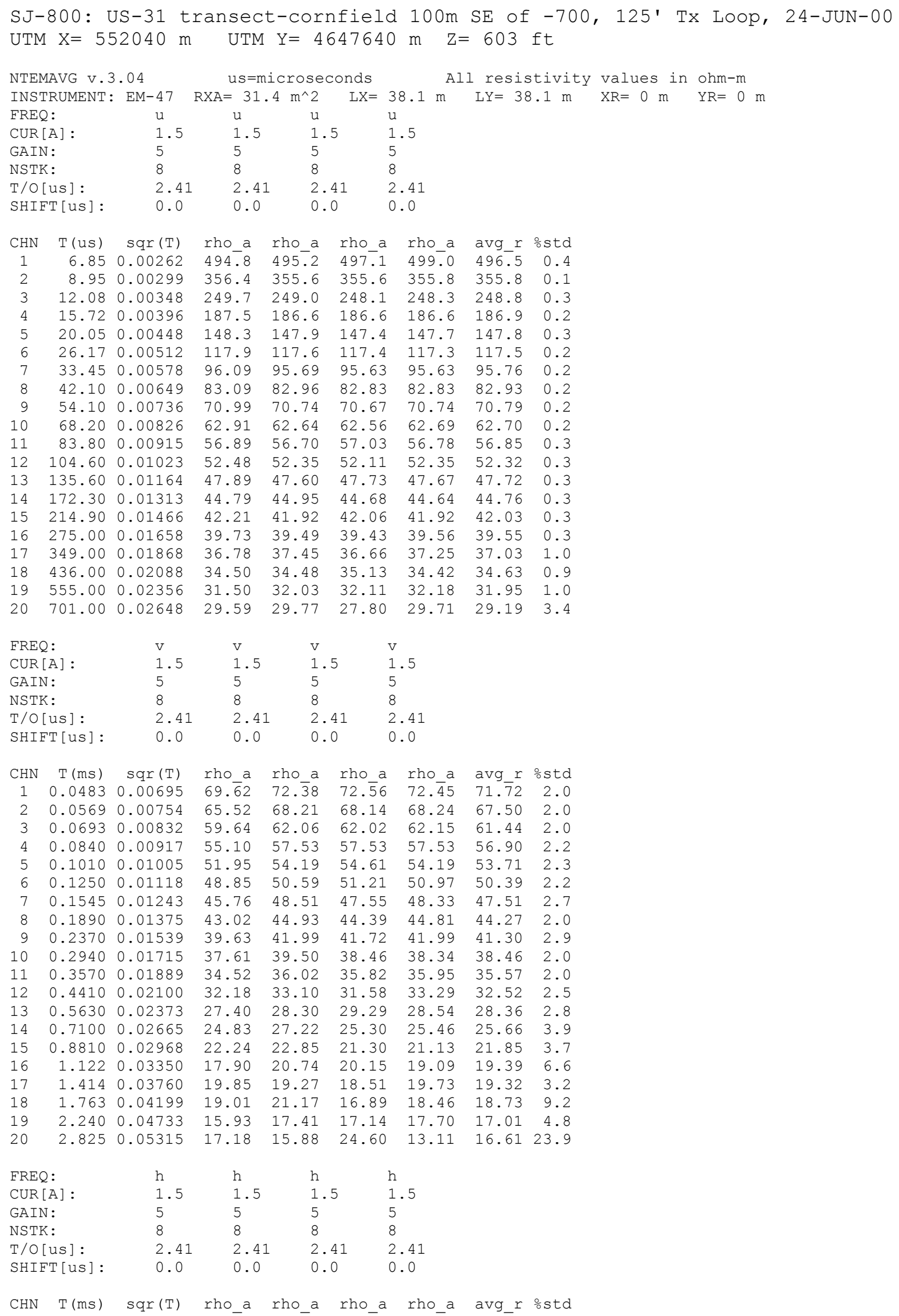



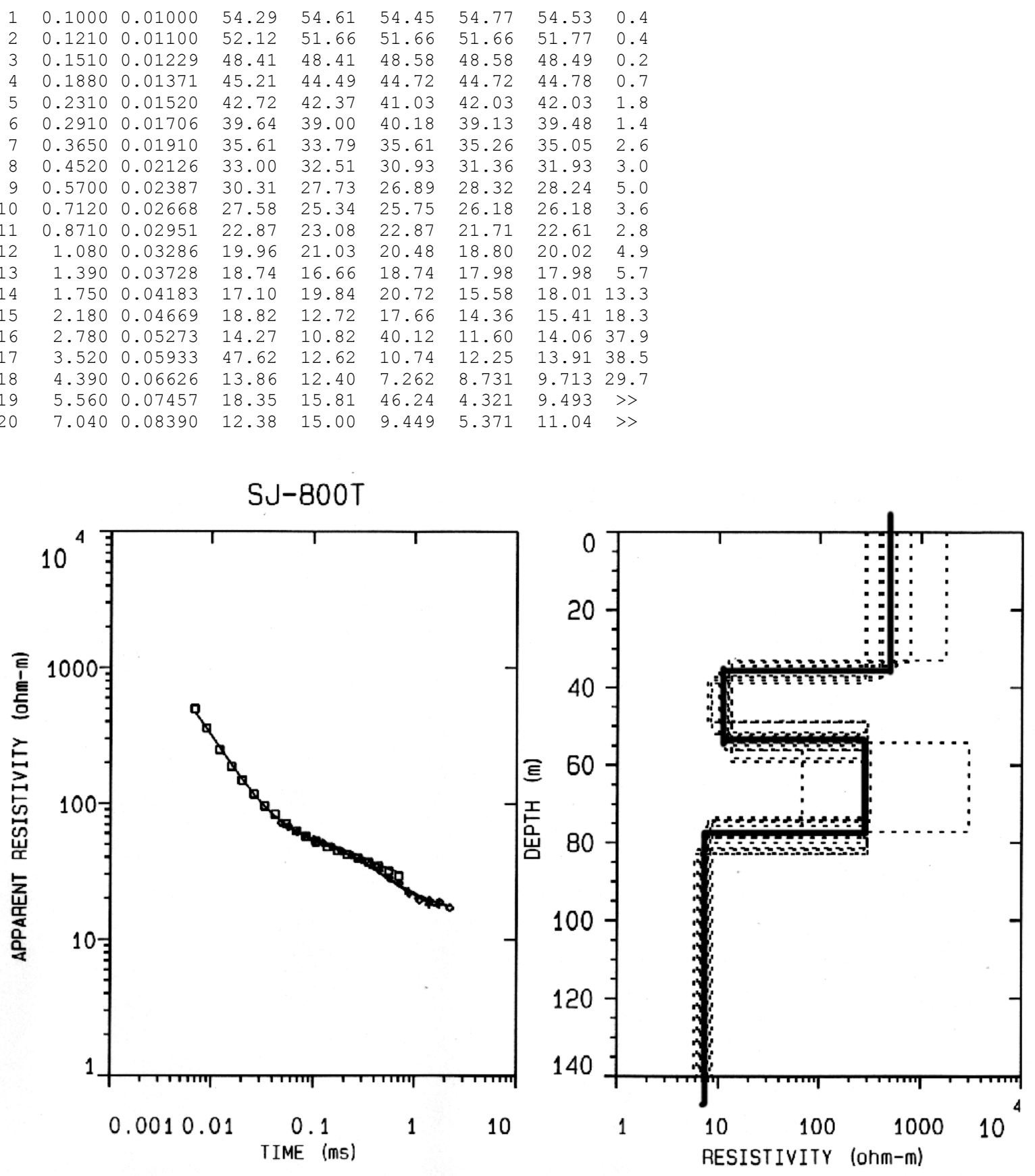


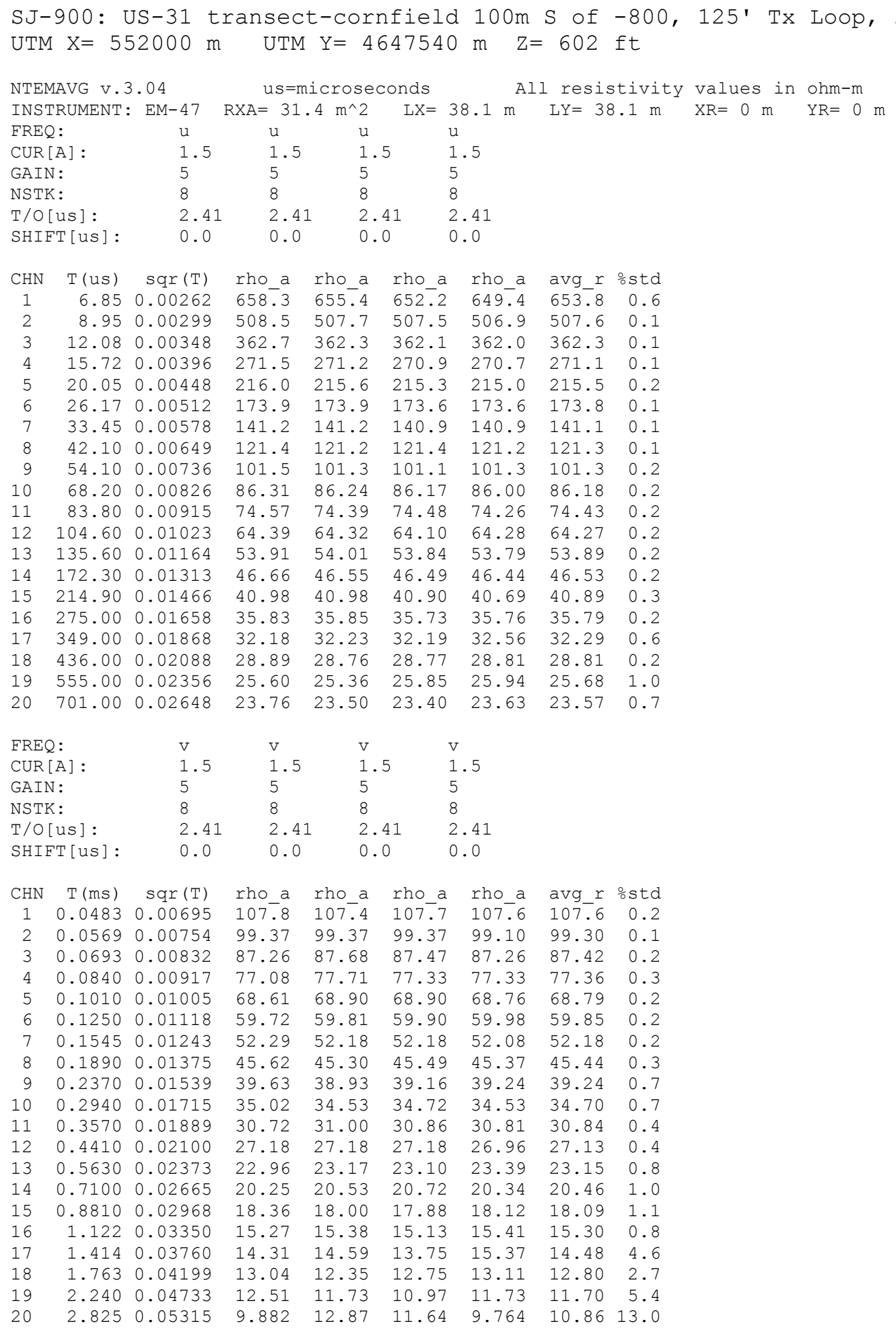



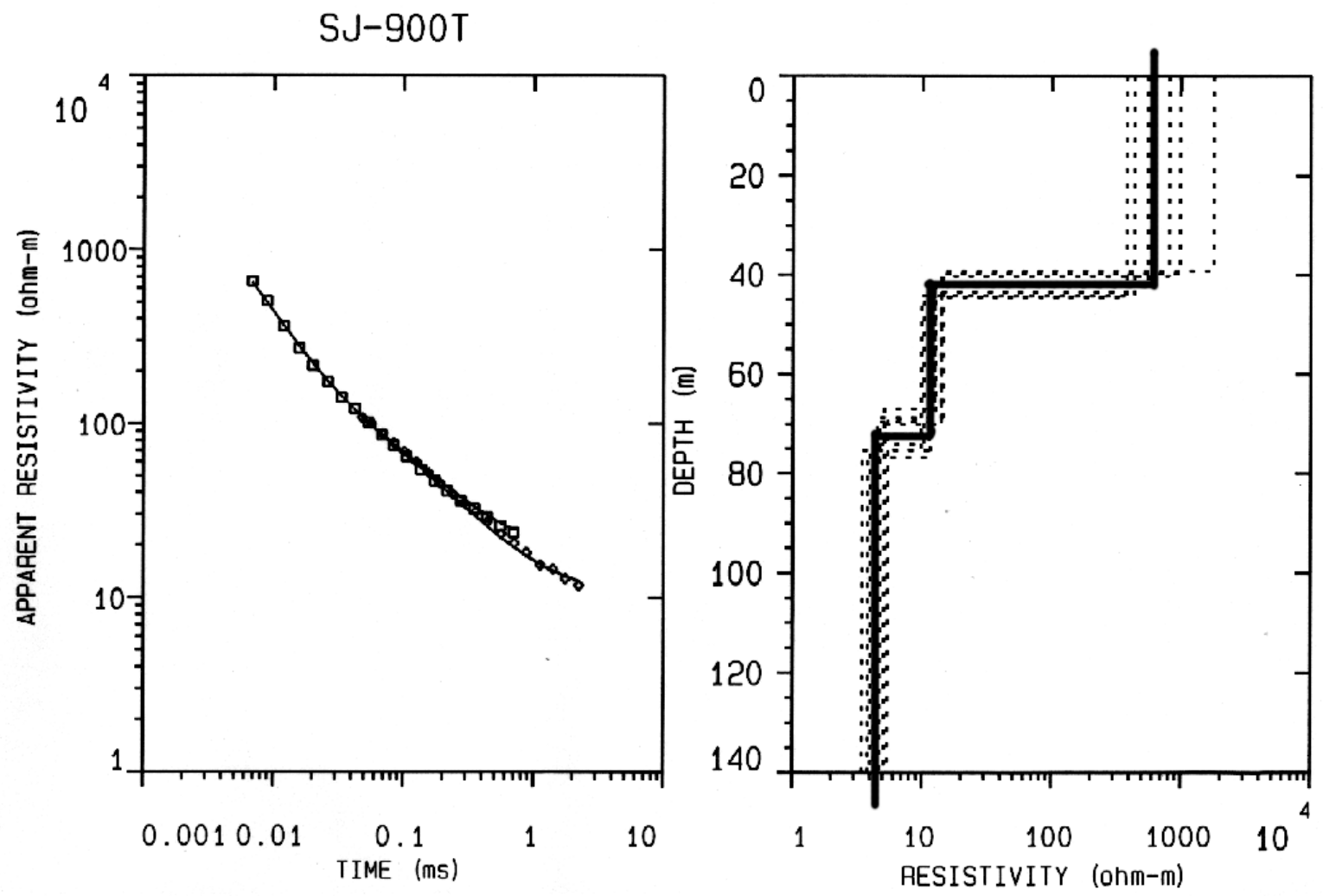


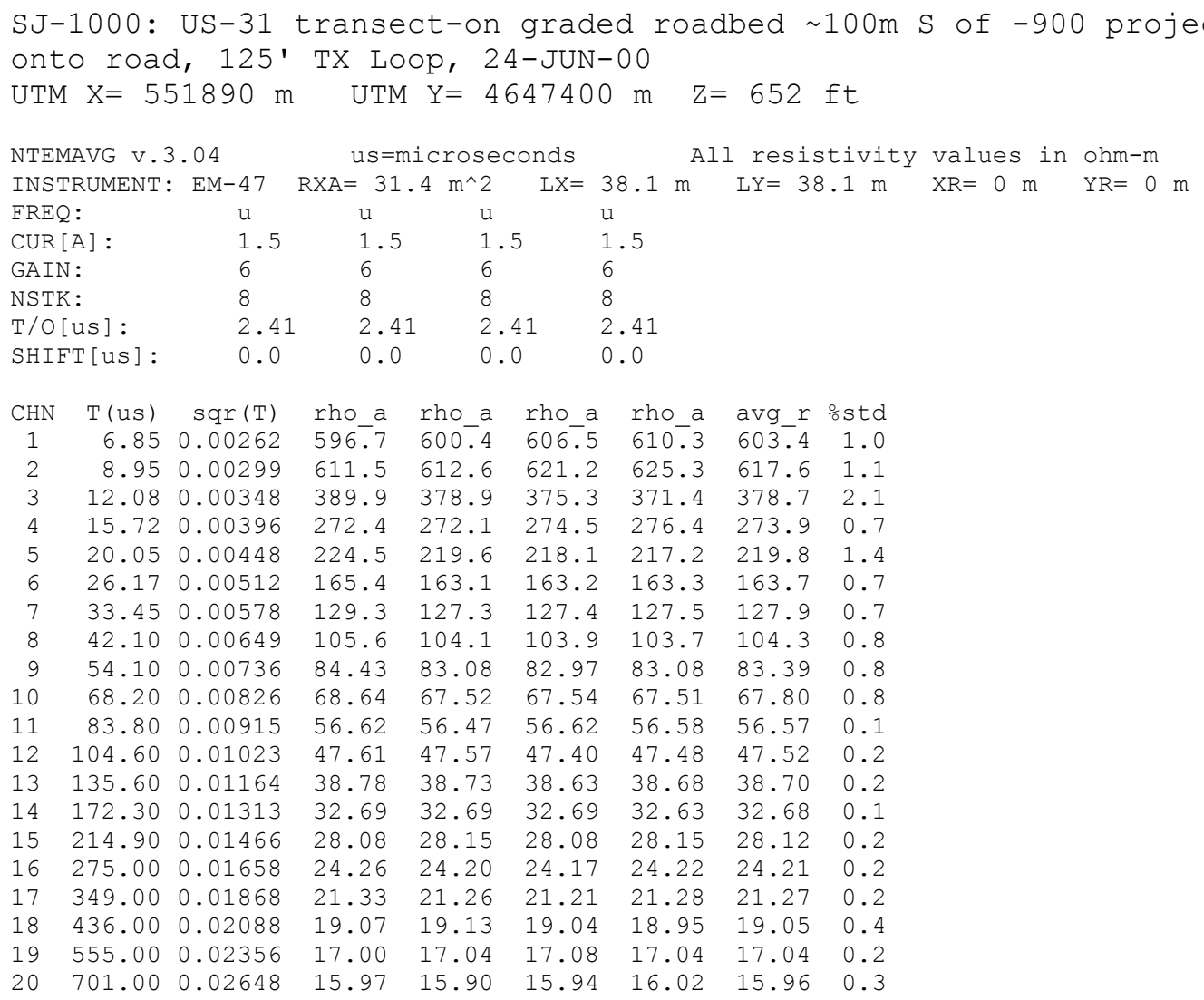

$\begin{array}{lllll}\text { FREQ : } & \mathrm{V} & \mathrm{v} & \mathrm{v} & \mathrm{v} \\ \text { CUR [A] : } & 1.5 & 1.5 & 1.5 & 1.5 \\ \text { GAIN : } & 6 & 6 & 6 & 6 \\ \text { NSTK : } & 8 & 8 & 8 & 8 \\ \text { T/O[us] : } & 2.41 & 2.41 & 2.41 & 2.41 \\ \text { SHIFT [us] : } & 0.0 & 0.0 & 0.0 & 0.0\end{array}$

$\begin{array}{ccccccccc}\text { CHN } & \text { T(ms) } & \text { sqr }(\mathrm{T}) & \text { rho a } & \text { rho_a } & \text { rho a } & \text { rho_a } & \text { avg_r } & \text { ostd } \\ 1 & 0.0483 & 0.00695 & 84 . \overline{5} 9 & 85 . \overline{16} & 85.06 & 85.06 & 84.97 & 0.3 \\ 2 & 0.0569 & 0.00754 & 75.05 & 75.76 & 75.38 & 75.63 & 75.46 & 0.4 \\ 3 & 0.0693 & 0.00832 & 63.48 & 64.06 & 63.67 & 63.98 & 63.80 & 0.4 \\ 4 & 0.0840 & 0.00917 & 54.31 & 54.52 & 54.68 & 54.68 & 54.55 & 0.3 \\ 5 & 0.1010 & 0.01005 & 46.86 & 47.46 & 46.91 & 47.14 & 47.09 & 0.6 \\ 6 & 0.1250 & 0.01118 & 39.88 & 40.08 & 40.21 & 40.13 & 40.07 & 0.4 \\ 7 & 0.1545 & 0.01243 & 33.96 & 34.14 & 34.20 & 34.25 & 34.14 & 0.4 \\ 8 & 0.1890 & 0.01375 & 29.06 & 29.32 & 29.25 & 29.24 & 29.22 & 0.4 \\ 9 & 0.2370 & 0.01539 & 24.66 & 25.03 & 24.69 & 24.89 & 24.82 & 0.7 \\ 10 & 0.2940 & 0.01715 & 21.57 & 21.62 & 21.53 & 21.60 & 21.58 & 0.2 \\ 11 & 0.3570 & 0.01889 & 18.92 & 19.10 & 18.96 & 19.10 & 19.02 & 0.5 \\ 12 & 0.4410 & 0.02100 & 16.58 & 16.75 & 16.75 & 16.76 & 16.71 & 0.5 \\ 13 & 0.5630 & 0.02373 & 14.25 & 14.63 & 14.36 & 14.47 & 14.43 & 1.1 \\ 14 & 0.7100 & 0.02665 & 12.57 & 12.66 & 12.67 & 12.80 & 12.68 & 0.7 \\ 15 & 0.8810 & 0.02968 & 11.28 & 11.34 & 11.43 & 11.30 & 11.34 & 0.6 \\ 16 & 1.122 & 0.03350 & 9.739 & 10.06 & 9.774 & 10.37 & 9.977 & 2.9 \\ 17 & 1.414 & 0.03760 & 8.726 & 8.844 & 8.984 & 9.199 & 8.934 & 2.3 \\ 18 & 1.763 & 0.04199 & 8.330 & 7.850 & 8.189 & 8.318 & 8.166 & 2.8 \\ 19 & 2.240 & 0.04733 & 7.453 & 6.966 & 7.995 & 7.804 & 7.528 & 6.2 \\ 20 & 2.825 & 0.05315 & 6.634 & 7.634 & 7.090 & 7.451 & 7.176 & 6.3\end{array}$

$\begin{array}{lllll}\text { FREQ : } & \mathrm{h} & \mathrm{h} & \mathrm{h} & \mathrm{h} \\ \text { CUR [A] : } & 1.5 & 1.5 & 1.5 & 1.5 \\ \text { GAIN : } & 6 & 6 & 6 & 6 \\ \text { NSTK : } & 8 & 8 & 8 & 8 \\ \text { T/O[us] : } & 2.41 & 2.41 & 2.41 & 2.41 \\ \text { SHIFT [us] : } & 0.0 & 0.0 & 0.0 & 0.0\end{array}$




$\begin{array}{crrrrrrrr}\text { CHN } & \text { T (ms) } & \text { sqr (T) } & \text { rho_a } & \text { rho_a } & \text { rho_a } & \text { rho_a } & \text { avg_r } & \text { ostd } \\ 1 & 0.1000 & 0.01000 & 52.05 & 51.91 & 52.05 & 52.27 & 52.07 & 0.3 \\ 2 & 0.1210 & 0.01100 & 44.85 & 45.14 & 45.30 & 45.14 & 45.11 & 0.4 \\ 3 & 0.1510 & 0.01229 & 37.73 & 38.05 & 38.10 & 38.05 & 37.98 & 0.4 \\ 4 & 0.1880 & 0.01371 & 31.95 & 31.80 & 32.06 & 31.85 & 31.91 & 0.4 \\ 5 & 0.2310 & 0.01520 & 27.67 & 27.73 & 27.79 & 27.85 & 27.76 & 0.3 \\ 6 & 0.2910 & 0.01706 & 23.53 & 23.66 & 23.51 & 23.59 & 23.57 & 0.3 \\ 7 & 0.3650 & 0.01910 & 20.49 & 20.18 & 20.21 & 20.51 & 20.35 & 0.9 \\ 8 & 0.4520 & 0.02126 & 17.76 & 17.84 & 17.84 & 17.94 & 17.84 & 0.4 \\ 9 & 0.5700 & 0.02387 & 15.54 & 15.58 & 15.28 & 15.64 & 15.51 & 1.1 \\ 10 & 0.7120 & 0.02668 & 13.59 & 13.93 & 13.89 & 13.71 & 13.78 & 1.2 \\ 11 & 0.8710 & 0.02951 & 12.48 & 11.89 & 12.20 & 12.20 & 12.19 & 2.0 \\ 12 & 1.080 & 0.03286 & 11.36 & 10.57 & 10.81 & 11.06 & 10.94 & 3.1 \\ 13 & 1.390 & 0.03728 & 10.00 & 8.585 & 9.313 & 9.605 & 9.340 & 6.6 \\ 14 & 1.750 & 0.04183 & 8.557 & 7.794 & 8.131 & 8.557 & 8.244 & 4.6 \\ 15 & 2.180 & 0.04669 & 7.288 & 7.532 & 7.288 & 7.288 & 7.347 & 1.6 \\ 16 & 2.780 & 0.05273 & 6.906 & 6.883 & 7.477 & 7.973 & 7.276 & 6.9 \\ 17 & 3.520 & 0.05933 & 5.804 & 5.545 & 5.697 & 7.606 & 6.043 & 13.1 \\ 18 & 4.390 & 0.06626 & 5.018 & 5.719 & 5.018 & 6.230 & 5.439 & 10.3 \\ 19 & 5.560 & 0.07457 & 4.202 & 5.408 & 4.449 & 6.173 & 4.913 & 17.1 \\ 20 & 7.040 & 0.08390 & 3.555 & 5.643 & 5.953 & 7.211 & 5.130 & 33.5\end{array}$
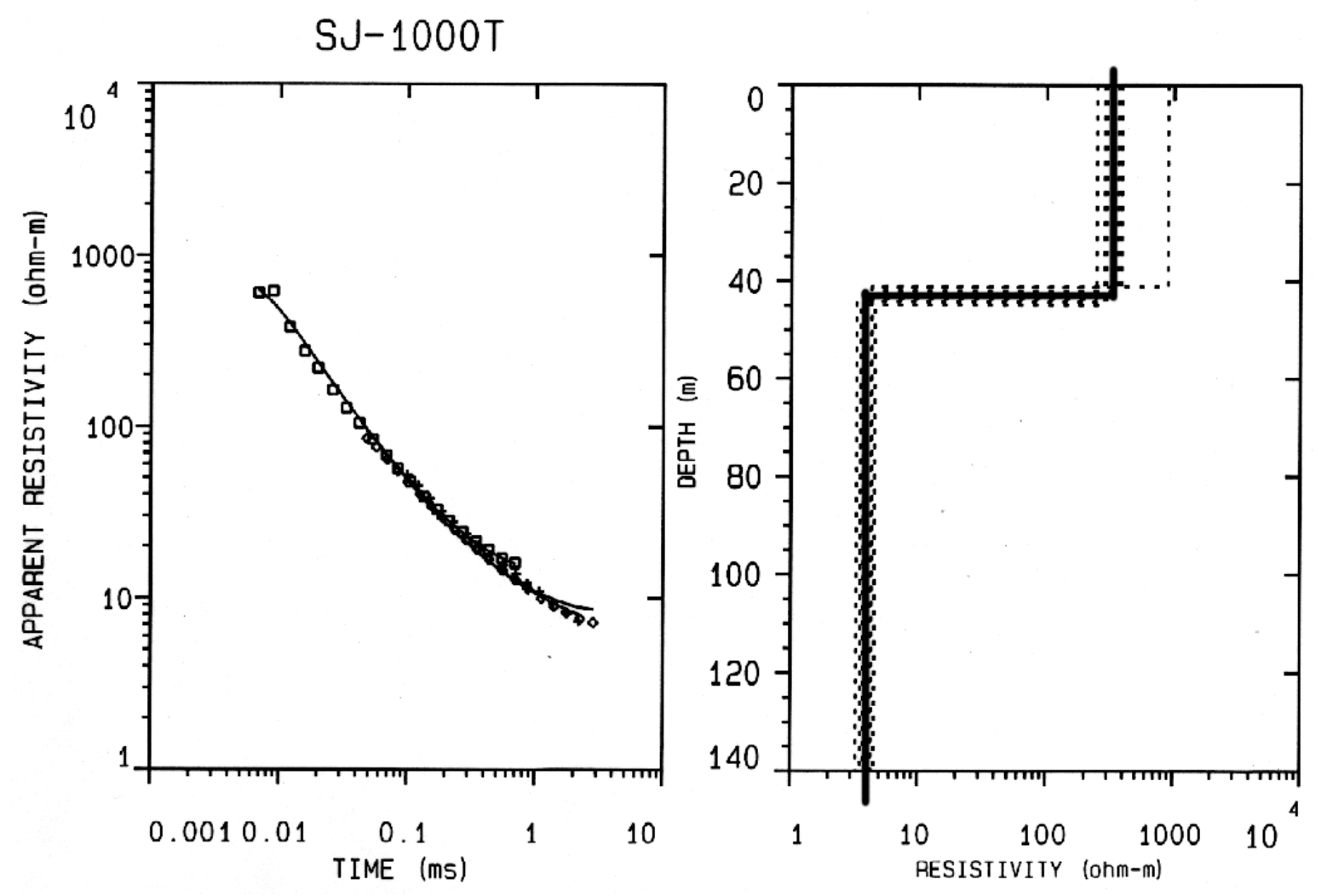


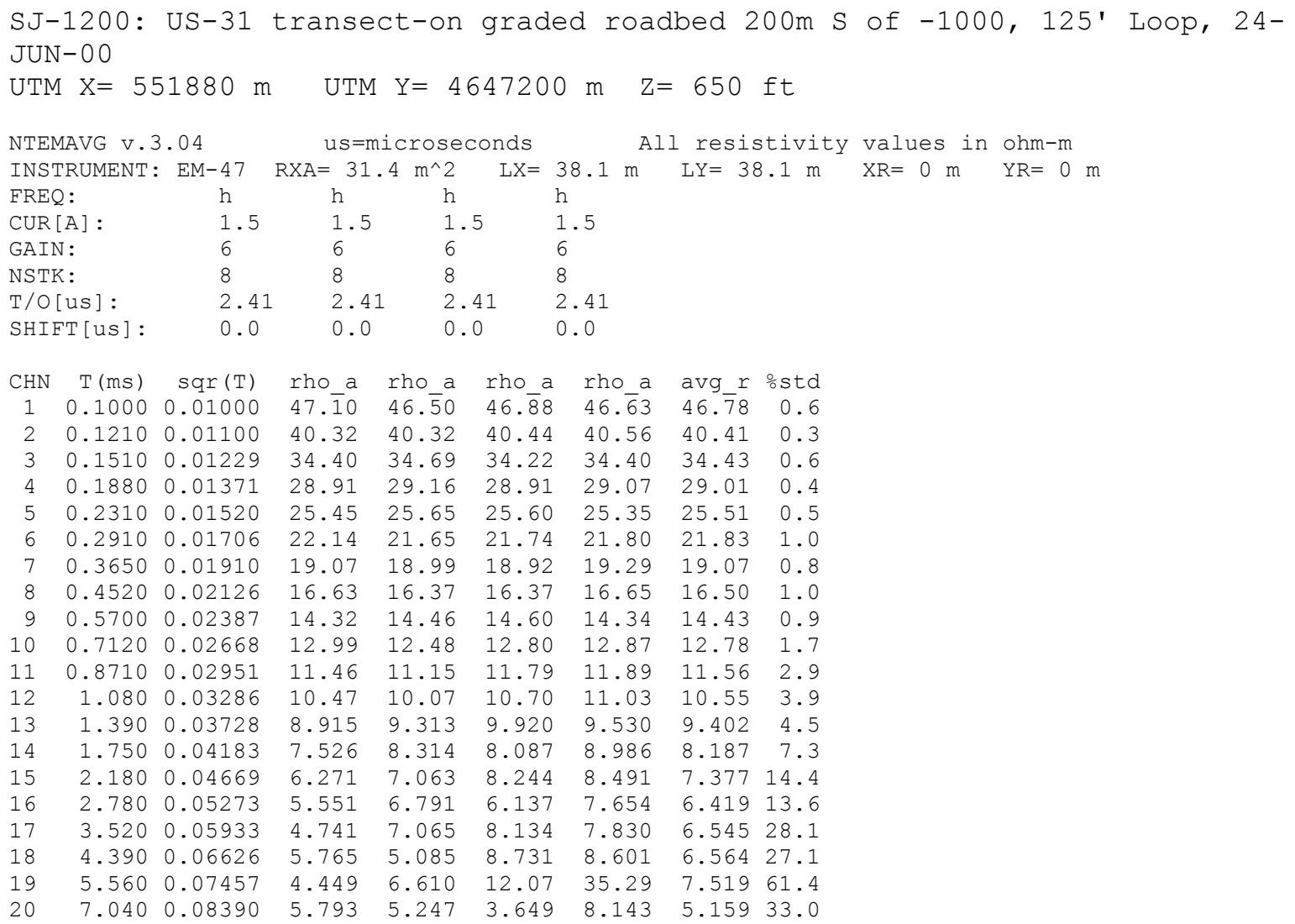

$\begin{array}{lllll}\text { FREQ : } & \mathrm{V} & \mathrm{V} & \mathrm{V} & \mathrm{V} \\ \text { CUR [A] : } & 1.5 & 1.5 & 1.5 & 1.5 \\ \text { GAIN : } & 6 & 6 & 6 & 6 \\ \text { NSTK : } & 8 & 8 & 8 & 8 \\ \text { T/O[us] : } & 2.41 & 2.41 & 2.41 & 2.41 \\ \text { SHIFT [us] : } & 0.0 & 0.0 & 0.0 & 0.0\end{array}$

$\begin{array}{ccccccccc}\text { CHN } & \text { T(ms) } & \text { sqr }(\mathrm{T}) & \text { rho a } & \text { rho_a } & \text { rho a } & \text { rho_a } & \text { avg_r } & \text { ostd } \\ 1 & 0.0483 & 0.00695 & 84 . \overline{1} 0 & 84 . \overline{3} 3 & 84 . \overline{3} 3 & 84 . \overline{27} & 84 . \overline{2} 6 & 0.1 \\ 2 & 0.0569 & 0.00754 & 73.98 & 74.21 & 74.15 & 73.94 & 74.07 & 0.2 \\ 3 & 0.0693 & 0.00832 & 62.24 & 62.13 & 62.42 & 62.35 & 62.28 & 0.2 \\ 4 & 0.0840 & 0.00917 & 53.01 & 53.25 & 53.01 & 53.13 & 53.10 & 0.2 \\ 5 & 0.1010 & 0.01005 & 46.08 & 46.22 & 46.13 & 46.00 & 46.11 & 0.2 \\ 6 & 0.1250 & 0.01118 & 39.20 & 39.10 & 39.20 & 39.39 & 39.22 & 0.3 \\ 7 & 0.1545 & 0.01243 & 33.61 & 33.54 & 33.73 & 33.70 & 33.65 & 0.3 \\ 8 & 0.1890 & 0.01375 & 29.04 & 29.11 & 29.11 & 28.83 & 29.02 & 0.5 \\ 9 & 0.2370 & 0.01539 & 24.90 & 24.61 & 24.84 & 24.79 & 24.79 & 0.5 \\ 10 & 0.2940 & 0.01715 & 21.90 & 21.86 & 21.97 & 21.97 & 21.92 & 0.2 \\ 11 & 0.3570 & 0.01889 & 19.34 & 19.20 & 19.42 & 19.31 & 19.32 & 0.5 \\ 12 & 0.4410 & 0.02100 & 16.91 & 17.08 & 17.19 & 16.87 & 17.01 & 0.9 \\ 13 & 0.5630 & 0.02373 & 14.68 & 14.60 & 14.77 & 14.61 & 14.66 & 0.5 \\ 14 & 0.7100 & 0.02665 & 13.15 & 13.67 & 12.99 & 13.50 & 13.32 & 2.3 \\ 15 & 0.8810 & 0.02968 & 11.80 & 11.64 & 12.14 & 11.19 & 11.68 & 3.4 \\ 16 & 1.122 & 0.03350 & 10.47 & 10.57 & 10.03 & 10.40 & 10.36 & 2.3 \\ 17 & 1.414 & 0.03760 & 9.763 & 9.111 & 9.878 & 9.661 & 9.592 & 3.7 \\ 18 & 1.763 & 0.04199 & 8.793 & 8.711 & 9.049 & 8.440 & 8.741 & 2.9 \\ 19 & 2.240 & 0.04733 & 8.624 & 7.879 & 8.262 & 8.015 & 8.183 & 3.9 \\ 20 & 2.825 & 0.05315 & 8.375 & 7.251 & 8.621 & 8.258 & 8.081 & 8.0\end{array}$

$\begin{array}{lllll}\text { FREQ : } & \mathrm{u} & \mathrm{u} & \mathrm{u} & \mathrm{u} \\ \text { CUR [A] }: & 1.5 & 1.5 & 1.5 & 1.5 \\ \text { GAIN : } & 5 & 5 & 5 & 5 \\ \text { NSTK : } & 8 & 8 & 8 & 8 \\ \text { T/O[us] : } & 2.41 & 2.41 & 2.41 & 2.41 \\ \text { SHIFT [us] : } & 0.0 & 0.0 & 0.0 & 0.0\end{array}$




$\begin{array}{rrrllllll}\text { CHN } & \text { T(us) } & \text { sqr (T) } & \text { rho_a } & \text { rho_a } & \text { rho_a } & \text { rho_a } & \text { avg_r } & \text { ostd } \\ 1 & 6.85 & 0.00262 & 131 \overline{5} . & 126 \overline{8} . & 125 \overline{1} . & 123 \overline{8} . & 126 \overline{7} . & 2.6 \\ 2 & 8.95 & 0.00299 & 449.0 & 449.3 & 449.8 & 450.7 & 449.7 & 0.2 \\ 3 & 12.08 & 0.00348 & 443.0 & 442.6 & 444.5 & 443.5 & 443.4 & 0.2 \\ 4 & 15.72 & 0.00396 & 263.4 & 264.5 & 264.3 & 265.2 & 264.4 & 0.3 \\ 5 & 20.05 & 0.00448 & 207.8 & 206.5 & 206.6 & 205.9 & 206.7 & 0.4 \\ 6 & 26.17 & 0.00512 & 162.9 & 162.3 & 162.1 & 162.1 & 162.4 & 0.2 \\ 7 & 33.45 & 0.00578 & 120.0 & 119.5 & 119.3 & 119.0 & 119.5 & 0.3 \\ 8 & 42.10 & 0.00649 & 93.86 & 93.50 & 93.33 & 93.33 & 93.50 & 0.3 \\ 9 & 54.10 & 0.00736 & 74.91 & 74.81 & 74.72 & 74.62 & 74.76 & 0.2 \\ 10 & 68.20 & 0.00826 & 60.49 & 60.32 & 60.36 & 60.27 & 60.36 & 0.2 \\ 11 & 83.80 & 0.00915 & 50.69 & 50.62 & 50.62 & 50.61 & 50.63 & 0.1 \\ 12 & 104.60 & 0.01023 & 42.59 & 42.54 & 42.58 & 42.57 & 42.57 & 0.1 \\ 13 & 135.60 & 0.01164 & 35.01 & 34.87 & 34.85 & 34.89 & 34.90 & 0.2 \\ 14 & 172.30 & 0.01313 & 29.64 & 29.70 & 29.59 & 29.68 & 29.65 & 0.2 \\ 15 & 214.90 & 0.01466 & 25.80 & 25.71 & 25.68 & 25.67 & 25.72 & 0.2 \\ 16 & 275.00 & 0.01658 & 22.28 & 22.36 & 22.25 & 22.37 & 22.32 & 0.3 \\ 17 & 349.00 & 0.01868 & 19.82 & 19.66 & 19.74 & 19.68 & 19.73 & 0.4 \\ 18 & 436.00 & 0.02088 & 17.69 & 17.77 & 17.75 & 17.78 & 17.75 & 0.2 \\ 19 & 555.00 & 0.02356 & 16.30 & 16.09 & 15.98 & 16.02 & 16.10 & 0.9 \\ 20 & 701.00 & 0.02648 & 14.90 & 15.11 & 15.18 & 15.01 & 15.05 & 0.8\end{array}$
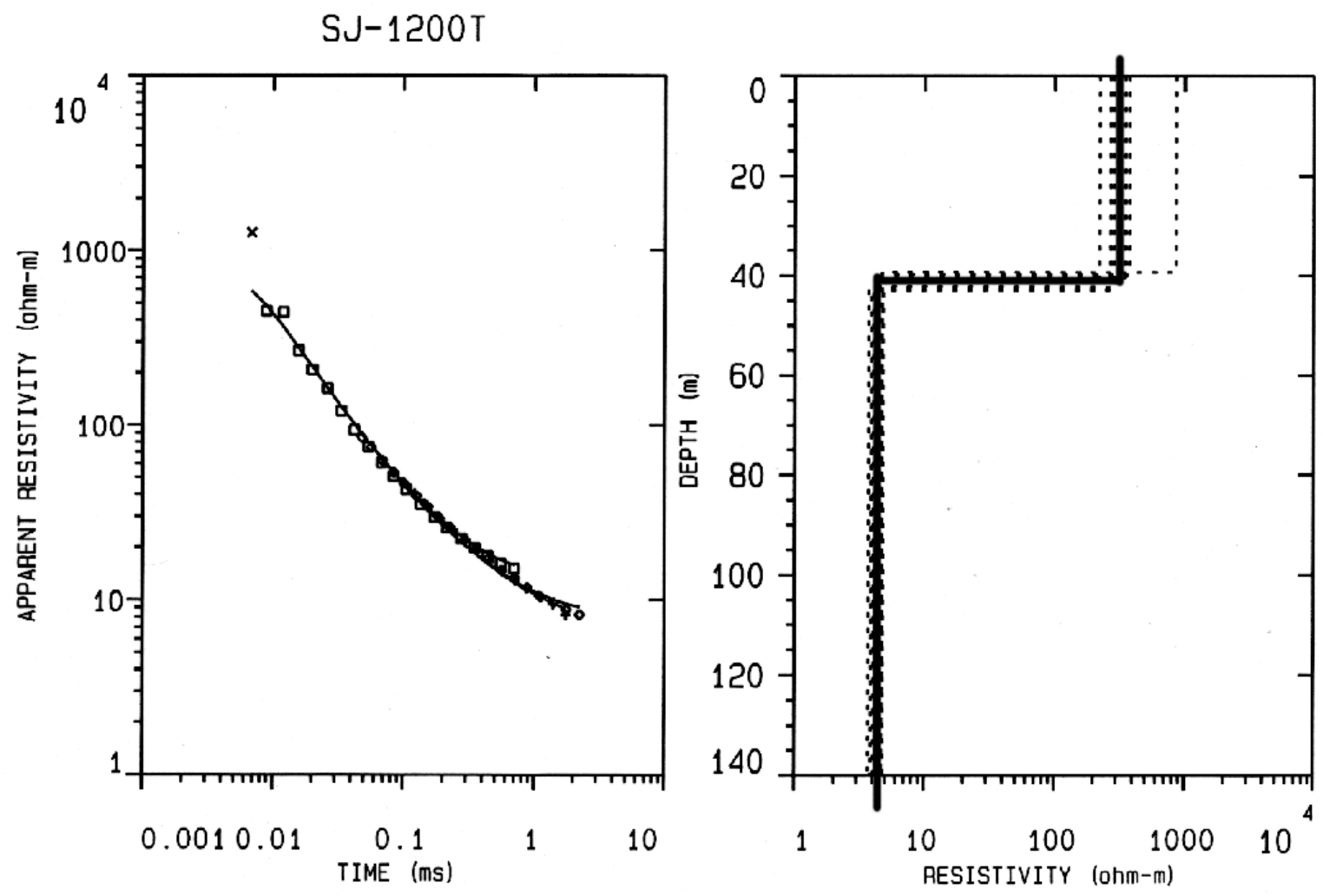